\title{
Toward a Hierarchical Model of Social Cognition: A Neuroimaging Meta-Analysis and Integrative Review of Empathy and Theory of Mind
}

\author{
Matthias Schurz \\ University of Oxford; Radboud University Nijmegen; and \\ University of Salzburg
}

Matthias G. Tholen

University of Salzburg

Daniel S. Margulies

Centre National de la Recherche Scientifique (CNRS), Paris, France

Jerome Sallet

University of Oxford and University of Lyon

\author{
Joaquim Radua \\ Institut d'Investigacions Biomèdiques August Pi i Sunyer \\ (IDIBAPS), Barcelona, Spain; King's College London; and \\ Karolinska Institutet \\ Lara Maliske \\ Technische Universität Dresden \\ Rogier B. Mars \\ University of Oxford and Radboud University Nijmegen
}

Philipp Kanske

Technische Universität Dresden and Max Planck Institute for Human Cognitive and Brain Sciences, Leipzig, Germany

\begin{abstract}
Along with the increased interest in and volume of social cognition research, there has been higher awareness of a lack of agreement on the concepts and taxonomy used to study social processes. Two central concepts in the field, empathy and Theory of Mind (ToM), have been identified as overlapping umbrella terms for different processes of limited convergence. Here, we review and integrate evidence of brain activation, brain organization, and behavior into a coherent model of social-cognitive processes. We start with a meta-analytic clustering of neuroimaging data across different social-cognitive tasks.
\end{abstract}

This article was published Online First November 5, 2020.

(D) Matthias Schurz, Wellcome Centre for Integrative Neuroimaging, Department of Experimental Psychology, University of Oxford; Donders Institute for Brain, Cognition, and Behaviour, Radboud University Nijmegen; and Centre for Cognitive Neuroscience, University of Salzburg. (D) Joaquim Radua, Imaging of Mood- and Anxiety-Related Disorders (IMARD) Group, Institut d'Investigacions Biomèdiques August Pi i Sunyer (IDIBAPS), Barcelona, Spain; Institute of Psychiatry, Psychology and Neuroscience, King's College London; and Department of Clinical Neuroscience, Centre for Psychiatric Research and Education, Karolinska Institutet. (D) Matthias G. Tholen, Centre for Cognitive Neuroscience, University of Salzburg. (D) Lara Maliske, Clinical Psychology and Behavioral Neuroscience, Faculty of Psychology, Technische Universität Dresden. (D) Daniel S. Margulies, Frontlab, Institut du Cerveau et de la Moelle Epinière, Centre National de la Recherche Scientifique (CNRS) UMR 7225, Paris, France. Rogier B. Mars, Wellcome Centre for Integrative Neuroimaging, Centre for Functional MRI of the Brain (FMRIB), Nuffield Department of Clinical Neurosciences, John Radcliffe Hospital, University of Oxford; and Donders Institute for Brain, Cognition, and Behaviour, Radboud University Nijmegen. Jerome Sallet, Wellcome Centre for Integrative Neuroimaging, Department of Experimental Psychology, University of Oxford; and Stem Cell and Brain Research Institute U1208, Institut national de la santé et de la recherche médicale (INSERM), Université Lyon 1, University of Lyon. (D) Philipp Kanske, Clinical Psychology and Behavioral Neuroscience, Faculty of Psychology, Technische Universität Dresden; and Max Planck Institute for Human Cognitive and Brain Sciences, Leipzig, Germany.

Matthias Schurz was supported by an Erwin Schrödinger Fellowship (FWFJ4009-B27), a Marie Skłodowska-Curie Individual Fellowship (MSCA-IF 844734), and the German Research Foundation Network 'Understanding Others' (SCHN 1481/2-1). The Wellcome Centre for Integrative Neuroimaging is supported by core funding from the Wellcome Trust (203139/Z/16/Z).
Joaquim Radua has received support from the Instituto de Salud Carlos III, Ministry of Economy and Competitiveness of Spain (PI19/00394, CPII19/ 00009), integrated into the Plan Nacional de I+D+I, and cofounded by ISCIII- Subdirección General de Evaluación and Fondo Europeo de Desarrollo Regional (FEDER). Matthias G. Tholen was supported by the Austrian Science Fund's Doctoral College 'Imaging the Mind' (W1233). Lara Maliske was supported by a scholarship of the Friedrich Ebert Foundation. Rogier B. Mars was supported by the Biotechnology and Biological Sciences Research Council (BBSRC) UK (BB/N019814/1) and the Netherlands Organization for Scientific Research NWO (452-13-015). Jerome Sallet was supported by a Wellcome Trust Henry Dale Fellowship (105651/Z/14/Z) and an IDEXLYON IMPULSION 2020 Grant (IDEX/IMP/2020/14). Philipp Kanske was supported by the German Federal Ministry of Education and Research within the ASD-Net (BMBF FKZ 01EE1409A), the German Research Foundation (KA 4412/2-1, KA 4412/4-1, KA 4412/5-1, CRC940/C07), Die Junge Akademie at the Berlin-Brandenburg Academy of Sciences and Humanities, the German National Academy of Sciences Leopoldina, and the German Research Foundation Network 'Understanding Others' (SCHN 1481/2-1). Figure 8 shows brain images created by the Human Connectome Project, WU-Minn Consortium (Principal Investigators: David Van Essen and Kamil Ugurbil; 1U54MH091657) funded by the 16 NIH Institutes and Centers that support the NIH Blueprint for Neuroscience Research; and by the McDonnell Center for Systems Neuroscience at Washington University.

Maps and files from the present analyses are available at: https://osf.io/ pav27/

Correspondence concerning this article should be addressed to Matthias Schurz, Donders Institute for Brain, Cognition, and Behaviour, Radboud University Nijmegen, Montessorilaan 3, 6525 HR Nijmegen, the Netherlands. E-mail: matthias.schurz@gmail.com 
Results show that understanding others' mental states can be described by a multilevel model of hierarchical structure, similar to models in intelligence and personality research. A higher level describes more broad and abstract classes of functioning, whereas a lower one explains how functions are applied to concrete contexts given by particular stimulus and task formats. Specifically, the higher level of our model suggests 3 groups of neurocognitive processes: (a) predominantly cognitive processes, which are engaged when mentalizing requires self-generated cognition decoupled from the physical world; (b) more affective processes, which are engaged when we witness emotions in others based on shared emotional, motor, and somatosensory representations; (c) combined processes, which engage cognitive and affective functions in parallel. We discuss how these processes are explained by an underlying principal gradient of structural brain organization. Finally, we validate the model by a review of empathy and ToM task interrelations found in behavioral studies.

\section{Public Significance Statement}

Empathy and Theory of Mind are important human capacities for understanding others. Here, we present a meta-analysis of neuroimaging data from 4,207 participants, which shows that these abilities can be deconstructed into specific and partially shared neurocognitive subprocesses. Our findings provide systematic, large-scale support for the hypothesis that understanding others' mental states can be described by a multilevel model of hierarchical structure, similar to models in intelligence and personality research.

Keywords: emotion, mentalizing, mirror neurons, perspective taking, social cognition

Supplemental materials: http://dx.doi.org/10.1037/bul0000303.supp

Successful social interaction requires representing not only the overt behavior of people but also its underlying forces such as thoughts and emotions. Over the last two decades, behavioral and brain imaging research has generated an abundance of evidence on how we manage to infer the unobservable mental states of others. At the same time, there has been increasing awareness of a lack of agreement regarding the concepts and taxonomy used to study these social processes. Clearly, different terms are being used to describe similar processes and, at times, similar terms for describing different processes (see Happé, Cook, \& Bird, 2017). In particular, two terms have been of central importance-empathy, generally referring to an affective route for understanding others (Gallese, 2003; Titchener, 1909), and Theory of Mind (ToM) or mentalizing, referring to cognitive representations of others' mental states (Adolphs, 2009; Kanske, 2018; Keysers \& Gazzola, 2009; Premack \& Woodruff, 1978). On a conceptual level, it has been argued that both are used as umbrella terms for studying a variety of different processes of limited convergence (see Schaafsma, Pfaff, Spunt, \& Adolphs, 2015, for ToM; see Bloom, 2017; Zaki, 2017, for empathy). This observation has also been reflected in recent literature reviews. Rather than finding broad and homogeneous networks, meta-analyses that explicitly categorized studies based on stimuli and instructions found multiple functional subdivisions among the neural correlates for ToM (Molenberghs, Johnson, Henry, \& Mattingley, 2016; Schurz, Radua, Aichhorn, Richlan, \& Perner, 2014; see also Mar, 2011; Van Overwalle, 2009; Van Overwalle \& Baetens, 2009) and empathy (Fan, Duncan, de Greck, \& Northoff, 2011; Gu, Hof, Friston, \& Fan, 2013; Lamm, Decety, \& Singer, 2011; Timmers et al., 2018).

The issues illustrated above are compounded by the fact that empathy and ToM are both thought to comprise affective and cognitive subforms, complicating the distinction between the terms. For instance, definitions of ToM include the ability to make inferences not only about others' cognitive mental states, such as beliefs and thoughts, but also about their desires and emotions (e.g., Frith \& Frith, 2006; Premack \& Woodruff, 1978). The latter feature has sometimes been referred to as "affective ToM" (e.g., Kalbe et al., 2010; Schlaffke et al., 2015; Sebastian et al., 2012; Shamay-Tsoory \& Aharon-Peretz, 2007). Relatedly, it was proposed that the processing of others' mental states engages ToM, irrespective of cognitive or affective content, whenever it requires metarepresentation (Leslie, Friedman, \& German, 2004), that is, representing a propositional attitude (e.g., "Sally is happy that ...", or "Sally wants that ..."). On the other hand, definitions of empathy contain emotional processes such as the sharing of others' feelings as well as cognitive processes such as reasoning about others' affective states (e.g., Dziobek et al., 2011; Shamay-Tsoory, Aharon-Peretz, \& Perry, 2009), referred to as "cognitive empathy" (Hooker, Verosky, Germine, Knight, \& D'Esposito, 2010; Walter, 2012). Even broader conceptualizations of empathy contain additional features such as empathic concern or compassion for another person (Davis, 1994; see also Zaki \& Ochsner, 2012). These variable models of empathy and ToM challenge an integration of findings across different fields and labs.

An important step to clarify current theories of social cognition is determining how different concepts relate to one another (e.g., in a multilayered manner; De Waal, 2012; see also De Waal, 2007; Preston \& Hofelich, 2012: Singer, 2006) and exploring how they are best grouped according to common underlying processes (Happé et al., 2017). This approach also advances a "deconstruction" of social processes (see Schaafsma et al., 2015), that is, the mapping of broad terms such as ToM and empathy to a set of underlying processes that are in turn linked to concrete experimental tasks. Such an endeavor also dovetails with the strategy promoted by the National Institute of Mental Health (NIMH) for 
studying mental disorders (Insel et al., 2010)— the Research Domain Criteria (RDoC) Projects.

We begin our article with a meta-analysis of neuroimaging studies and then move on to review the corresponding behavioral findings. Neuroimaging data provide a useful starting point because brain activity reported in standard space is readily comparable across studies and can be used to generate a comprehensive picture of task-by-task interrelations (i.e., activation overlaps). This serves as a framework for reviewing behavioral studies on task-by-task correlations. Building on previous meta-analytic work (Schurz et al., 2014), we sorted studies according to stimuli and task instructions. In the present study, we included task groups not only from the ToM literature (e.g., False Belief, Reading the Mind in the Eyes tasks) but also from the field of empathy (e.g., Observing Pain, Evaluating Situated Emotions tasks). A central additional feature of the present study is a hierarchical clustering of meta-analytic results (see Laird et al., 2011; Riedel et al., 2015). Specifically, after obtaining meta-analytic result maps for each task group, we determined their overlaps (via image correlation) and clustered similar maps together. This produced a hierarchical tree (dendrogram), which characterizes relations among brain activation networks for different task groups.

The main goal of this clustering is to estimate latent factors, that is, common neurocognitive components engaged by different empathy and ToM tasks, which is in line with previous perspectives on empathy and ToM (e.g., De Waal, 2007; Preston \& Hofelich, 2012). In theory, components engaged by different tasks could be related in various forms. Multiple components could largely overlap, one component could be a subcomponent of another, or components could have some elements in common but additionally contain distinct processes (see Happé et al., 2017, for discussion). The clustering tree we generated is flexible enough to capture any of these relations. Identifying common components is also supported by the argument that whatever is pivotal for social cognition as measured in empathy and ToM studies should be reflected in common activation across several tasks. This way, activation driven by idiosyncratic elements of task design is ruled out by the overlap (see Mar, 2011). In addition, our clustering across empathy and ToM tasks clarifies theories of subprocesses for these domains. To illustrate, cognitive empathy and affective ToM could represent two independent and self-contained social abilities or could be overlapping and to some extent redundant concepts.

\section{Method}

\section{Literature Search and Study Selection}

We reviewed the neuroimaging literature on ToM and empathy to get an overview of the different experimental tasks that were used and sorted studies with similar stimuli and instructions into task groups. All studies from ToM and empathy task groups were retrieved from database searches using PubMed and ISI Web of Science (core collection). Our review included literature published up to November 2019. Neuroimaging studies were identified by the keywords neuroimaging or fMRI or $P E T$ and were assigned to ToM groups when they included theory of mind or mentalizing or mindreading and to empathy groups when they included empathy, or empathetic, or altruism, or sympathy, or emotional contagion, or compassion. For ToM, we incorporated the literature from a previous meta-analysis (Schurz et al., 2014) into the present sample. Articles were retained if they matched one of the empathy and ToM task groups defined previously, irrespective of the terminology used by the authors. All studies included in the task groups had to further fulfill the following selection criteria (see Radua et al., 2012): Reported coordinates had to correspond to standard space (MNI or TAL) and stem from whole-brain analysis using a consistent threshold throughout the whole brain. Data from clinical samples were removed. If a study reported more than one contrast, the one that best corresponded to the other studies from the task group was selected. Altogether, we included 103 studies from the ToM literature divided into six task groups: False Belief $(n=25)$, Trait Judgments $(n=19)$, Strategic Games $(n=13)$, Rational Actions $(n=11)$, Social Animations $(n=20)$, and Reading the Mind in the Eyes $(n=15)$. We identified 85 studies from the empathy literature that we divided into five task groups: Observing Pain $(n=21)$, Observing Emotions $(n=$ 25), Sharing Emotions or Pain $(n=12)$, Evaluating Situated Emotions $(n=15)$, and Reasoning about Emotions $(n=12)$. Thus, our meta-analyses cover a total of 188 studies.

\section{Meta-Analysis Methods}

For each of the 11 task groups, we carried out an effect-sizebased meta-analysis using the Signed Differential Mapping method (SDM 4.31, Radua et al., 2012, www.sdmproject.com). The SDM method is based on the positive features from existing peak probability methods for meta-analysis, such as activation likelihood estimation (ALE, Eickhoff et al., 2016) or multilevel kernel density analysis (MKDA, Wager, Lindquist, \& Kaplan, 2007). In addition, it incorporates the effect sizes of reported activations, thus extracting more detailed information from the published literature. Based on $t$ values and sample sizes reported in studies, SDM creates effect-size (Hedge's $g$ values) and variance maps (derived from the distribution of effect sizes). ${ }^{1}$ Statistical significance of meta-analytic maps was assessed by permutation tests that randomize the location of the voxels within the standard gray-matter template. One hundred random maps were generated by permutation for each metaanalysis. We report all results for the MNI space and at a statistical threshold of $p<.005$ uncorrected (voxel-level) and a cluster threshold of 10 voxels (see Figures 1 and 2). This threshold was found to optimally balance sensitivity and specificity and to be an approximate equivalent to a corrected threshold of $p<.05$ in original neuroimaging studies (Radua et al., 2012). For contrasts between meta-analyses, we used the SDM linear model function, calculating the difference between effect-size estimates from two meta-analyses while accounting for differences in sample size and within- and between-study

\footnotetext{
${ }^{1}$ Hedge's $g$ values are derived from $t$ statistics or equivalently from $p$ values or $z$ scores. Effect sizes around reported peak coordinates $(<20$ $\mathrm{mm}$ ) are estimated based on an anisotropic un-normalized Gaussian kernel. The mean brain activity for each task group is determined by a randomeffects model, with each study being weighted by the inverse of the sum of its variance plus an estimate of between-study heterogeneity (DerSimonian \& Laird, 1986). This enables studies with larger sample sizes or lower variabilities to contribute more strongly.
} 
Theory of Mind: Meta-analyses for separate task groups

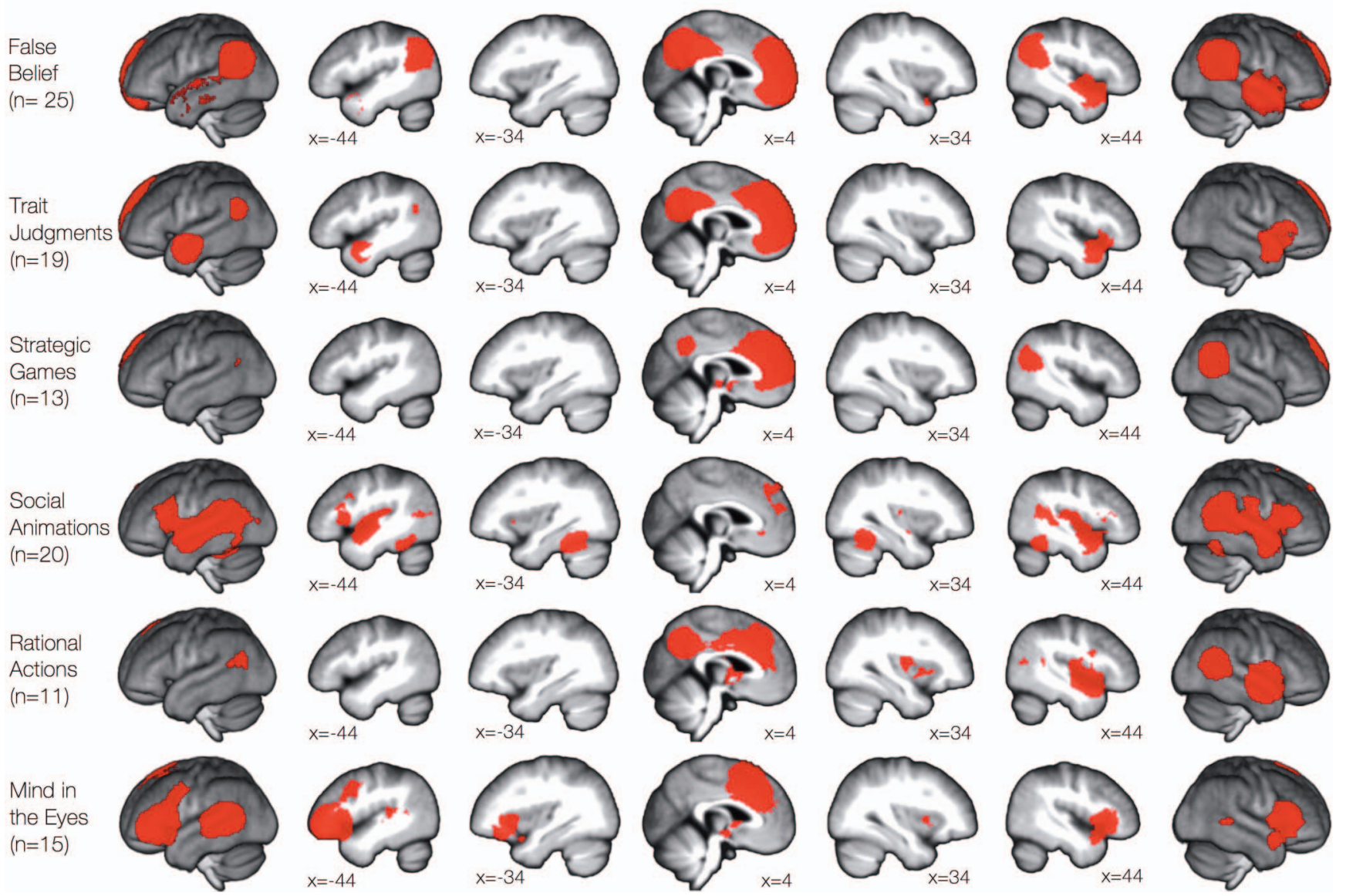

Figure 1. Results of separate meta-analyses for task groups from Theory of Mind. Maps were thresholded at a voxel-wise threshold of $p<.005$ uncorrected and a cluster extent threshold of 10 voxels. See the online article for the color version of this figure.

variability. To determine common activation in multiple contrasts, we applied conjunction minimum analysis (e.g., Nichols, Brett, Andersson, Wager, \& Poline, 2005) via the image calculator utility of SPM12 (www.fil.ion.ucl.ac.uk). Note that, as the ultimate goal of our meta-analyses was to cluster result-maps based on similarities in whole-brain activation patterns, we did not carry out analyses of publication bias. ${ }^{2}$

\section{Hierarchical Clustering Analysis}

After obtaining meta-analytic result maps for all 11 task groups, we applied agglomerative hierarchical clustering to them (see, e.g., Laird et al., 2015; Riedel et al., 2015, 2018). Searching for a hierarchical structure is consistent with several previous conceptualizations of social cognition as a multilayered or multilevel phenomenon (De Waal, 2012; Preston \& De Waal, 2002; Schaafsma et al., 2015; Singer, 2006). To our knowledge, this is the first clustering of SDM effect-size meta-analysis maps. Therefore, we compared several settings for discriminative performance (see the online supplemental materials) and found unthresholded effect-size maps (Hedges' g) and Pearson correlation coefficients to best capture image dissimilarity among our meta-analyses.
Clustering consisted of three steps. In Step 1, we transformed the unthresholded meta-analytic effect-size maps into feature vectors containing voxel values and concatenated them horizontally, forming a matrix of $n$ task groups (i.e., 11) and $p$ voxels (i.e., 902629). Based on these, we calculated pairwise Pearson correlation coefficients between all feature vectors, from which we derived an $n$-by- $n$ dissimilarity matrix ( $1-r$ values) reflecting whole-brain multivoxel dissimilarity between maps. In Step 2, we grouped meta-analyses into clusters by applying agglomerative hierarchical clustering in MATLAB 8.1 (The Math Works, Inc., 2013). For linkage, we selected the linkage average method, which represents a compromise between the clustering's sensitivity to outliers and its tendency to form long chains of elements per cluster. As a

\footnotetext{
${ }^{2}$ Our meta-analytic clustering is based on patterns (i.e., data-vectors) which capture activation across thousands of brain locations, that have been computed separately for 11 task types. As publication bias in neuroimaging studies can be region- and task-specific, an estimation thereof would produce a very high number of possible sub-analyses. Although such an extensive analysis goes beyond the scope of our meta-analytic clustering project, further work is needed to systematically address publication bias in the social neurosciences.
} 


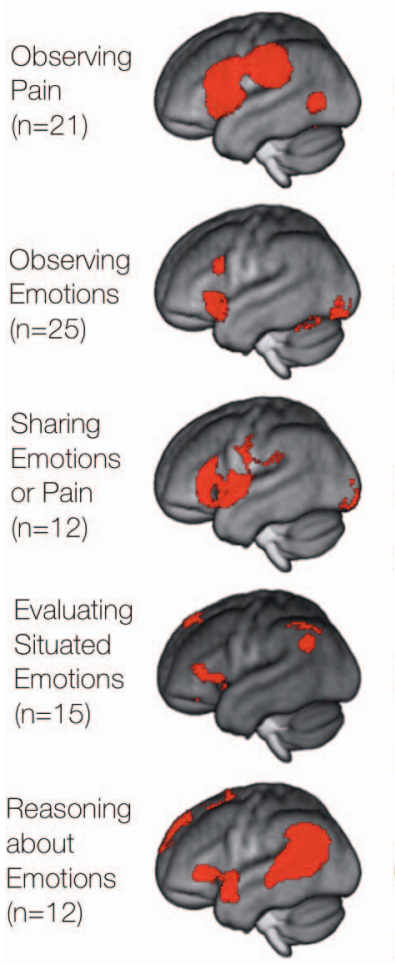

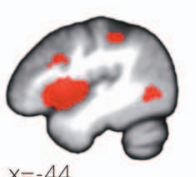

$x=-44$
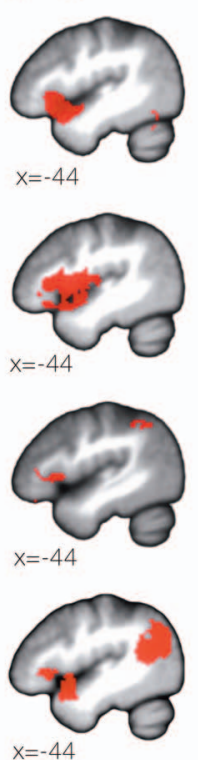

$x=-44$
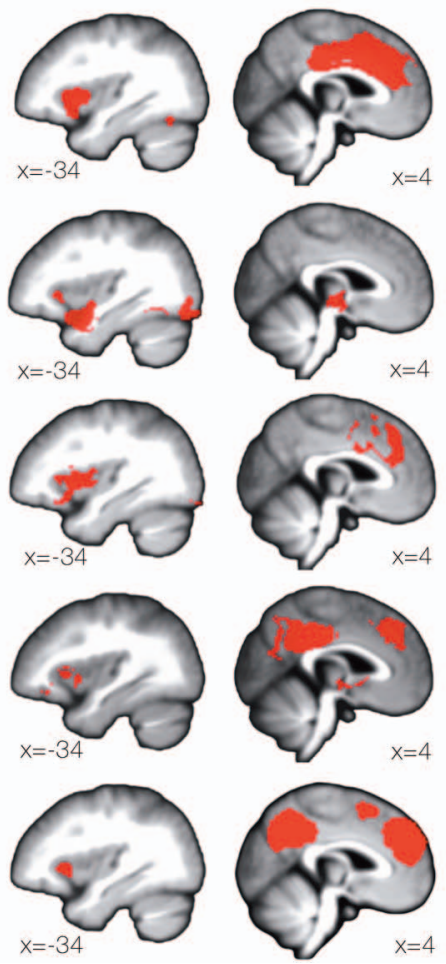
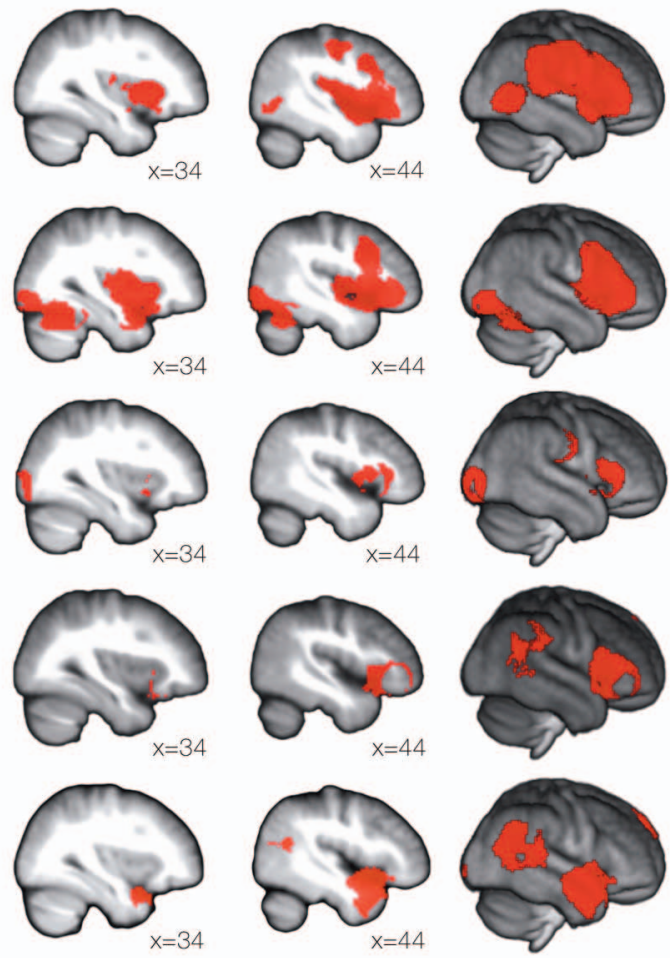

Figure 2. Results of separate meta-analyses for empathy task groups. Maps were thresholded at a voxel-wise threshold of $p<.005$ uncorrected and a cluster extent threshold of 10 voxels. For Reasoning about Emotions, we selected a common type of task that we found not only in the empathy literature but also in ToM studies. See the online article for the color version of this figure.

distance measure, we selected euclidean, which considers both the profile and magnitudes of task-to-task similarities. Euclidean is among the most widely used distance measures and the default setting for MATLAB's hierarchical clustering. In Step 3, we evaluated different solutions based on the dendrogram from our clustering. Based on previous works (e.g., Laird et al., 2015; Riedel et al., 2015, 2018) we relied on two metrics for this step: (a) cophenetic distance and (b) density of task separation. Figure 3 shows both measures for different clustering solutions; Figure 4 shows the underlying dendrogram. The cophenetic distance between clusters at a given model order (i.e., number of clusters) reflects dissimilarity between subclusters. ${ }^{3}$ A clustering optimum is indicated by high difference in cophenetic distances when moving from lower to higher model orders as this indicates that introducing new subclusters produces substantially different (i.e., distant) brain activity patterns. The second metric we used, density of task separation, indicates whether separating clusters into subclusters maintains a balanced distribution of task groups across subclusters (as opposed to producing disproportionately large/small subclusters, such as a cluster consisting of only one task group). ${ }^{4}$ Decreases in the density of task separation indicate good solutions and reflect a split into subclusters with balanced numbers of task groups. Taking our two clustering metrics together, an optimal solution is indicated by a model order with a relatively high difference in cophenetic distance and a relatively low density of task separation.
To check the stability of our clustering, we repeated the procedure with leave-one-out jackknife sensitivity analysis. ${ }^{5}$ Figure $3 \mathrm{~A}$ shows the range of clustering metrics found across our jackknife repeats $(n=5000)$, which was taken as a guide for selecting the best clustering solutions. Furthermore, for the three-cluster solution (which we present as a main result later), we show the consistency with which task groups were assigned to clusters across iterations of our jackknife analysis (see bar plots in Figure 3B). In general, good consistency (agreement for more than $90 \%$ of iterations) was found for most task groups (except for Rational Actions).

\footnotetext{
${ }^{3}$ The relative difference in cophenetic distances $d_{\mathrm{c}}$ when transitioning from one model order $(x)$ to the next higher one $(x+1)$ can be derived from the cophenetic distances $\mathrm{c}_{\mathrm{x}}$ and $c_{\mathrm{x}+1}$ in the form of $d_{\mathrm{c}}=\left(c_{\mathrm{x}+1}-c_{\mathrm{x}}\right) /\left(c_{\mathrm{x}+1}\right)$.

${ }^{4}$ If cluster $i_{0}$ consisted of $n_{0}$ task groups at model order $x$, and at model order $x+1$ was separated into subclusters $i_{1}$ and $i_{2}$ with $n_{1}$ and $n_{2}$ task groups, then the density of task separation can be calculated as $d_{\mathrm{s}}=n_{1} / n_{0}$, with $n_{1}>n_{2}$.

${ }^{5}$ That is, we removed one random study from each task group (simultaneously), calculated the meta-analyses with the remaining studies, clustered the new results, replaced the removed studies, and repeated the process. We carried out 5,000 clusterings based on leave-one-out samples and summarized the metrics across all of them in Figure 3.
} 


\section{Finding optimal clustering solution}

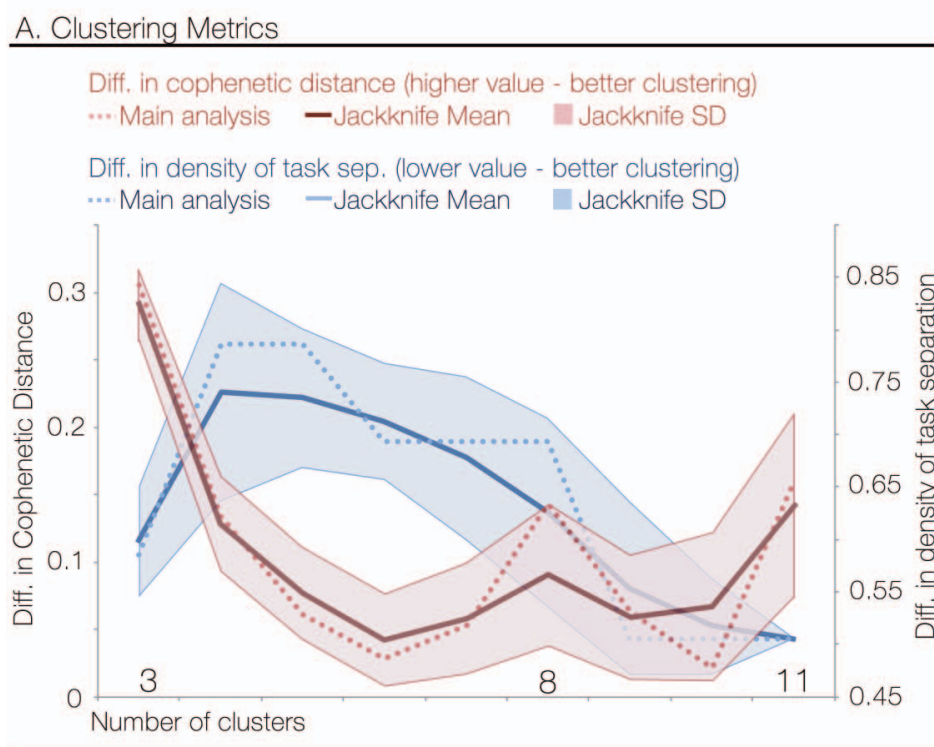

Labels: Empathy (E_)

E_OP... Observing Pain

E_OE... Observing Emotions

E_SH... Sharing Emotions or Pain
B. Stability of 3 Cluster Solution

\% Jackknife replicates with task group in cluster:

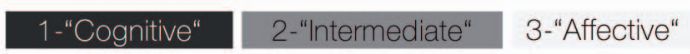

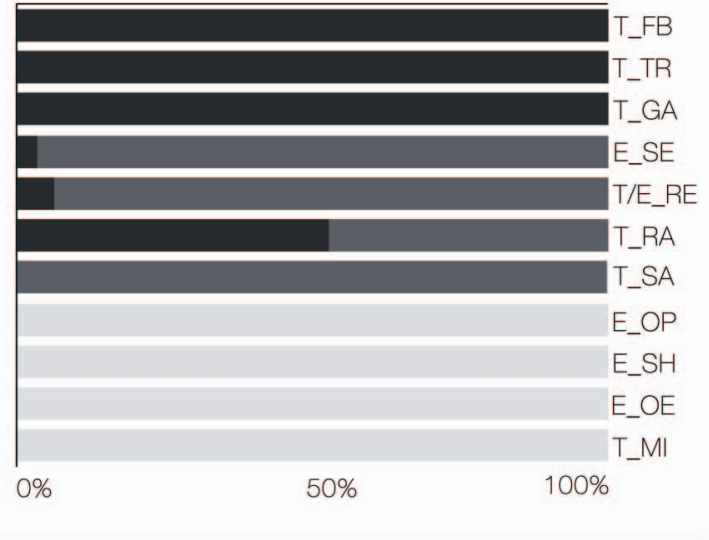

Theory of mind (T_)

T_FB... False Belief

T_TR... Trait Judgments

T_GA... Strategic Games
T_SA... Social Animations

T_RA... Rational Actions

T_Ml... Mind in the Eyes

Figure 3. (A) Evaluation and comparison of different clustering solutions. The plot shows changes in two metrics when moving from 2- to 3-, 3- to 4- ..., and 10- to 11-cluster solutions. The first metric, shown in red (dark grey) and on the left $y$ axis, gives the relative difference in cophenetic distances when moving from one model to the next. A relatively high difference in cophenetic distances indicates that introducing new subclusters results in a better separation of brain activity patterns and thus good clustering. The second metric, shown in blue (light grey), shows the density of task separation, reflecting whether separating clusters into subclusters maintains a balanced number of task groups in each subcluster. The relatively low density of task separation indicates good clustering. Preferred clusterings in terms of both metrics are indicated on the $x$ axis: 3, 8, and 11. Metric changes are shown for the clustering of complete meta-analyses (main analysis) and clusterings based on leave-one-out jackknife sensitivity analysis with 5,000 repeats (jackknife mean, standard deviation $[S D]$ ). (B) Stability of the assignment of task groups (i.e., associated meta-analytic maps) to clusters for the three-cluster solution, based on leave-one-out jackknife sensitivity analysis. The bars indicate the percentage of jackknife repeats for which task groups were assigned to the same clusters as in the main analysis. See the online article for the color version of this figure.

\section{Analysis of Overlap With Other Maps}

For a broader perspective on our meta-analysis, we compared our main results (see Figure 5) with an extensive set of automatically generated meta-analyses across a wide range of topics. This step allows us to discuss our findings in relation to brain activation for a wide range of other social and also nonsocial processes. We used the decoding tool of the neurosynth database (Yarkoni, Poldrack, Nichols, Van Essen, \& Wager, 2011) for this analysis, which we accessed via the larger neuroimaging repository neurovault.org (Gorgolewski et al., 2015). In keeping with the recommended input specifications, we created unthresholded versions of mean and contrast maps for decoding. ${ }^{6}$ In Figures 6 and 7, we showed the neurosynth decoding results as Pearson correlation coefficients, describing image similarity between our maps and automatically generated meta-analyses for research topics ("terms") identified by text mining of literature databases. For clarity, we show only the most strongly correlated social and nonsocial terms found with neurosynth decoding. ${ }^{7}$ In addition, we discarded terms of little interest for the current article, such as for example neuroanatomical labels (e.g., $m p f c, p s t s){ }^{8}$

\footnotetext{
${ }^{6}$ As result maps from meta-analytic contrasts originally contain positive (e.g. map1 > map2) and negative (e.g. map2 $>$ map1) values, we next removed (masked) all negative values from these images to obtain clearly interpretable decoding results. To illustrate, after masking, results for decoding of the contrast (map1 > map2) provides results that can be specifically linked to activations in map 1 .

${ }^{7}$ A large number of correlated terms is found by neurosynth decoding. For clarity, we decided to select a small number (five) of top-ranked associations to highlight major themes linked to our results. Note that terms found formed topically coherent clusters (see Figures 6 and 7-terms cluster around the topics language, default mode network function, and sensory-affective processing). Therefore, in our discussion, we interpreted the relation of our maps to major themes identified by neurosynth rather than individual terms.

${ }^{8}$ We further discarded technical/unspecific terms (e.g. independent component, task, state) and conceptually redundant terms (e.g. dmn and mode are redundant with default) from our selection.
} 


\section{Results of clustering for ToM and Empathy}

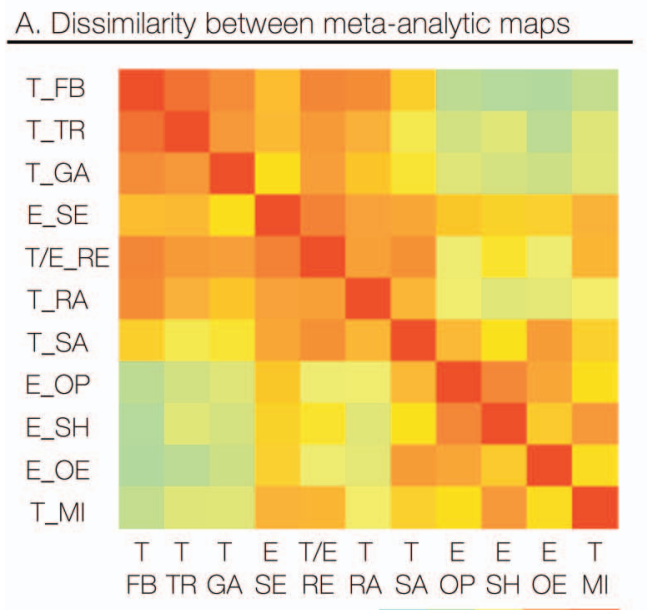

\section{B. Dendrogram from clustering}

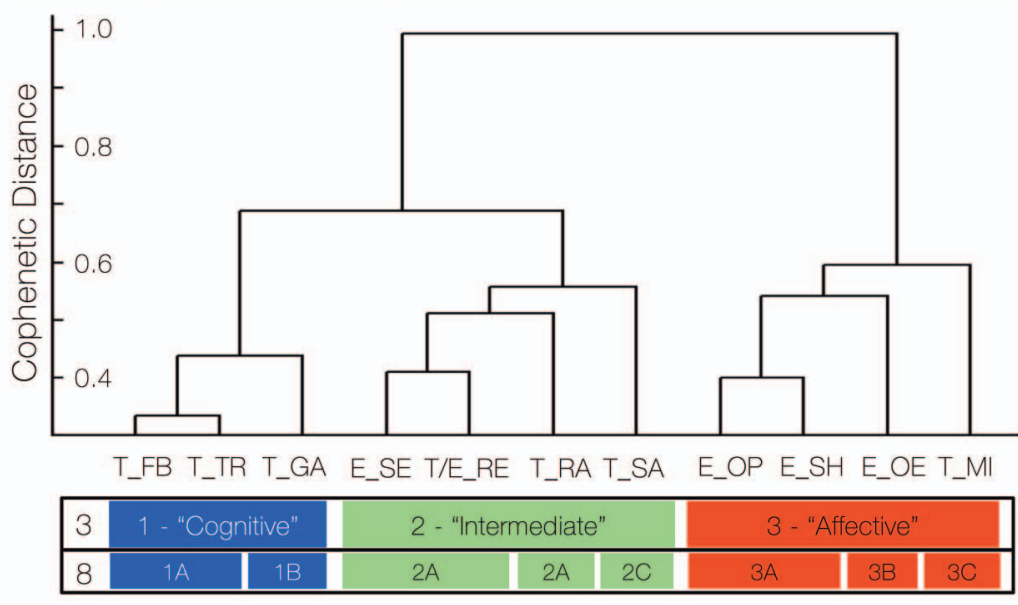

Dissimilarity $1.0 \quad 0.5 \quad 0.0$

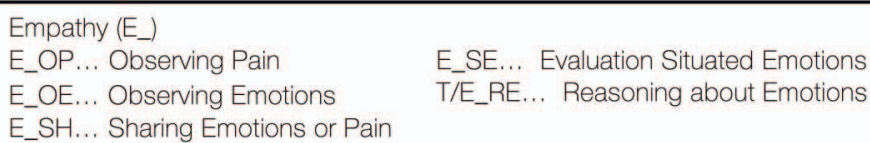

Labels: Theory of mind ( $\left.T_{-}\right)$

T_FB... False Belief

T_TR... Trait Judgments

T_SA... Social Animations

T_RA... Rational Actions

T_GA... Strategic Games

T_Ml... Mind in the Eyes

Figure 4. (A) Degree of dissimilarity between meta-analytic result maps (given as 1-Pearson's $r$ ). High dissimilarity reflects little correspondence or overlap between brain maps. (B) Dendrogram from hierarchical clustering. The height of the branches indicates cophenetic distances and thus the dissimilarity between subclusters at that model order. Color bars indicate positions of the three- and eight-cluster solutions with respect to the dendrogram. See the online article for the color version of this figure.

To further characterize the neurocognitive processes linked to our meta-analysis maps, we calculated the overlap of our metaanalysis with a whole-brain map of brain connectivity organization (Margulies et al., 2016) and a resting-state connectivity parcellation atlas (Yeo et al., 2011). We determined overlaps with these maps by conjunction analysis ${ }^{9}$ and summarized them as a variant of the dice score: For each meta-analysis map, we calculated the percentage of voxels it comprised that fell within different parts of each connectivity map. ${ }^{10}$

\section{Results and Discussion}

In the next sections, we describe the task groups that we found in the ToM and empathy literature and briefly review some of the rationale behind each type of task. These task groups will then be input for our key analysis, the meta-analytic clustering, which follows in the Clustering section. Concrete task examples are given in Table 1 for ToM and Table 2 for empathy task groups. We also illustrate the meta-analytic result maps for each task group in Figures 1 and 2.

\section{Task Groups: ToM}

False belief. False Belief tasks have been widely used in developmental psychology and were quickly adapted for neuroimaging using the story format (e.g., Gallagher et al., 2000). These False Belief stories had a particular logical structure. As illustrated in Table 1, stories typically first introduce a person and his/her true belief about a state of affairs. Unknown to that person, this state changes thereafter. As a result, the person's belief becomes false. Participants are then asked a question related to that belief. To account for this structure of False Belief stories, our meta-analysis only included more recent studies presenting false photograph control conditions of similar form (e.g., Dodell-Feder, KosterHale, Bedny, \& Saxe, 2011; Saxe \& Kanwisher, 2003), see Table 1 for examples. Note that for False Belief tasks, we found many more eligible studies in the literature than for other task groups (38 studies in total). To avoid large differences in size between task groups, we randomly selected 25 studies from this large sample of False Belief tasks.

Trait judgments. Inspired by the discovery of brain areas specialized for conceptual knowledge about different classes of inanimate stimuli (e.g., tools, houses), Trait Judgment tasks were introduced. These tasks, which aimed to find brain areas with a

\footnotetext{
${ }^{9}$ For overlaps with resting-state networks, we used the seven-network parcellation by Yeo et al. (2011), more specifically a MNI transformed version (liberal mask, see https://surfer.nmr.mgh.harvard.edu/fswiki/ CorticalParcellation; Yeo et al., 2011).

For the connectivity gradient, a partitioned version consisting of 20 maps was used, each corresponding to a five-percentile step along its progression. All resting-state/gradient-percentile maps were in turn overlaid with our meta-analysis result maps by determining conjunction images after binarizing all inputs (in SPM12). Because all inputs conformed to the MNI space, only adjustment of images in terms of size and resolution was required (which we implemented via the reslice function in SPM12, with the resting-state/gradient-percentile maps being the image-defining space)

${ }^{10}$ That is, if $i 1$ is a meta-analysis map and $i 2$ a connectivity map, we calculated $n$ voxels in (i1\&i2) / $n$ voxels in i1.
} 


\section{Clustering ToM and empathy}

tasks at different levels
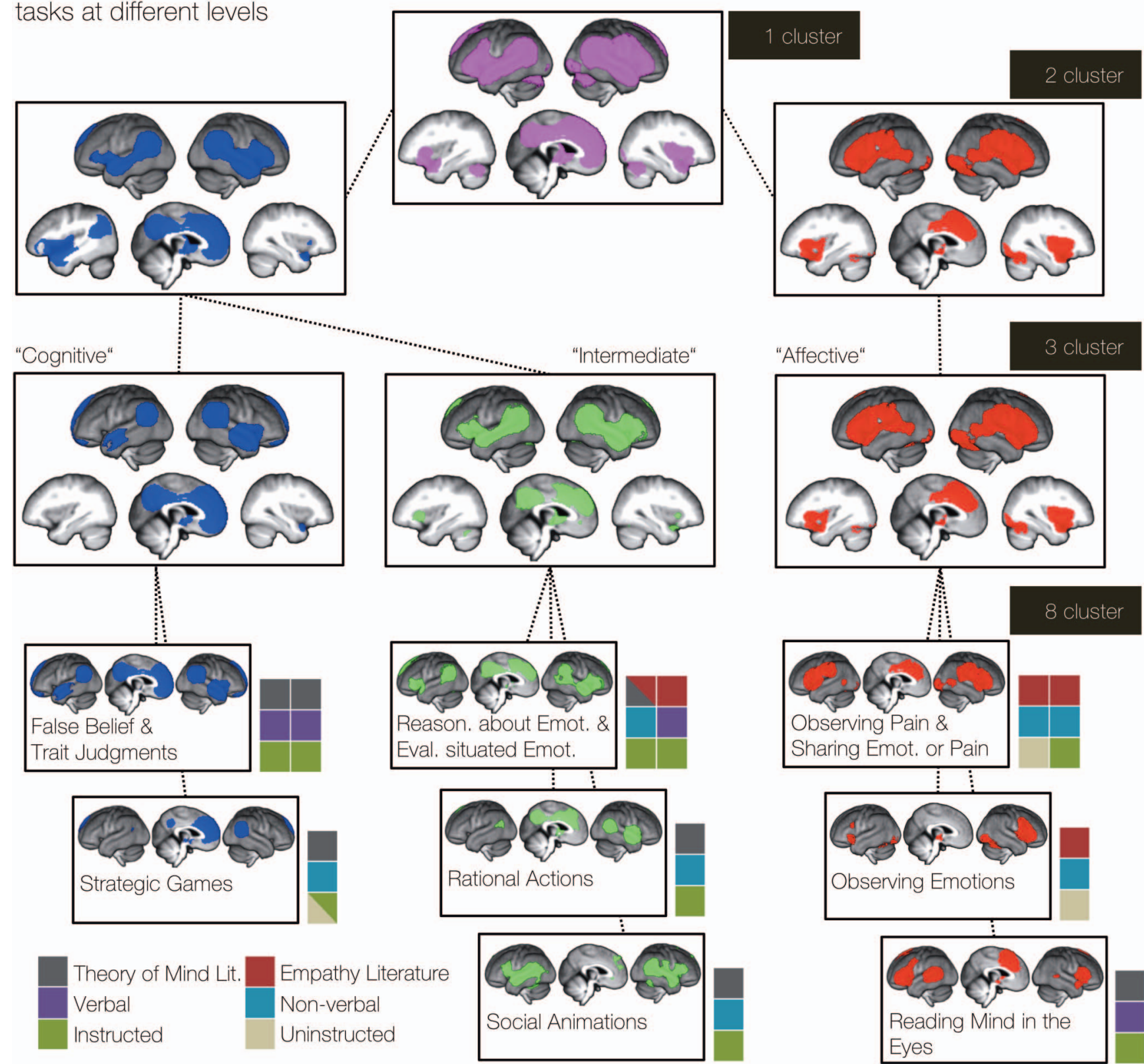

Figure 5. Mean brain activation for clusters at different model orders. We carried out pooled metaanalyses, that is, one separate meta-analysis per cluster, where all its task groups are joined together. Analyses were thresholded at a voxel-wise threshold of $p<.005$ uncorrected and a cluster extent threshold of 10 voxels. The one-cluster solution is shown for illustrative purposes only and was not evaluated or compared against other clusterings. Colors indicate how the three-cluster solution relates to both higherand lower-level clusterings: blue-cognitive cluster (left column), green-intermediate cluster (middle column), red-affective cluster (right column). At the lowest level of the dendrogram, we indicate for each cluster some exemplary stimulus and task categorizations. The eight-cluster solution was selected as a representative low-level clustering. However, note that the 11-cluster solution shows favorable clustering metrics but corresponds to what has been shown in Figures 1 and 2 (i.e., complete separation into individual task groups). See the online article for the color version of this figure. 

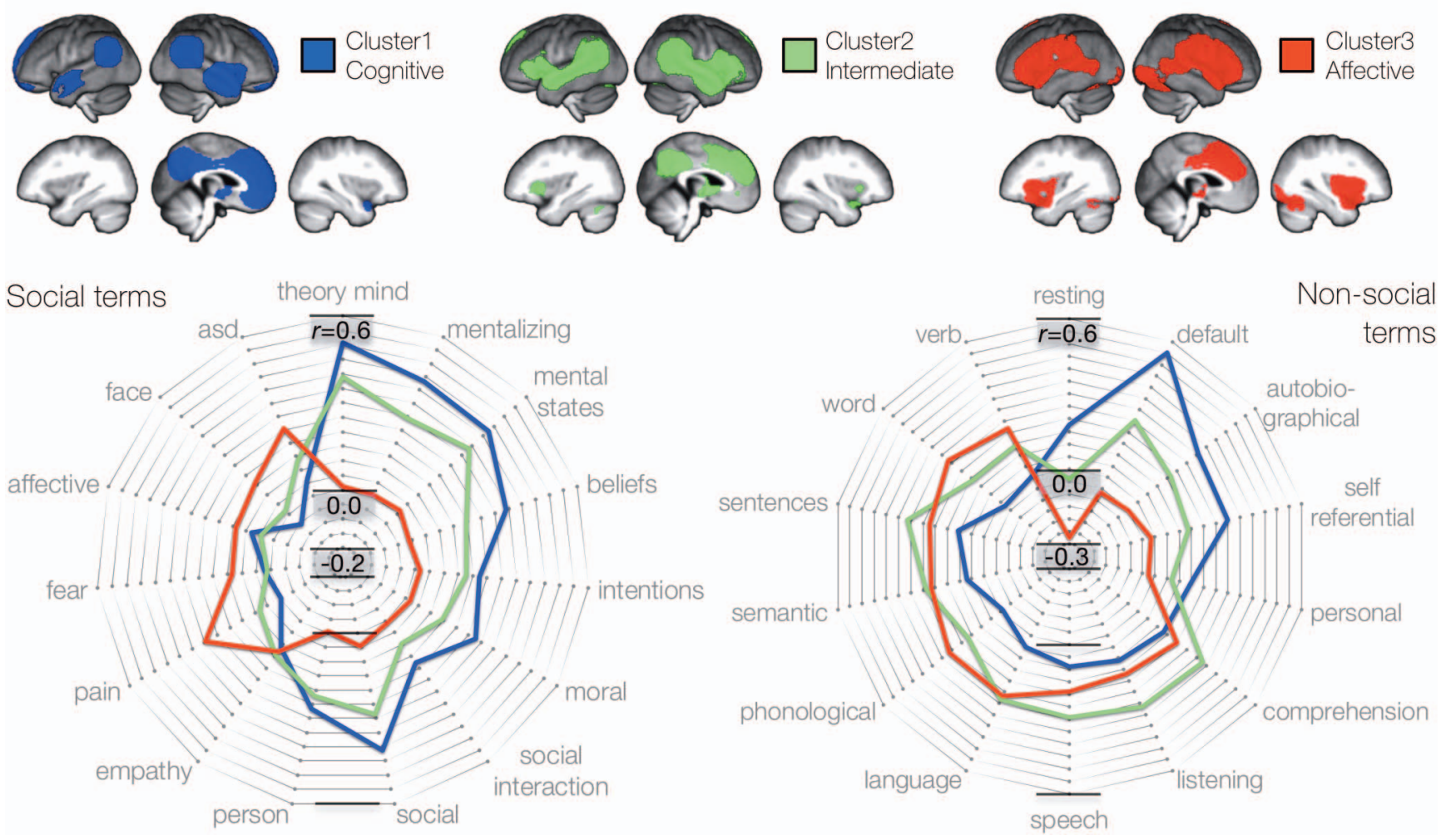

Figure 6. Mean brain activation from meta-analyses for the three-cluster solution (pooled meta-analyses), at a voxel-wise threshold of $p<.005$ uncorrected and a cluster extent threshold of 10 voxels. The polar plots show results from large-scale meta-analytic decoding (www.neurosynth.org; Yarkoni et al., 2011). Meta-analysis maps were compared with an extensive set of automatically generated meta-analyses across a wide range of topics (terms), and findings of highest convergence (image correlation, i.e., Pearson's $r$ ) are shown. For each of our three clusters, we show the five most strongly correlated terms found for social and nonsocial topics (for further details, see the Analysis of Overlap With Other Maps section). The abbreviation "asd" (identfied by neurosynth text mining) stands for autism spectrum disorder. See the online article for the color version of this figure.

comparable level of specialization for conceptual knowledge about persons (e.g., Mitchell, Heatherton, \& Macrae, 2002), quickly became widely used. Trait Judgment tasks in our meta-analysis presented participants with written material concerning another person's traits (e.g., adjectives, opinions, or personal episodes). Usually, the person was only described verbally to participants. However, a few studies presented photographs of the person characterized (e.g., faces, body parts, or the person as a whole). Control conditions for Trait Judgments diverted attention away from these mental states by asking for linguistic judgments on trait words (e.g., "Is this word written in upper- or lowercase?") or presented words/statements that did not contain mental states.

Strategic games. Early studies used Strategic Games for studying ToM based on the idea that feedback from a social partner-indicated by their moves in the game-may trigger spontaneous mentalizing. Even when not explicitly asked to "mindread," participants would spontaneously try to guess (i.e., infer) the intentions of the other player (e.g., Rilling, Sanfey, Aronson, Nystrom, \& Cohen, 2004). This relates to the notion of an "intentional stance" (e.g., Dennett, 1971), that is, a disposition to reason about the beliefs, desires, and intentions of others (Gallagher, Jack, Roepstorff, \& Frith, 2002). Our meta-analysis included studies where participants were asked to play a game with another player with whom they could compete or cooperate (e.g., the prisoner's dilemma game). Players received feedback about the decision of the other player, but they could not see each other. The contrast of interest was typically brain activation for playing strategic games with a human partner compared with playing with a computer (which follows a simple algorithm).

Social animations. Social Animations were introduced (Castelli, Frith, Happé, \& Frith, 2002; Castelli, Happé, Frith, \& Frith, 2000) as a low-level alternative to verbal or cartoon-based materials used in the field (e.g., Baron-Cohen et al., 1994; Fletcher et al., 1995; Happé et al., 1996). The idea was to trigger ToM processes with minimal input to distinguish central mechanisms for mental-state attribution from other, potentially stimulusrelated, processes. Studies in this task group presented video animations of simple geometrical shapes or objects which performed movements resembling intentional or social interactions. This type of stimulus is based on the classical-triangles task by 
Neurosynth decoding: Meta-analytic contrasts between clusters
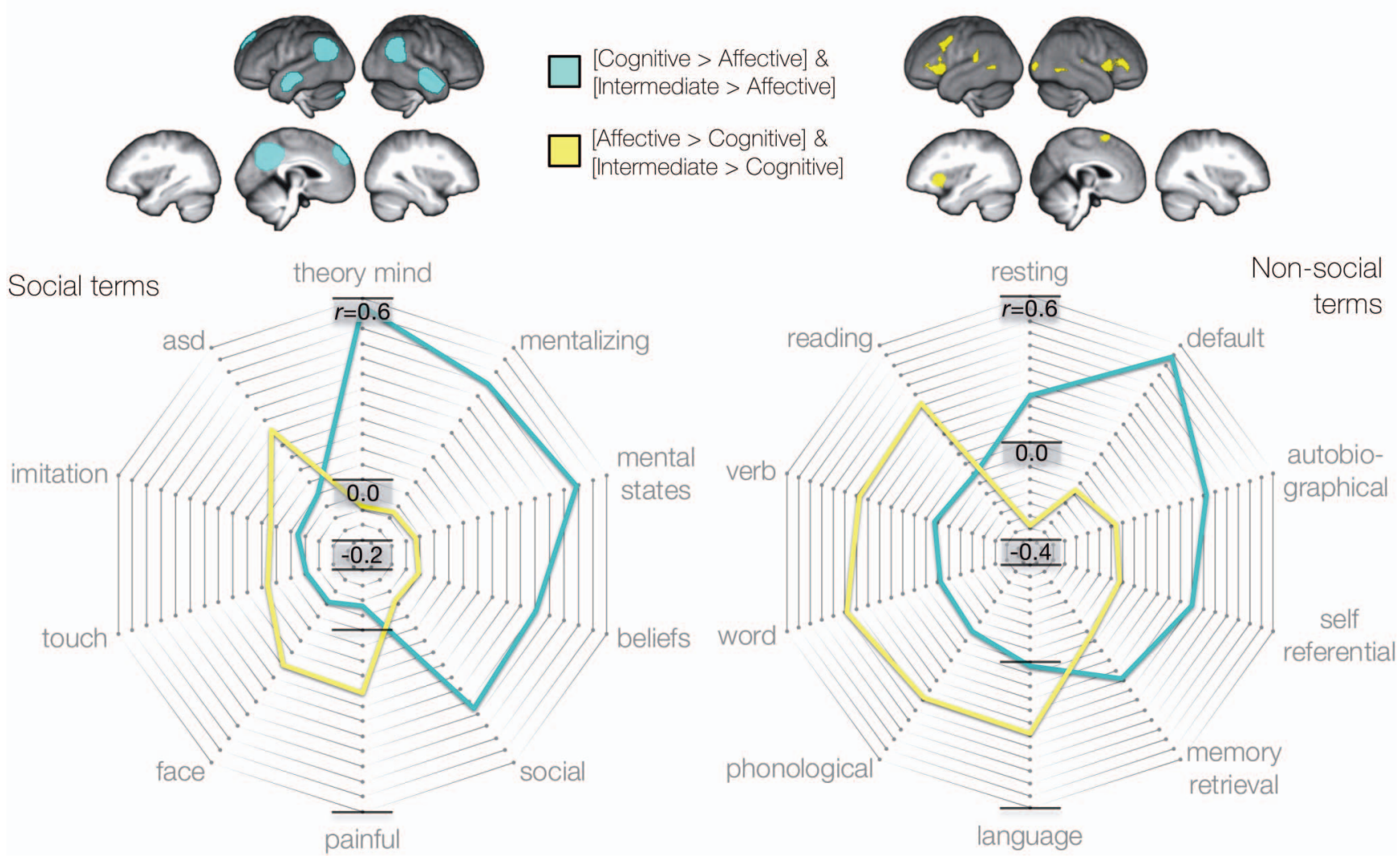

Figure 7. Meta-analytic contrasts for the three clusters tailored to find specific commonalities between the intermediate and each of the other two clusters. Maps are shown at a voxel-wise threshold of $p<.005$ uncorrected and a cluster extent threshold of 10 voxels. Meta-analytic decoding (www.neurosynth.org; Yarkoni et al., 2011) results are given in polar plots, expressed as image correlation, that is, Pearson's $r$. For each contrast, we show the five most strongly correlated terms found for social and nonsocial topics. Because we did not find any specific commonalities between the cognitive and affective clusters (at the statistical threshold), no decoding was done for this contrast. See the online article for the color version of this figure.

Heider and Simmel (1944). In control conditions, the animations showed random or purely mechanical movements (e.g., resembling the movement of billiard balls on the table). For each movie, participants were asked to explain/decide if an interaction between two shapes took place. One study in this task group showed similar movies in the experimental and control conditions but varied instructions (e.g., by asking participants to focus on physical properties in the control condition).

Reading the mind in the eyes. The Reading the Mind in the Eyes Test was introduced in neuroimaging research based on its capacity to dissociate social from more general abilities or intelligence and was linked to ToM and mind-reading abilities in earlier work (Baron-Cohen, Ring, et al., 1999). To illustrate, it was found that adults with high-functioning autism spectrum disorder (Baron-Cohen, Jolliffe, Mortimore, \& Robertson, 1997), as well as parents of children with autism spectrum disorder (Baron-Cohen \& Hammer, 1997), show deficits on this task but not children with William's syndrome (Tager-Flusberg, Boshart, \& Baron-Cohen, 1998). Neuroimaging studies using the Reading the Mind in the
Eyes task presented a photograph of the eye region of a face and asked participants to think about the person's mental state or indicate which adjective (among several options) best described the person's mental state. Control conditions showed similar photographs but asked for physical judgments of the persons depicted (e.g., gender or age) or, in one exceptional case, simply asked for passive viewing of a fixation cross. Note that for the sake of sample coherence (and in light of the empathy tasks we compare here), we did not include two studies from the Reading the Mind in the Eyes sample in Schurz et al. (2014) because these studies asked participants for more basic emotion judgments.

Rational actions. Early studies presenting cartoons were introduced as a nonverbal alternative to story-based mentalizing (see, e.g., Brunet, Sarfati, Hardy-Baylé, \& Decety, 2000). This was in part to circumvent difficulties in studying social cognition in schizophrenia accompanied by speech disorganization (Brunet, Sarfati, \& Hardy-Baylé, 2003; Sarfati, Hardy-Baylé, Besche, \& Widlöcher, 1997). All tasks in the Rational Actions group presented short cartoons and asked participants to predict a likely 
Table 1

Examples of Studies in Theory of Mind Task Groups

\begin{tabular}{|c|c|c|}
\hline Author & Experimental condition & Control condition \\
\hline \multicolumn{3}{|l|}{ False belief ( 25 studies) } \\
\hline $\begin{array}{l}\text { Oliver, Vieira, Neufeld, Dziobek, \& } \\
\text { Mitchell, } 2018\end{array}$ & $\begin{array}{l}\text { Read a short vignette involving a person with } \\
\text { a false belief. Predict the behavior of this } \\
\text { person based on her belief. Stimuli adapted } \\
\text { from Dodell-Feder, Koster-Hale, Bedny, } \\
\text { and Saxe (2011) (e.g., "The morning of } \\
\text { high school dance Sarah placed her high } \\
\text { heel shoes under her dress and then went } \\
\text { shopping. That afternoon, her sister }\end{array}$ & $\begin{array}{l}\text { Read a short vignette involving a photograph/physical } \\
\text { representation of the past, and a description of how } \\
\text { things depicted have changed by now. Answer a } \\
\text { question about the outdated scene shown (e.g., } \\
\text { "Old maps of the islands near Titan are displayed } \\
\text { in the Maritime Museum. Erosion has since taken } \\
\text { its toll, leaving only the three largest islands. Near } \\
\text { Titan today there are many islands." [Yes or No]) }\end{array}$ \\
\hline
\end{tabular}

Saxe \& Kanwisher, 2003 under Sarah's bed. Sarah gets ready assuming her shoes are under the dress" [Yes or No])

Read a short vignette involving a person with a false belief. Answer a question about her belief (e.g., "John told Emily that he had a Porsche. Actually, his car is a Ford. Emily doesn't know anything about cars so she believed John. When Emily sees John's car, she thinks it is a ...?" [Porsche or Ford])

Trait judgments (19 studies)

Ma et al., 2011

Read a written statements conveying trait diagnostic information about persons (describing behavior). Then read a single trait-adjective and indicate whether it is consistent with the behavior of that person (e.g., "Tolvan gave her sister a hug ... consistent with [friendly]?")

Zhu, Zhang, Fan, \& Han, 2007

Read a personality trait adjective (e.g., brave, childish) and indicate whether it correctly describes a former American president (Bill Clinton, Yes or No).

Strategic games (13 studies)

Takahashi, Izuma, Matsumoto,

Matsumoto, \& Omori, 2015

Play the matching-pennies game against a human. Both players are asked to choose one of two options at the same time. For one player, the goal is to choose the same options as the other. For the other player, the goal is to choose a different option.

Kircher et al., 2009

Play the prisoner's dilemma game (iterated version). You play with a human player for game points. Both players choose a cooperative or defective strategy on each trial. If both players choose defective, they gain almost no game points at all. If both choose cooperative, both gain some game points. If players choose differently, the defective player gains more points.

Social animations (20 studies)

Moessnang et al., 2016

Watch a video animation of two interacting triangles, which involve influence on each other's mental states (e.g., coaxing). Indicate whether a social/goal-directed/ random movement was shown, and indicate the feeling of both triangles (Positive/Negative). Respond via button press to both questions.

Castelli, Happé, Frith, \& Frith, 2000

Watch video animation of two interacting triangles (e.g., portraying a scene where mother and child are playing). Explain verbally what was happening (after fMRI).

Read a false-photograph vignette. Answer a question concerning the outdated content in the photo (e.g., "A photograph was taken of an apple hanging on a tree branch. The film took half an hour to develop. In the meantime, a strong wind blew the apple to the ground. The developed photograph shows the apple on the ... ?" [Tree or Ground])

Read a written statement about a person doing something. This behavior is neutral and does not convey trait diagnostic information about the person. Indicate the gender of the person in the sentence (e.g., "Tolvan gave her mother a bottle ... is Tolvan male or female?")

Read a personality trait adjective (e.g., brave, childish) and indicate whether it is written in lower- or uppercase (Yes or No)

Play the matching-pennies game against a computer. Both players are asked to choose one of two options at the same time. For one player, the goal is to choose the same options as the other. For the other player, goal is to choose a different option.

Play the prisoner's dilemma game (iterated version). You play with a computer for game points.

Watch a video animation of two triangles which interact in a goal-directed manner (e.g., one chasing the other). Indicate whether a social/goaldirected/random movement was shown, and indicate the feeling of both triangles (Positive/Negative). Respond via button press to both questions.

Watch video animation of two randomly moving triangles. Explain verbally what was happening (after fMRI).

(table continues) 
Table 1 (continued)

\begin{tabular}{|c|c|c|}
\hline Author & Experimental condition & Control condition \\
\hline \multicolumn{3}{|l|}{ Reading the mind in the eyes (15 studies) } \\
\hline Baron-Cohen et al., 1999 & $\begin{array}{l}\text { View a photograph showing the eye region of } \\
\text { a face. Indicate which of two words (e.g., } \\
\text { concerned versus unconcerned) describes } \\
\text { the mental state of that person (button } \\
\text { press). }\end{array}$ & $\begin{array}{l}\text { View a photograph showing the eye region of a face. } \\
\text { Indicate whether the person is male or female } \\
\text { (button press). }\end{array}$ \\
\hline Bos et al., 2016 & $\begin{array}{l}\text { View a photograph showing the eye region of } \\
\text { a face. Indicate if a mental state word } \\
\text { presented before (e.g., shy, hostile, playful) } \\
\text { matches the photo. }\end{array}$ & $\begin{array}{l}\text { View a photograph showing the eye region of a face. } \\
\text { Indicate whether a nonmental state word presented } \\
\text { before (e.g., woman, curly hair, heavy eyebrows) } \\
\text { matches the photo. }\end{array}$ \\
\hline \multicolumn{3}{|l|}{ Rational actions (11 studies) } \\
\hline $\begin{array}{l}\text { Brunet, Sarfati, Hardy-Baylé, \& } \\
\text { Decety, } 2000\end{array}$ & $\begin{array}{l}\text { View a cartoon story and predict what will } \\
\text { happen based on the intentions of a } \\
\text { character (no false belief). Choose a } \\
\text { logical story ending from several options } \\
\text { shown in pictures (e.g., "A prisoner is in } \\
\text { his cell. First, he breaks the bars of his } \\
\text { prison window. Then he walks to his bed." } \\
\text { Indicate what will happen next ... "The } \\
\text { prisoner ties a rope from the sheets on his } \\
\text { bed/the prisoner shouts out loud to get } \\
\text { some attention.") }\end{array}$ & $\begin{array}{l}\text { View cartoon stories and predict what will happen } \\
\text { (press button) based on physical causality (e.g., "A } \\
\text { person is standing in front of a slide. A large ball } \\
\text { is coming down the slide, heading towards that } \\
\text { person." Indicate what will happen next ... "The } \\
\text { ball knocks over the person/the ball rests on the } \\
\text { ground and the person stands beside it.") }\end{array}$ \\
\hline $\begin{array}{l}\text { Heleven, van Dun, \& Van Overwalle, } \\
2019\end{array}$ & $\begin{array}{l}\text { View cartoon stories showing a person over a } \\
\text { sequence of events. The order of pictures } \\
\text { (i.e., events) is jumbled. Indicate the } \\
\text { correct order of pictures based on the } \\
\text { intentions of the character (button press). }\end{array}$ & $\begin{array}{l}\text { View cartoon stories showing a sequence of events. } \\
\text { The order of pictures (i.e., events) is jumbled. } \\
\text { Indicate the correct order of pictures based on } \\
\text { physical causality (button press). }\end{array}$ \\
\hline
\end{tabular}

Note. For a complete list, see the online supplemental materials.

ending based on the rational intentions of the protagonist (implied in their current actions). To keep the task group conceptually homogeneous and distinct from others, we did not include studies which featured false-belief-related cartoons (e.g., deception), emotional scenes, or centrally featured communicative acts (communicative intentions). In control conditions, questions about the nonmental aspects of the scenes were asked, for example, physical causality.

\section{Task Groups: Empathy}

Observing pain. Pain has been a central theme in empathy research, as it was argued that it represents one of the most salient forms of suffering in others (Ochsner et al., 2008; Zaki, Ochsner, Hanelin, Wager, \& Mackey, 2007). Empathizing with another's suffering is an essential feature of human social behavior, seen as a critical precursor for more sophisticated forms of empathy and central to moral reasoning (e.g., Morrison, Lloyd, Di Pellegrino, \& Roberts, 2004). Furthermore, because of its high saliency, pain is an effective stimulus for engaging participants in a task and measuring their brain activity. Studies in this task group presented pictures or videos showing a person's face or body parts in painful situations. Tasks did not ask for an explicit judgment related to the painful stimuli but rather for passive viewing or simple tasks demonstrating attentional engagement (e.g., asking which trial type was shown or to detect visual changes in a fixation cross between trials). Whereas all experimental conditions presented painful stimulations of body parts or faces, the control conditions presented neutral physical stimulations (e.g., being touched by a Q-tip) or no stimulation.
Observing emotions. Recognizing others' emotional states constitutes a process supporting empathy (e.g., Baron-Cohen, 2002; Schulte-Rüther, Markowitsch, Fink, \& Piefke, 2007). However, an even stronger relationship between the observation of (facial) emotions and empathy has been suggested. Based on mirror neuron theories (e.g., Rizzolatti \& Craighero, 2004), it was hypothesized that the (covert) mirroring of observed facial expressions triggers activity in emotional brain areas and thus an empathetic response (Carr, Iacoboni, Dubeau, Mazziotta, \& Lenzi, 2003; Wicker et al., 2003). Researchers explored these relationships in the context of simple passive viewing tasks presenting facial expressions. Because the same task type has also been widely used in other fields of neuroimaging research, we obtained additional studies for this task group from a large sample of suitable research (Fusar-Poli et al., 2009) to achieve $n=25$ as the sample size. ${ }^{11}$ All studies in our task group presented pictures or videos of faces displaying basic emotional expressions (e.g., anger, fear, happiness, or disgust). Participants were not asked for explicit emotion judgments but passively viewed the stimuli or made judgments regarding nonemotional stimulus characteristics (e.g., gender or physical properties). In control conditions, faces showed neutral expressions, or no stimuli were presented at all.

Sharing emotions or pain. Whereas the previous task groups have been related to more automatically occurring processes, the

\footnotetext{
${ }^{11}$ After identifying facial emotion viewing studies in the empathy literature, we added studies to this sample to achieve a task group of 25 studies. We randomly selected additional studies from a meta-analysis on implicit (uninstructed) facial emotion recognition (Fusar-Poli et al., 2009).
} 
Table 2

Examples of Studies in Empathy Task Groups

\begin{tabular}{|c|c|c|}
\hline Author & Experimental condition & Control condition \\
\hline \multicolumn{3}{|l|}{ Observing pain (21 studies) } \\
\hline Olsson, Nearing, \& Phelps, 2007 & $\begin{array}{l}\text { Watch a video of a model undergoing fear- } \\
\text { conditioning situations (receiving a } \\
\text { shock). No response. }\end{array}$ & $\begin{array}{l}\text { Watch a video of a model undergoing fear-conditioning } \\
\text { situations (not receiving a shock). No response. }\end{array}$ \\
\hline $\begin{array}{l}\text { Bos, Montoya, Hermans, Keysers, } \\
\text { \& van Honk, } 2015\end{array}$ & $\begin{array}{l}\text { Watch videos of hands under painful } \\
\text { (needle) stimulation. Watch attentively } \\
\text { and detect changes in the fixation cross } \\
\text { appearing between videos. }\end{array}$ & $\begin{array}{l}\text { Watch videos of hands under nonpainful (cotton swab) } \\
\text { stimulation. Watch attentively and detect changes in } \\
\text { the fixation cross appearing between videos. }\end{array}$ \\
\hline \multicolumn{3}{|l|}{ Observing emotions ( 25 studies) } \\
\hline Critchley et al., 2000 & $\begin{array}{l}\text { View a picture of a face with an emotional } \\
\text { expression (anger, fear). Judge the } \\
\text { gender of the person (button press). }\end{array}$ & $\begin{array}{l}\text { View a picture of a face with a neutral expressions. } \\
\text { Judge the gender of the person (button press). }\end{array}$ \\
\hline Toller et al., 2015 & $\begin{array}{l}\text { View a video of a face showing fearful } \\
\text { expression. Relax and focus on the } \\
\text { actor's eyes. }\end{array}$ & View a video of landscapes. Relax and do nothing. \\
\hline \multicolumn{3}{|l|}{ Sharing emotions or pain (12 studies) } \\
\hline $\begin{array}{l}\text { Preis, Schmidt-Samoa, Dechent, \& } \\
\text { Kroener-Herwig, } 2013\end{array}$ & $\begin{array}{l}\text { View a picture of a body part (hand) under } \\
\text { painful stimulation. Imagine how the } \\
\text { person in the picture feels and rate their } \\
\text { pain (VAS). }\end{array}$ & $\begin{array}{l}\text { View a picture of a body part (hand) under nonpainful } \\
\text { stimulation. Imagine how the person in the picture } \\
\text { feels and rate their pain (VAS). }\end{array}$ \\
\hline $\begin{array}{l}\text { Reniers, Völlm, Elliott, \& Corcoran, } \\
2014\end{array}$ & $\begin{array}{l}\text { View a picture of a face with a sad } \\
\text { expression. Imagine what the person in } \\
\text { the picture is feeling. No response in the } \\
\text { scanner. }\end{array}$ & $\begin{array}{l}\text { View a picture of a face with a neutral expression. } \\
\text { Imagine what the person in the picture is feeling. No } \\
\text { response in the scanner. }\end{array}$ \\
\hline \multicolumn{3}{|l|}{$\begin{array}{l}\text { Evaluating situated emotions ( } 15 \\
\text { studies) }\end{array}$} \\
\hline Kanske et al., 2015 & $\begin{array}{l}\text { Watch a video of a person telling about a } \\
\text { negative autobiographical event. Rate } \\
\text { how you feel and how much compassion } \\
\text { you feel with the person in the video } \\
\text { (button press). }\end{array}$ & $\begin{array}{l}\text { Watch a video of a person telling about a neutral } \\
\text { autobiographical event. Rate how you feel and how } \\
\text { much compassion you feel with the person in the } \\
\text { video (button press). }\end{array}$ \\
\hline Reyes-Aguilar et al., 2017 & $\begin{array}{l}\text { Read a short vignette about an emotionally } \\
\text { negative or positive event, then view a } \\
\text { picture of the person to whom it } \\
\text { happens. Think about what this person is } \\
\text { feeling (no overt response). }\end{array}$ & $\begin{array}{l}\text { Read a short vignette about an emotionally neutral } \\
\text { event, then view a picture of the person to whom it } \\
\text { happens. Think about what this person is feeling (no } \\
\text { overt response). }\end{array}$ \\
\hline \multicolumn{3}{|l|}{ Reasoning about emotions ( 12 studies) } \\
\hline $\begin{array}{l}\text { Hooker, Verosky, Germine, Knight, } \\
\text { \& D’Esposito, } 2010\end{array}$ & $\begin{array}{l}\text { View a series of pictures with two persons. } \\
\text { One person realizes that he/she } \\
\text { mistakenly had a false belief regarding } \\
\text { an emotion-triggering state of affairs. } \\
\text { That leads to a change in his/her } \\
\text { emotions. Indicate whether the pictures } \\
\text { show a social (i.e., emotional) change, a } \\
\text { physical change, or no change (button } \\
\text { press). }\end{array}$ & $\begin{array}{l}\text { View a series of pictures with two persons. One person } \\
\text { has a false belief regarding an emotion-triggering } \\
\text { state of affairs. Nothing changes over the next } \\
\text { pictures (so the person does not realize that he/she } \\
\text { had a false belief). Indicate whether the pictures } \\
\text { show a social (i.e., emotional) change, a physical } \\
\text { change, or no change (button press). }\end{array}$ \\
\hline Völlm et al., 2006 & $\begin{array}{l}\text { View a cartoon story showing two persons. } \\
\text { One is in an emotion-triggering } \\
\text { situation. Predict what the other person } \\
\text { will do to make this person feel better } \\
\text { (button press). }\end{array}$ & $\begin{array}{l}\text { View a cartoon story showing two persons in a neutral } \\
\text { everyday situation. Predict what will happen next } \\
\text { based on physical causality (button press). }\end{array}$ \\
\hline
\end{tabular}

Note. For a complete list, see the online supplemental materials. VAS = Visual Analog Scale (allows ratings along a continuous scale).

present task group probes more voluntary and explicit forms of empathy (see, e.g., de Greck, Shi, et al., 2012; de Greck, Wang, et al., 2012) that are possibly linked to top-down regulatory processes (see van der Heiden, Scherpiet, Konicar, Birbaumer, \& Veit, 2013). The task group contains comparable stimuli as the previous categories (faces with basic emotions, body parts in painful situations), but here participants were explicitly instructed to share the emotional state of the target (e.g., "feeling into" her). In some instances, participants were additionally asked to rate the experi- enced or expressed emotion. In control conditions, participants made similar judgments but based on faces with neutral emotional expressions or body parts under nonpainful stimulation.

Evaluating situated emotions. Another group of studies added situational context to empathy tasks. Here, researchers argued that empathy involves more than just focusing on another person but also considers how they are embedded in a situation and contextual background (e.g., Regenbogen et al., 2012; Ruby \& Decety, 2004). Tasks presenting such contextual information were 
taken to measure a more naturalistic form of empathy (see Mathur, Harada, Lipke, \& Chiao, 2010; Zaki, Weber, Bolger, \& Ochsner, 2009), different from previous task groups presenting (over) simplified stimuli. Studies asked participants to judge a person's emotion based on the situation they were experiencing (e.g., by selecting among alternatives). The situational context was either verbally described by the target person or given as a written narrative. The target person was additionally shown to participants in all tasks, either in a picture or video (telling the story of how the event happened). Control conditions either asked for similar judgments in the context of emotionally neutral content or diverted attention away from emotional material by asking for physical judgments (e.g., judging whether the person was shown on the left or right side of the screen).

Reasoning about emotions. The intersection between empathy and ToM is a recurrent topic in research, bearing concepts such as cognitive empathy (Hooker et al., 2010; Preston \& de Waal, 2002; Schnell, Bluschke, Konradt, \& Walter, 2011; ShamayTsoory et al., 2009), affective ToM (Mier et al., 2010; Schlaffke et al., 2015; Sebastian et al., 2012), mentalizing about emotion (Hooker Verosky, Germine, Knight, \& D’Esposito, 2008), and emotional perspective taking (Derntl et al., 2010, 2012). Across the diversity of labels, we identified several tasks with coherent stimuli and instructions, which were characterized by combining mental state reasoning with emotion judgments. The interrelation between those elements could go in either direction. One set of studies asked participants to infer a future rational action (and therefore, rational intention) triggered by an emotion. Another set of studies asked for inferences about an emotion or emotional change triggered by beliefs or a belief revision (e.g., a person becomes aware of an emotionally relevant object or event). The typical stimulus format in this task group was pictures or cartoons (but we accepted one additional task with a verbal story format). Control conditions asked for inferences about future events based on physical causality or other forms of less complex inference. Although it can be strongly linked to both empathy and ToM literature, we cover this task group in the section on empathy tasks. This is because a (weak) majority of these studies were found by empathy-related keywords. Note, however, that labeling this task as an empathy (or ToM) task has no effect on our clustering, which is purely driven by the features of our meta-analytic brain activation maps, irrespective of terminology.

\section{Clustering}

Based on the meta-analytic result maps obtained for all 11 task groups, we carried out clustering. This is the central step of our analysis, which allows us to estimate an appropriate number of subcomponents of ToM and empathy. For an overview of correspondences between task groups, we show the image dissimilarity of the 11 meta-analyses in Figure 4A. In Figure 4B, we present a dendrogram that illustrates task-by-task and cluster-by-cluster relations. Based on the information shown in the dendrogram, we selected an optimal clustering based on two features (see Figure 3A). First, our desired model ensures a good separation of brain activation patterns between clusters. Second, the components of a good model should be sufficiently abstract to generalize across concrete instances, that is, multiple task groups, rather than picking up variance related to one outlier task group.
Metrics show that among all clusterings, the three-cluster solution shows the best performance (see Figure 3A). This result is of central relevance to our aim to find common neurocognitive components across ToM and empathy tasks. We will argue throughout the next sections and in our Conclusion section (A Hierarchical Perspective) that the three-cluster solution reflects central processes for social cognition.

Although we also observed that the simpler two-cluster solution already explains part of the variation in brain activation, the three-cluster solution explains substantial additional variance. ${ }^{12}$ Therefore, we will discuss both the two- and three-cluster solution as high-level clustering solutions (i.e., those that divide the data only in a small number of clusters). Across all clustering solutions, we found clusterings with further explanatory values at model orders 8 and 11, with the 11-cluster solution performing particularly well. As we will explain in the next sections, the hierarchical structure of our clustering allows us to adopt a multilevel perspective on our results, consistent with previous conceptualizations of social cognition as a multilayered or multilevel phenomenon (De Waal, 2012; Preston \& De Waal, 2002; Schaafsma et al., 2015; Singer, 2006). The Russian doll model, for instance, proposes that the core functions of motor mimicry and emotional contagion are embedded in several layers of more complex processes, ranging up to perspective taking (De Waal, 2007; De Waal \& Preston, 2017). In the next sections, we will discuss the two-, three-, and 11-cluster solution. Finally, we will integrate them by proposing a multilevel model of social-cognitive processes in our Conclusion section (A Hierarchical Perspective). Also note that the multilevel nature of our results evades potential concerns regarding publication bias. For example, a common form of publication bias is the tendency to preferentially report results that correspond to well-established standard findings in a field. Arguably, this may drive increased coherence within empathy and ToM studies, respectively, and thus inflate evidence for a two-cluster solution (empathy-vs.-ToM). However, such a publication bias cannot account for our three- and 11-cluster solutions, because they cover results across empathy and ToM fields.

\section{High-Level Clusterings}

Two-cluster solution. The two-cluster solution shows that our approach could retrace large parts of the classical ToM versus empathy distinction made in the literature (see, e.g., Bzdok et al., 2012; Kanske, Böckler, \& Singer, 2017; Preston \& Hofelich, 2012; Walter, 2012). The networks that we found for the two-cluster solution (see Figure 5) broadly converged with typical ToM (e.g., Koster-Hale \& Saxe, 2013; Mitchell, 2009; Molenberghs et al., 2016; Saxe \& Kanwisher, 2003; Van Overwalle, 2009) and empathy areas, respectively (e.g., Bzdok et al., 2012; Singer \& Lamm, 2009; Timmers et al., 2018). Of six task groups retrieved from the ToM literature, five ended up in a common cluster. On the other

\footnotetext{
${ }^{12}$ Although the twofold clustering fell out of range for our metric calculation, its explanatory power is shown in the dendrogram in Figure $4 \mathrm{~B}$. Because of the hierarchical nature of our clustering, good performance for both the two- and three-cluster solution are compatible observations: The three-cluster solution contains the division made in the two-cluster solution (i.e. it does not lose this information). In addition, it adds another division (by splitting the cluster containing mostly ToM tasks in two halves), which explains substantial additional variance.
} 
hand, three of five task groups from the empathy literature were grouped together. Figure 5 illustrates how the remaining three task groups end up at somewhat unexpected positions in higher levels of the clustering.

The first group was the Reading the Mind in the Eyes task, which researchers originally described as "an advanced test of theory of mind" (e.g., Baron-Cohen, Ring, et al., 1999). This task clustered together with other task groups drawn from the empathy literature (see Figure 5). Brain activation in the left inferior frontal gyrus, anterior insula, and anterior cingulate cortex (see also Molenberghs et al., 2016) largely overlapped with areas found for the other empathy tasks in the cluster. Despite asking participants to select high-level mental-state-related words such as interested, affectionate, or contented, it has been suggested that the Reading the Mind in the Eyes test might engage processing of emotional states and detection of subtle facial cues. Oakley, Brewer, Bird, and Catmur (2016) found that Reading the Mind in the Eyes task performance is more strongly related to individual differences in alexithymia than in autism spectrum disorder, suggesting that it measures emotion recognition ability in addition to, or even rather than, ToM abilities. Furthermore, as we review in more detail in the Behavioral Separability of Tasks From the Three-Cluster Solution section, task performance correlations in nonimpaired participants link the Reading the Mind in the Eyes test to face-based emotion categorization (Olderbak et al., 2015) but not to processing of beliefs (e.g., Strange Stories task: Dziobek et al., 2006; Rice, Anderson, Velnoskey, Thompson, \& Redcay, 2016). In addition, a link to more intermediate tasks combining cognitive and affective elements has been reported (Ferguson \& Austin, 2010; see the Behavioral Separability of Tasks From the Three-Cluster Solution section for further explanation).

The other task groups that clustered unexpectedly were Evaluating Situated Emotions and Reasoning about Emotions. We will discuss potential processes underlying these tasks later in the Intermediate Cluster (Cluster 2) section. While Evaluating Situated Emotions tasks have been labeled empathy tasks in previous research, studies from the Reasoning about Emotions group have been described more heterogeneously. Similar paradigms have been linked to cognitive empathy (Hooker et al., 2010), affective ToM (Schlaffke et al., 2015), or mentalizing about emotion (Hooker et al., 2008). We assigned the task group to empathy as it contained more studies with empathy- than ToM-related keywords. However, such an a priori assignment is debatable. Note, however, that our data-driven clustering would have assigned this task group at the same position irrespective of our labeling as empathy or Theory of Mind.

Three-cluster solution. The three-way clustering reflects a central result of our analysis and will be discussed in depth throughout the next sections. Finally, in the Conclusion section (A Hierarchical Perspective), we propose that it reflects the higher, central level of a hierarchical multilevel model of social-cognitive processes. Figure 5 shows the activated networks for the three clusters. For simplicity, we will refer to these clusters as cognitive (1), affective (3), and intermediate (2). The task-by-task dissimilarity matrix in Figure 4A suggests that the cognitive and affective clusters form opposite poles with largely distinct brain activity profiles while the intermediate cluster bears similarities to both poles. This observation is further supported by a weaker image correlation between the (unthresholded) cognitive and affective cluster maps ( $r=.46$ ) compared with correlations between the intermediate and other two maps (intermediate-cognitive $r=.80$, intermediate-affective $r=.76$ ).

For the functional description of the three clusters, we applied neurosynth functional decoding (Yarkoni et al., 2011), a tool that allows a brain activation map to be compared with an extensive set of automatically generated meta-analyses across a wide range of topics ("terms"). Highest convergence with social and nonsocial terms is shown in Figures 6 and 7. Based on this broad decoding, we can discuss our findings in the context of not only classical theories of social processes but also alternative theories that suggest more general-purpose processes to underlie ToM (e.g., Buckner \& Carroll, 2007; Corbetta, Patel, \& Shulman, 2008; Heyes, 2018; Heyes \& Frith, 2014) and empathy (e.g., Barrett, Lindquist, \& Gendron, 2007; Lindquist, Satpute, \& Gendron, 2015; Wager et al., 2016; but see Lieberman, Burns, Torre,\& Eisenberger, 2016; Lieberman \& Eisenberger, 2015).

Cognitive cluster (Cluster 1). Brain activation for the cognitive cluster (see Figure 5) was mainly found in the cortical midline and temporoparietal areas. Strongest activation was found in the anterior cingulate cortex and medial prefrontal cortex. This activation cluster extended along the cortical midline to the precuneus and parts of the midcingulate cortex. Bilateral temporoparietal areas included the right posterior superior temporal gyrus, right supramarginal gyrus, left posterior middle temporal gyrus, and inferior parietal lobule. Additional areas were found in bilateral anterior temporal cortices and a smaller subcortical cluster (caudate). Compared with a resting-state network atlas of the brain (Yeo et al., 2011), activations for cluster 1 showed the most prominent overlap with the default mode network (DMN). More specifically, $56 \%$ of voxels in cluster 1 fell within the DMN, followed by smaller overlaps with the frontoparietal network (9\%) and the ventral attention network (also known as the salience network, 9\%).

Neurosynth decoding (see Figure 6) for social terms found the strongest associations with theory of mind, mentalizing, and related terms, characterizing the cognitive cluster as most prototypical of ToM. For nonsocial terms, the strongest associations were found for default, self-referential, and autobiographical. These later decoding results mirror neurocognitive accounts of understanding others that emphasize the role of the DMN (see Buckner \& Carroll, 2007; Bzdok et al., 2013; Mars, Neubert, et al., 2012; Mars, Sallet, et al., 2012; Meyer, Davachi, Ochsner, \& Lieberman, 2019; Spreng, Mar, \& Kim, 2009; Spreng et al., 2010; Spunt, Meyer, \& Lieberman, 2015).

It has been argued (e.g., Andrews-Hanna, Smallwood, et al., 2014) that self-generated cognition decoupled from the physical world is mediated by the DMN. This becomes relevant for ToM because we do not have immediate perceptual access to others' mental states (see Frith \& Frith, 2003; Lieberman, 2007). For example, the self-projection hypothesis (Buckner \& Carroll, 2007) states that the DMN uses past experiences in an adaptive fashion to imagine perspectives and events beyond those that emerge from the immediate environment. In line with that, overlapping parts of the DMN have been found implicated in other- and self-related mental state reasoning (e.g., Mitchell et al., 2005; Murray, Schaer, \& Debbané (2012)).

Related theories were formulated in the ToM field (independent of the DMN), linking ToM to a decoupling mechanism that allows 
the separation of beliefs from reality (Frith \& Frith, 2003, 2012; Gallagher \& Frith, 2003), metarepresentation of mental states in the form of propositional attitudes (Leslie et al., 2004), the processing of covert (i.e., unobservable) mental states (Gobbini, Koralek, Bryan, Montgomery, \& Haxby, 2007), or perspective differences (Perner \& Leekam, 2008; Perner \& Roessler, 2012).

An interesting feature of the cognitive cluster is that it contained a specific subset of tasks from the ToM literature: False Belief tasks, Trait Judgments, and Strategic Games. Whereas generalpurpose DMN theories usually make no predictions regarding the type of ToM task that should engage this network, theories from the ToM field usually associate False Belief tasks with decoupling (e.g., Frith \& Frith, 2003) and processing of covert mental states (Gobbini et al., 2007). Relatedly, Strategic Games require tracking potential deception (and thus beliefs) and therefore can also be linked to decoupling.

Less frequently mentioned by DMN/decoupling theories is the processing of personality traits (i.e., Trait Judgments). Arguably, personality traits could be seen as mental states that are abstracted (i.e., generalized) across concrete instances and are sometimes also decoupled from observable behavior (e.g., a person might perform the same dangerous action either out of courage or recklessness). Moreover, it was hypothesized that the transient (e.g., beliefs) and stable (e.g., traits) mental states of others are jointly processed by a multilevel representation (Tamir \& Thornton, 2018) where knowledge about a person's traits is used to guide expectations about transient mental states (Conway, Catmur, \& Bird, 2019; Tamir \& Thornton, 2018; see also Thornton, Weaverdyck, \& Tamir, 2019). To illustrate, a particularly distrustful person might be harder to deceive and therefore less likely to have a false belief (Conway et al., 2019).

Affective cluster (Cluster 3). For the affective cluster, we found brain activation (see red in Figure 5) across the right frontal cortex, peaking in the inferior frontal gyrus, and extending to the right insula and temporal pole, pre- and postcentral gyri, as well as the supramarginal gyrus. Further areas were activated in the left inferior frontal gyrus, insula, temporal areas, and supramarginal gyrus. Another large area was activated in the supplementary motor area and the adjacent medial frontal gyrus and midcingulate cortex. Two smaller areas were also found in the left inferior occipital gyrus and left cerebellum. Overlaps with resting-state networks (Yeo et al., 2011) for cluster 3 were mainly found in the ventral attention network (26\%), the somatosensory network $(16 \%)$, and the DMN (14\%). The most prominent social terms found with neurosynth decoding were pain, fear, affective, and face (as well as the clinical term asd - autism spectrum disorder). For nonsocial terms, we found high loadings on several languagerelated terms, such as word, phonological, language, or semantic (for a discussion of the possible roles of language processes, see the Possible Roles of Language Processes in the Three-Cluster Solution section). In line with the terms pain and fear found by neurosynth decoding, strong activation for the affective cluster was found in the left insula. This structure has been described as part of a core network that activates whenever we witness the suffering of others (e.g., Bzdok et al., 2012; Lamm et al., 2011; Preckel, Kanske, \& Singer, 2018). To illustrate, studies on empathy for pain and other negative emotions consistently found activation in the anterior insula and anterior cingulate cortex (Jabbi, Swart, \& Keysers, 2007; Jackson, Meltzoff, \& Decety, 2005; Kanske, Böck- ler, Trautwein, \& Singer, 2015; Singer et al., 2004; Tholen, Trautwein, Böckler, Singer, \& Kankse, 2020). Activation patterns in these areas were found to predict the affective and emotional states of an observed other. Such a relationship could be found across different modalities such as pain, disgust, or unfairness (CorradiDell'Acqua, Tusche, Vuilleumier, \& Singer, 2016; but see Krishnan et al., 2016), which suggests that parts of these brain areas encode affective rather than sensory features of stimuli. Moreover, the same areas were found to be active not only during emotion observation but also when participants themselves experienced an emotion first-hand (e.g., Lamm et al., 2011; Rütgen et al., 2015). This has been taken as evidence for shared networks in empathy (Carrillo et al., 2019; Corradi-Dell'Acqua et al., 2016; Gallese \& Goldman, 1998; Preston \& de Waal, 2002; see also Alcalá-López, Vogeley, Binkofski, \& Bzdok, 2019). In addition to the left insula, the affective cluster showed activation in the left inferior frontal/ precentral gyrus and postcentral (somatosensory) and supramarginal gyri, which again have been linked to shared networks. In particular, the premotor cortex has been linked to the mirroring of emotional expressions, that is, the covert (or overt) imitation of observed emotional facial expressions (cf. Adolphs, 2009; Carr et al., 2003; Decety \& Jackson, 2004; Gazzola, Aziz-Zadeh, \& Keysers, 2006; Pfeifer \& Dapretto, 2009; Shamay-Tsoory et al., 2009). The shared-networks hypothesis was embedded in the general framework of mirror neurons (Gallese, 2003; Gallese \& Goldman, 1998; Rizzolatti \& Craighero, 2004) and is compatible with theories of common coding for action and perception (Keysers \& Gazzola, 2009; Keysers, Kaas, \& Gazzola, 2010) and perceptionaction models (e.g., de Waal \& Preston, 2017; Preston, 2007; Preston \& de Waal, 2002; Preston \& Hofelich, 2012). These models assume that seeing an emotional expression automatically activates the corresponding motor- and somatosensory representations in the observer (producing an embodied representation), which facilitates the decoding/understanding of these emotional states. Such an interpretation is also supported by our neurosynth decoding results, identifying the terms action and motor for the affective cluster.

Tasks in the affective cluster broadly align with the notion of an empathy core network for witnessing the pain or emotions of others. The cluster contained those three task groups from the empathy literature which present relatively simple stimuli concerning others' pain and emotions without any context or additional information (Observing Pain, Observing Emotions, Sharing Emotions or Pain). In addition, it included the Reading the Mind in the Eyes task from the ToM literature, which also fits this description. Interestingly, shared network (e.g., Preston \& de Waal, 2002) and mirroring (e.g., Gallese \& Goldman, 1998) accounts often contain the notion that the implicated processes are taking place spontaneously (or automatically), that is, in the absence of explicit task instructions (see also Cracco et al., 2018; Heyes, 2011). Our results show that for half of the task groups in the affective cluster, participants were not explicitly instructed to empathize with others. This suggests that at least part of the processes linked to affect sharing do not need to be volitionally initiated, in keeping with the aforementioned accounts.

Intermediate cluster (Cluster 2). Whereas the cognitive and affective clusters reflect two largely independent processes, the intermediate cluster takes an interesting position between them. In this section, we illustrate how it combines cognitive and affective 
elements in terms of activated brain areas and included task groups. We found brain activation for the intermediate cluster in large parts of the bilateral temporal lobes, spanning from the posterior superior temporal gyri to the anterior temporal lobes. We observed activation in areas overlapping with parts of the cognitive cluster (cluster 1), including the bilateral temporoparietal cortex and precuneus. Furthermore, we also found some convergence among activations found for the affective cluster, such as in the left insula and inferior frontal gyrus. In terms of overlaps with restingstate networks (Yeo et al., 2011), activations for cluster 2 fell in the DMN (43\%), the Ventral Attention Network (18\%), and the Frontoparietal Network (10\%). To further investigate activation for this cluster, we carried out a set of meta-analytic contrasts tailored to identify commonalities between the intermediate cluster and the other two clusters. ${ }^{13}$ Analyses confirmed significant activation specific for the cognitive and intermediate clusters in the precuneus, dorsal-posterior medial prefrontal cortex, bilateral temporoparietal, and anterior temporal areas (see Figure 7). Overall, these activations were more pronounced in the right hemispheric areas. For the intermediate and affective clusters, the strongest common activations were found in the left insula and furthermore in the bilateral inferior frontal gyri, left precentral gyrus, left superior temporal gyrus, and supplementary motor area. Decoding of the intermediate cluster showed largely a combination of terms already found for the cognitive and affective clusters. Notably, however, some language-related terms showed higher loadings on the intermediate cluster compared with both other clusters: sentences, speech, listening, and comprehension. When decoding activations common to the intermediate and cognitive clusters (see Figure 7), we found social terms such as theory of mind, mentalizing, and mental states and nonsocial terms such as default, self-referential, and autobiographical. Decoding commonalities between the intermediate and the affective cluster, we found social terms such as touch, painful, face, and imitation (as well as the clinical term asd), and nonsocial terms such as phonological, reading, word, and language.

Together, meta-analytic contrast maps and decoding results (see Figure 7) highlight that the intermediate cluster combines cognitive and affective processes. Although theories proposed several variants of this combination, the fact that we found one intermediate cluster also suggests a common process. This common process could account for the concepts affective ToM (Mier et al., 2010; Schlaffke et al., 2015; Sebastian et al., 2012), cognitive empathy (Hooker et al., 2010; Preston et al., 2007; Preston \& de Waal, 2002; Schnell et al., 2011; Shamay-Tsoory et al., 2009; Walter, 2012), and emotional perspective taking (Derntl et al., 2010, 2012).

The notion that the intermediate cluster combines cognitive and affective processes is also supported by its anatomical position in terms of macroscale connectivity architecture (see Figure 8). Furthermore, it is reflected by the combination of different features in this cluster's tasks. With respect to cognitive processes, the task groups Reasoning about Emotions, Social Animations, and Rational Actions all involve mental-state reasoning (i.e., about goals, intentions, or beliefs) by definition. Also, the event narratives presented in the Evaluating Situated Emotions task group provide rich information for inferring not only the feelings of a person but also their thoughts and desires. In line with this notion, Zaki et al. (2009) found that accurate empathetic judgments based on event narratives are accompanied by the corecruitment of more affective areas (premotor cortex, inferior parietal lobule) and more cognitive areas that have been linked to mentalizing (e.g., medial prefrontal cortex, superior temporal sulcus). Besides cognitive features, most tasks from the intermediate cluster also call for affective processing. Although the Evaluating Situated Emotions and Reasoning about Emotions tasks do so by definition, there is evidence that Social Animations trigger affective processes as well. Tasks from this group mostly depict affective scenarios (e.g., mocking, tricking, coaxing) and have been reported to elicit subjective emotional responses (Rimé, Boulanger, Laubin, Richir, \& Stroobants, 1985). The involvement of affective processes is less clear for Rational Actions, which did not include explicitly affective stimuli. Possibly in relation to this, our clustering stability analysis (Figure 3B) found that this task group frequently changed membership in favor of the cognitive cluster. Taken together, our task groups suggest that the degree to which affect-laden contents and mental-state inference occur together determines whether cognitive and affective networks work in concert.

\section{Possible Roles of Language Processes in the Three-Cluster Solution}

A notable finding from neurosynth decoding was that both the intermediate and affective clusters showed high loadings on languagerelated terms. Possible contributions of language processes were discussed both in the empathy and ToM literature. In the empathy field, at least two alternative views have been proposed on the topic. Based on mirroring accounts, a first line of theorizing followed the observation that areas with mirror properties (e.g., Broca's area, BA 44/45) overlap with areas traditionally linked to speech production in humans (e.g., Rizzolatti \& Craighero, 2004). It was hypothesized that this overlap might reflect that human language, including phonology and syntax, is embedded in the organizational properties of the motor system. Accordingly, the motor system represents an evolutionary precursor of language functions (e.g., Gallese, 2008; but see Toni, De Lange, Noordzij, \& Hagoort, 2008). Our decoding might therefore not necessarily reflect language processing per se but rather motor/mirror processes taking place in the same regions. A second line of theorizing suggests a more direct role of language in emotion processing and categorization. It has been repeatedly found that brain networks for emotion processing overlap with large parts of networks for semantic cognition (Binder, Desai, Graves, \& Conant, 2009; Lindquist, Wager, Kober, Bliss-Moreau, \& Barrett, 2012; see also Brooks et al., 2017). Thus, psychological constructionist accounts have suggested that concepts available as words (e.g., anger, disgust, fear) shape how people understand their experiences as specific emotions (e.g., Barrett et al., 2007; Lindquist et al., 2015, 2017; Wilson-Mendenhall, Barrett, Simmons, \& Barsalou, 2011). Emotions have been taken to arise from a combination of conceptual processing supported by language and more basic experiences of affect such as the feeling of pleasure or displeasure. Furthermore, the role of semantic knowledge has been discussed in ToM related accounts, and previous meta-analyses (e.g.,

\footnotetext{
${ }^{13}$ To find specific commonalities in the intermediate and cognitive clusters (i.e. that go beyond what is also found for the affective cluster), we computed the conjunction of contrasts cognitive $>$ affective $\&$ intermediate $>$ affective. Likewise, for specific commonalities between the intermediate and affective clusters, we computed intermediate $>$ cognitive \& affective $>$ cognitive. For completeness, we also computed the contrast cognitive $>$ intermediate \& affective $>$ intermediate, which found no significant activations
} 


\section{Positioning the cognitive, intermediate and affective cluster along a principal gradient of macroscale cortical organization}

\section{A. Principal gradient of cortical organization}
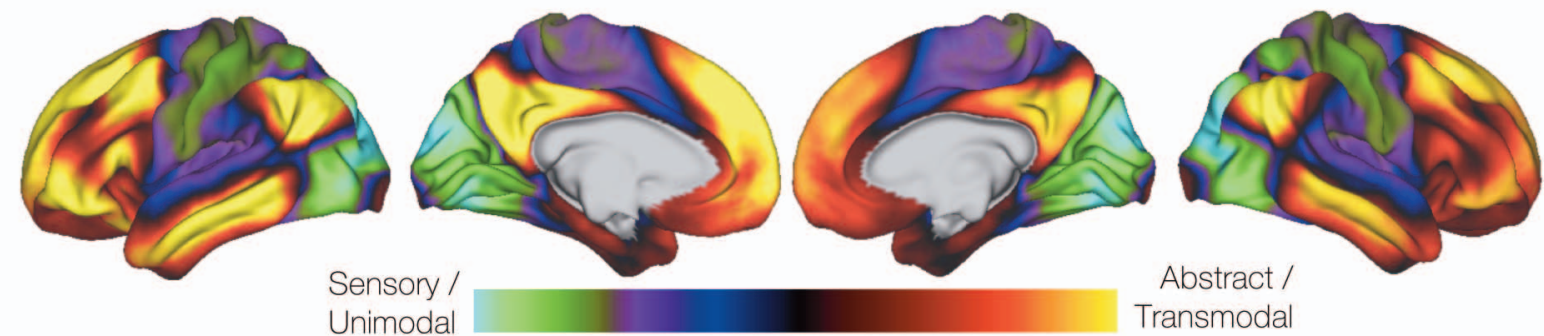

B. Mapping of meta-analyses on principal gradient
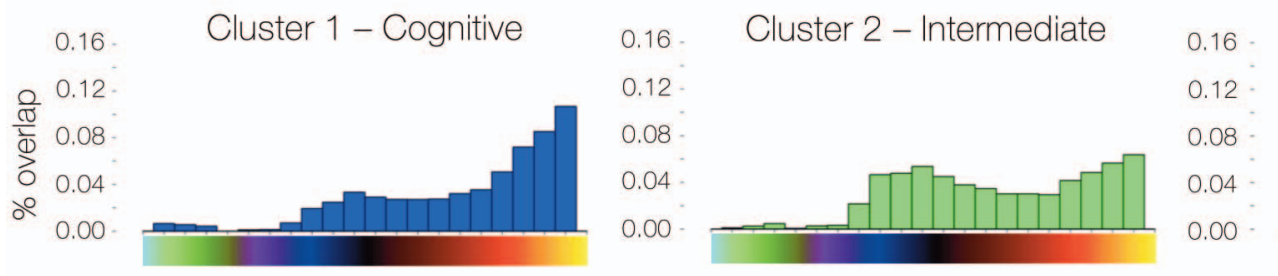

Cluster 3 - Affective
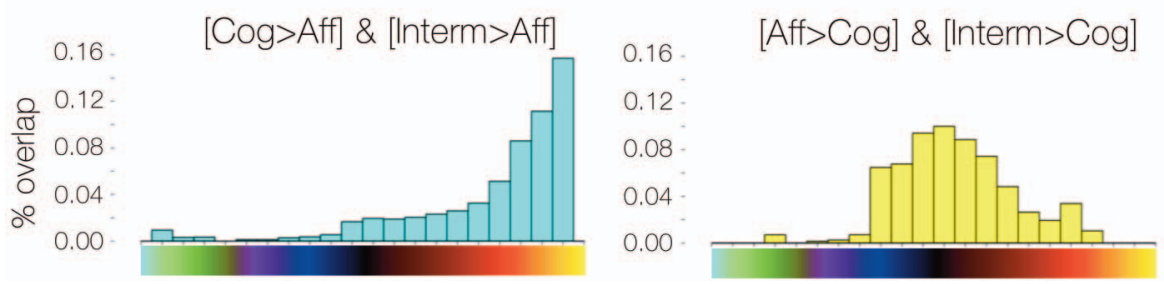

Figure 8. (A) Whole-brain map of connectivity organization, capturing continuous changes (i.e., a principal gradient) of brain connectivity patterns across the cortex. Gradient ranges from sensory and unimodal areas in the sensorimotor, auditory, and visual cortex (green-blue/dark grey), to increasingly abstract and transmodal areas (red-yellow/light grey) which largely correspond to the brain's default mode network. This gradient was determined by analyzing resting-state connectivity data from a large sample of healthy adults (Human Connectome Project, $n=820$ ). (B) Percentiles along the gradient were split into 20 distinct maps. For each map, we calculated the overlap with our meta-analyses. The bar charts provide the percent overlap between percentile maps and meta-analyses, that is, what percent of voxels in a meta-analysis map overlapped with each percentile map (normalizing results across differently sized meta-analysis maps). See the online article for the color version of this figure.

Andrews-Hanna, Smallwood, et al., 2014; Mar, 2011) showed widespread overlap between default mode and language-related processes. For example, it was hypothesized that ToM involves mental-state concepts that we learn (as children) by communicating with expert mind readers (e.g., Heyes \& Frith, 2014). Moreover, some forms of mentalizing have been linked to the retrieval of social semantic scripts (e.g., Frith \& Frith, 2003; Gallagher \& Frith, 2003), which contain knowledge about which activities take place in different contexts. Taken together, these theories suggest that both ToM- and empathyrelated processing involves language capabilities. Interestingly, while decoding showed weaker loadings for the cognitive cluster (containing some classical verbal ToM tasks) on language-related terms (e.g., "sentences", "language"), stronger relations were found for the affective and intermediate clusters.

\section{Behavioral Separability of Tasks From the Three-Cluster Solution}

Exploring the broader implications of the three-cluster model, we next evaluated whether our neural task clustering is mirrored by a behavioral task clustering. Therefore, we reviewed behavioral literature on healthy adults (i.e., different studies than those in our meta-analysis ${ }^{14}$ ) for reports of performance correlations among social cognition tasks. If the three clusters we found on the neural

\footnotetext{
${ }^{14}$ We reviewed independent literature to find behavioral correlations. All studies we report here are different from the neuroimaging studies in our meta-analysis except Kanske et al. (2015). Because of its large sample size and thus robust results, we also discuss the behavioral data of this neuroimaging study.
} 
level reflect different neurocognitive processes of social cognition, then behavioral studies presenting tasks similar to those in our neuroimaging meta-analysis should find a corresponding pattern of task-by-task intercorrelations. In particular, we followed up two observations from our neural clustering. First, the cognitive and affective clusters showed largely distinct neural networks. Therefore, behavior linked to tasks from cognitive versus affective clusters may be uncorrelated (or weakly correlated). Second, the intermediate cluster showed neural overlap with both the cognitive and the affective clusters. We therefore expect that tasks linked to this cluster show more widespread behavioral intercorrelations. Specifically, studies should report intercorrelations both between tasks from the cognitive and intermediate clusters, as well as the affective and intermediate clusters.

With respect to the first prediction, behavioral studies clearly support the independence between processes associated with the cognitive and affective clusters. Kanske, Böckler, Trautwein, ParianenLesemann, and Singer (2016) tested both belief reasoning (cognitive cluster) and evaluation of emotions (affective cluster) in a large sample of nonimpaired adults using a combined-task setup (the EmpaToM task). The authors found that behavioral performance in these two measures was uncorrelated. Also, when additional data-driven composites of several ToM and empathy tasks were used, no association was found. Similarly, no correlation was found between performance in the Reading the Mind in the Eyes (affective) and Strange Stories (cognitive, because strange stories present various beliefrelated contents, see, e.g., Happé, 1994; White, Hill, Happe, \& Frith, 2009) tasks. This observation was made both for 7- to 12-year-old children (Rice et al., 2016) and for adults (Dziobek et al., 2006). In addition, double dissociations in cognitive versus affective task performance have been found for patients with lesions in different brain areas (e.g., Shamay-Tsoory \& Aharon-Peretz, 2007; Shamay-Tsoory et al., 2009).

With respect to our second, and maybe less obvious, prediction, several studies report relevant results. Regarding associations between tasks from the affective and intermediate clusters, Lockwood, Bird, Bridge, and Viding (2013) found a positive correlation between accuracy for ratings of social animations (in our intermediate cluster) and judgments of one's affective reaction to emotional faces (affective cluster). Interestingly, correlations were also found between biological motion perception (affective/intermediate cluster) and the Reading the Mind in the Eyes task (affective) both in adults (Miller \& Saygin, 2013) and 7- to 12-year-old children (Rice et al., 2016). ${ }^{15}$ Biological motion perception can be linked to the affective cluster because of its relation to action perception (and thus perception-action cycles for affect sharing; see, e.g., de Waal \& Preston, 2017; Keysers et al., 2010). However, stimuli are also related to a task falling in the intermediate cluster (Social Animations), and as we illustrate in Figure 9, brain activation for biological motion overlaps most prominently with that for our intermediate cluster.

Another behavioral task that we tentatively link to the intermediate cluster is the Faux Pas test (e.g., Baron-Cohen, O'Riordan, Jones, Stone, \& Plaisted, 1999). Understanding a faux pas (e.g., observing someone who is hurting another person's feelings out of ignorance) requires the processing of not only belief-like states (e.g., someone's ignorance) but also their affective consequences (e.g., subsequent regret/embarrassment due to accidentally hurting someone's feelings). Correspondingly, Ferguson and Austin (2010) found an association in performance between the Faux Pas test (intermediate) and the Reading the Mind in the Eyes task (affective) in a large sample of nonimpaired adults.

With respect to correlations between tasks from cognitive and intermediate clusters, results are more mixed. In a sample of nonimpaired adults, Brewer, Young, and Barnett (2017) found no correlation between behavioral performance on social animations (intermediate cluster) and the Strange Stories task (cognitive cluster). The authors noted, however, that this could be linked to range restrictions in scores (as nonimpaired adults often show ceiling effects on ToM tests linked to our cognitive cluster). Interestingly, when rerunning the correlation analysis for a pooled sample of nonimpaired adults and adults with autism spectrum disorder, Brewer et al. (2017) found an association between performance on Social Animations and Strange Stories. Similarly, for 7- to 12 year-old children (Rice et al., 2016), a correlation between behavioral performance in biological motion perception (affective/intermediate) and Strange Stories (cognitive) was found.

\section{Positioning the Three Clusters Along a Principal Gradient of Macroscale Cortical Organization}

To further characterize functional relations between the intermediate and the cognitive and affective clusters, we projected our clusters' activation maps along a principal gradient of macroscale cortical organization, which describes a functional spectrum along the cortical surface based on functional connectivity patterns (Margulies et al., 2016). The gradient characterizes continuous changes in these patterns, which reflect changes in functional roles: increased distance (in terms of connectivity) from primary sensory and motor areas reflects increasingly abstract and multimodal processing (Margulies et al., 2016). As shown in Figure 8A, unimodal sensory and motor representations lie at one end while abstract multimodal representations lie at the other end of the connectivity gradient. Grounding this map also in brain structure, Margulies et al. (2016) showed that each region's position on the connectivity gradient strongly predicts the area's spatial (i.e., geodesic) distance along the cortical surface to higher-order association areas (at the top of the gradient).

We reasoned that if the intermediate cluster represents the parallel involvement of cognitive and affective processes, its position along the gradient should coextend with the positions of both other clusters. Conversely, if the intermediate cluster represents a unique and largely independent functional process, its position along the gradient should be distinct. As shown in Figure 8B, the intermediate cluster tended to overlap with the locations of both the cognitive and affective clusters rather than any other positions. The cognitive cluster was located close to the transmodal end of the gradient (85th-95th percentiles), supporting its functional interpretation in terms of abstract, stimulusindependent thought. The affective cluster was located toward the middle of the gradient (35th-55th percentiles), which indicates more sensory-based and unimodal processing.

These findings support our interpretation that the intermediate cluster combines cognitive and affective processes, which is notable

\footnotetext{
${ }^{15}$ Also note that our assignment of the Reading the Mind in the Eyes task to the affective cluster is reflected by behavioral findings. For example, Olderbak et al. (2015) reported a positive correlation between the Reading Mind in the Eyes task and a face-based emotion categorization task.
} 

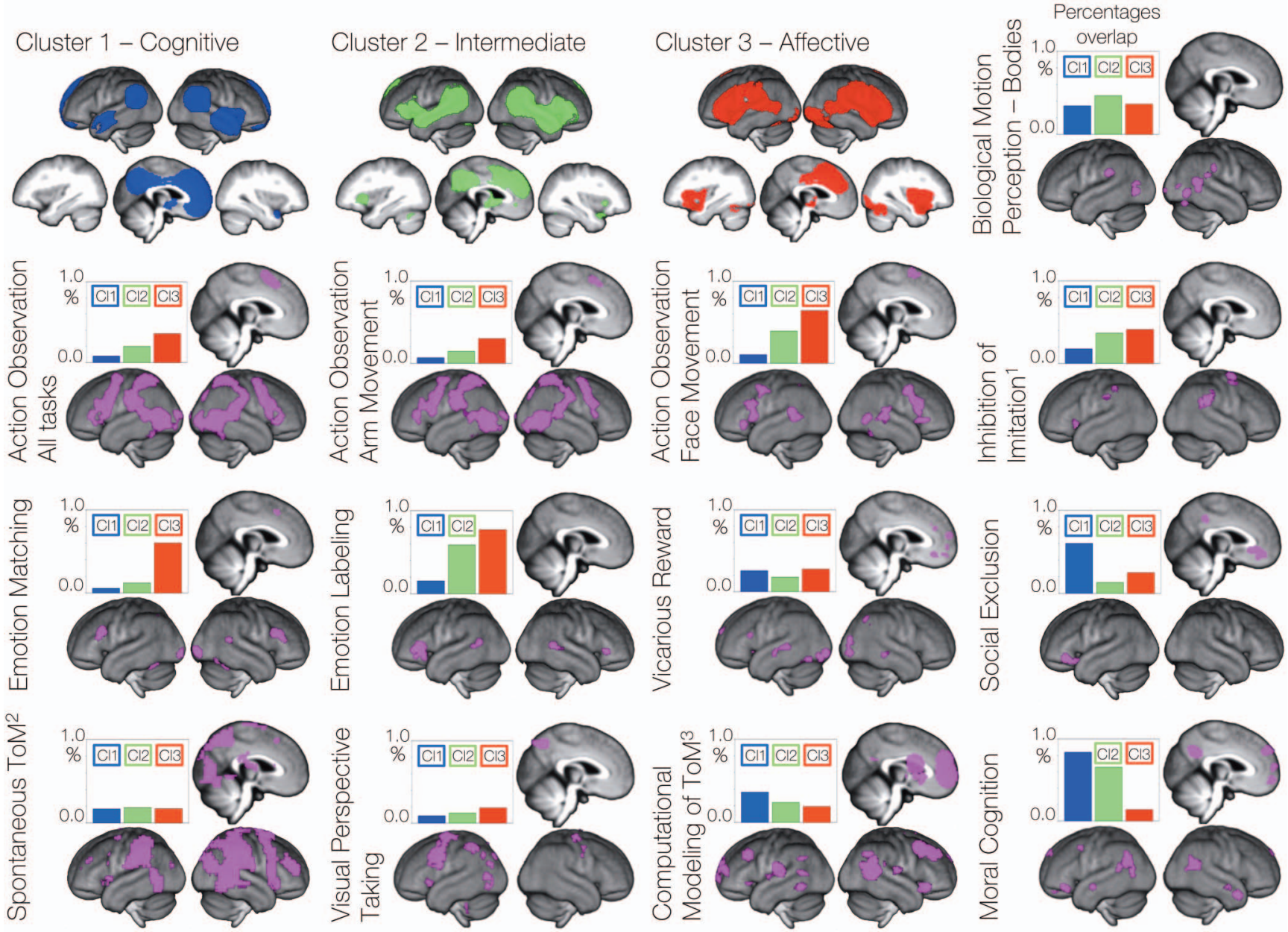

Figure 9. Overlaps between our three-cluster solution and meta-analyses on related topics of social cognition. For each topic map, we indicate the percentage of voxels falling into each of the three meta-analytic clusters. Note that percentage values are relative to the size of each topic-related map (e.g., maps containing extensive areas of activation may feature more regions outside our three clusters). Therefore, the relative patterns of overlaps within each topic map are of main interest. See the Relation to Other Meta-Analyses on Social Cognition section for more details. Footnotes:

${ }^{1}$ For exploratory purposes, we show an uncorrected map of the meta-analysis results by Darda and Ramsey (2019).

2 Map from Boccadoro et al. (2019) shows results from a multistudy analysis on spontaneous ToM (not a meta-analysis, based on original data), three studies, $n=68 .{ }^{3}$ Map from Cheong et al. (2017) shows the most consistent overlaps across five published studies, summarized based on expanding reported coordinates into 15-mmradius spheres. See the online article for the color version of this figure.

for several reasons. During passive rest, spontaneous fluctuations of brain activity in corresponding areas and networks (e.g., affective: Ventral Attention Network; cognitive: DMN) have been found to be unrelated (e.g., Alcalá-López et al., 2018) and sometimes even anticorrelated (Bzdok et al., 2013; Chai, Castañón, Öngür, \& WhitfieldGabrieli, 2012; Fox et al., 2005; Zhou et al., 2018). During tasks requiring externally focused attention, an inhibitory relation was found between the ventral attention network and the DMN, which is considered to reflect the former down-regulating the latter to reduce interference from task-unrelated processes (Goulden et al., 2014; Trautwein, Singer, \& Kanske, 2016; Wen, Liu, Yao, \& Ding, 2013; see also Anticevic et al., 2012). Although these findings suggest that areas linked to the cognitive and affective clusters are functionally segregated in many task contexts, our meta-analysis identified a cluster of tasks (intermediate) where cognitive and affective processes operate conjointly.

\section{Low-Level Clustering}

As we take a multilevel perspective on our results, we also consider clusterings beyond our central, high-level, three-cluster solution. We will focus on the relation between high- and lowlevel clusterings again in our Conclusion section (A Hierarchical Perspective). Across the entire spectrum of solutions, our metrics also pointed to two more low-level solutions, with 8 and 11 clusters. This suggests that brain activation contains additional 
variability that goes beyond what is captured at our central high level (three clusters). In particular, the 11-cluster solution showed good performance, implying that task-to-task variability is large enough that each gets assigned to a cluster of its own by the algorithm. One possible explanation for this additional heterogeneity includes differences in stimuli and task instructions, which might be unrelated to central processes linked to empathy and ToM. We illustrate the role of stimuli and task instructions in our additional color coding in Figure 5. For the sake of brevity, we only map out two popular distinctions: verbal versus nonverbal stimuli and instructed versus uninstructed tasks. ${ }^{16}$ Note that several other (and partially related) categorizations have been discussed elsewhere but go beyond the scope of our exemplary illustration (see, e.g., Fan et al., 2011; Mar, 2011; Molenberghs et al., 2016; Timmers et al., 2018; Van Overwalle, 2009). Consistent with the idea of finding more abstract classes of functioning at higher levels, none of the clusters at model order 3 contains tasks from only one category (e.g., only verbal tasks). ${ }^{17}$ At lower levels, parts of subclusterings are accompanied by separations in terms of task or stimulus formats. For example, the three task groups False Belief, Trait Judgments, and Strategic Games cluster together at a higher level (three-cluster solution), but Strategic Games are separated at a lower level (eight-cluster solution). These tasks differ in that two of the former are verbal (sentences or words) whereas the latter is nonverbal (strategic decision-making). Although this pattern demonstrates that stimulus format is implicated in parts of lower-level cluster separations, other observations demonstrate that this does not provide a perfect explanation. For example, as also illustrated in Figure 5, the Reading the Mind in the Eyes task falls into the same categories as Trait Judgment tasks: verbal and instructed. In addition, both tasks are drawn from the ToM literature. Nevertheless, the two tasks end up at opposite positions in the clustering (see Figure 4B), and their activation maps show relatively low similarity (see Figure 4A). Therefore, we conclude that although stimulus and task format drives part of the variability in meta-analytic activations, it does not provide a complete account of them. As we will argue in detail in our Conclusion section (A Hierarchical Perspective), this pattern supports a multilevel model for social-cognitive processes, similar to what has been suggested in other fields such as intelligence and personality research. The three-cluster solution (higher level) may reflect more abstract and broad classes of functioning. The eight- and 11-cluster solutions (lower level) capture additional variability, which possibly describes how central processes are applied in concrete contexts of particular tasks. For such task contexts, both the stimulus format and the task instructions play important roles.

\section{Relation to Other Meta-Analyses on Social Cognition}

The present meta-analysis and review focused on processes involved in inferring others' unobservable mental states and thus on the literature on empathy and ToM. For the sake of coherence and practical limitations, we did not carry out meta-analyses for other topics in social cognition. For example, we did not cover related processes such as action observation ("mirroring"). Furthermore, we did not include tasks which involved mental state inference as a subcomponent employed alongside other diverse processes. This was the case, for example, for the topics of moral cognition, social exclusion, or social decision-making. However, we illustrate recently published meta-analyses on these topics below and characterize the overlap with our meta-analytic clusters.

Figure 9 shows overlaps between thresholded maps from our three-cluster solution and maps from other meta-analyses on social topics. For a meta-analysis on biological motion perception focusing on whole-body movement such as walking or dancing (Grosbras, Beaton, \& Eickhoff 2012), we found the highest overlap with the intermediate cluster. Moreover, the map also showed overlaps with both the cognitive and affective clusters. However, note that the intermediate cluster spatially overlaps with both other clusters (see top row in Figure 9). For a meta-analysis on action observation or mirroring (Hardwick, Caspers, Eickhoff, \& Swinnen, 2018), we illustrate overlaps specifically for meta-analysis on (a) all types of action observation, (b) observation of actions performed with arms, and (c) observation of actions performed with faces. For all three maps, we found the largest overlap with the affective cluster and, to a lesser extent, also with the intermediate cluster. For a meta-analysis on inhibition of imitation (Darda \& Ramsey, 2019; see also Brass, Ruby, \& Spengler, 2009; Hogeveen et al., 2015), we again found preferential overlaps for the affective and intermediate clusters.

Next, we overlaid our three-cluster solution to maps from related meta-analyses on more affective topics. For a meta-analysis on emotion matching (Dricu \& Frühholz, 2020), that is, matching expressions of a target face and several other faces, overlap was clearly highest with our affective cluster. For an additional metaanalysis on emotion labeling (Dricu \& Frühholz, 2020), we found considerable overlaps with both the affective and intermediate clusters. In this meta-analysis, tasks required participants to match facial, vocal, or bodily expressed emotions with one label out of several alternatives. For a meta-analysis on vicarious reward processing (Morelli, Sacchet, \& Zaki, 2015; see also Apps, Rushworth, \& Chang, 2016; Lockwood, Apps, Roiser, \& Viding, 2015), we found limited overlaps of equal size for the cognitive and affective clusters. In this group of tasks, participants would, for example, witness how another person wins money, gets praised by another person, or receives a pleasant touch.

We further included a meta-analysis on Social Exclusion tasks (Vijayakumar, Cheng, \& Pfeifer, 2017) in our overlap analysis. Here, participants experienced being rejected mostly in the context of a virtual ballgame (Cyberball), and some additional social judgment/chatroom contexts. Overlaps for this meta-analysis were mainly found with our cognitive cluster and, to a lesser extent, also with our affective cluster. For a multistudy analysis $(n=68)$ on Spontaneous ToM (Boccadoro et al., 2019), we found equal degrees of overlap with our three clusters, and thus, no preference for affective, intermediate, or cognitive clusters became clear. Tasks

\footnotetext{
${ }^{16}$ We define verbal stimuli as items of written or spoken language that contain task-relevant information and go beyond trivial task cues (e.g. recurring instruction cues or response category reminders). The category instructed tasks contains all tasks that explicitly instruct participants to infer, judge, or think about the mental states (cognitive or affective) of others.

${ }^{17}$ Figure 5 shows that at model order 3, the cognitive cluster contains only one nonverbal task, which may give rise to the impression that it features more verbal tasks than the other two. Note, however, that our jackknife clustering analysis found that the nonverbal task group Rational Actions frequently changes membership between the cognitive and intermediate clusters, which weakens the coherence of a predominantly verbal interpretation of the cognitive cluster.
} 
in this multistudy analysis presented an uninstructed False Belief task, in which participants watched videos of an agent witnessing some but not all events happening in a room, thus developing a false belief about where a certain object has been placed (e.g., inside vs. outside a box). Somewhat similarly, for a meta-analysis on Visual Perspective Taking (Schurz, Aichhorn, Martin, \& Perner, 2013), we found no prominent overlap with any one of our three clusters (but see Dumontheil, Küster, Apperly, \& Blakemore, 2010; Santiesteban, Banissy, Catmur, \& Bird, 2012). Visual Perspective Taking tasks require participants to judge what another person can see or how another person sees an object. For a summary map of studies on the computational modeling of ToM (Cheong, Jolly, Sul, \& Chang, 2017), that is, studies using gametheoretical approaches to model how individuals engage strategic reasoning in competitive and cooperative contexts, we observed a slight preference in overlap with our cognitive cluster and a further overlap with the intermediate cluster. Finally, for a meta-analysis on Moral Cognition (Bzdok et al., 2012; see also Eres, Louis, \& Molenberghs, 2018), large overlaps were found for the cognitive and intermediate clusters and comparatively little for the affective cluster. Moral Cognition tasks featured scenarios with moral violations or dilemmas and required participants to make appropriate judgments on the actions of one individual toward others.

\section{Summary and Conclusion}

\section{A Hierarchical Perspective}

More than two decades of neuroimaging and behavioral research have produced substantial data and a rich variety of theories and perspectives on the neurocognitive processes underlying the human ability to understand other minds. However, there has been an increasing awareness of disagreement concerning the concepts and taxonomy underlying social processes (Happé et al., 2017; Schaafsma et al., 2015; Spunt \& Adolphs, 2017). This metaanalysis aimed to support the development of a coherent and balanced theoretical model of major cognitive factors underlying the ability to understand other people's minds. We have argued that neuroimaging data provides a good starting point for such a model, as other sources-such as behavioral data-have yet to provide a complete picture of task-by-task interrelations. As we have reviewed in the Behavioral Separability of Tasks From the Three-Cluster Solution section, behavioral intercorrelations were only studied for a limited number of tasks, some of which suffer from range restrictions in scores (e.g., nonimpaired adults showing ceiling effects in some traditional ToM tasks).

The present meta-analysis used hierarchical clustering to sort and group neural patterns elicited across a range of empathy and ToM tasks. Such a hierarchical approach shares characteristics with previous work conceptualizing social cognition as a multilayered or multilevel phenomenon (De Waal, 2012; Preston \& De Waal, 2002; Schaafsma et al., 2015; Singer, 2006). An advantage of the clustering method applied here is that it provides a datadriven answer to the question of how many factors or latent variables are sufficient and appropriate for modeling social cognition. Results suggest the answer is twofold: On the one hand, the best overall clustering performance was reached when the data were divided into a three-cluster solution. However, further local peaks in performance were found when the data were split into eight and 11 clusters. The higher-level, three-cluster solution provides a solid foundation of evidence for the assumption that empathy and ToM share certain processes, and therefore brain activity, across different tasks and stimuli. However, the concurrent existence of an additional lower level of clustering (essentially by task) highlights the question of the appropriate level of concreteness and detail in neurocognitive accounts of social cognition. Will it be possible to formulate a highly specific mechanism that can be applied to all tasks and contexts? We rather suggest modeling social cognition by multilevel theories, similar to models in other fields such as intelligence research. There, some accounts feature a central construct which reflects a latent variable that indicates a broader, more abstract neurocognitive function (e.g., dynamic control via a multiple-demand network; Duncan, 2013). Turning to individual tasks specifies how this function manifests in a concrete context and for a particular problem. Task contexts can have different degrees of relevance for ecological social cognition. While some tasks may contain spurious processes related to idiosyncratic elements of a paradigm (see, e.g., Mar, 2011, for discussion), other tasks may resemble to some extent a real-life problem (such as trying to guess a person's mental state based on their facial expression). Modeling our data as a multilevel construct accounts for the diversity in how social abilities manifest as well as for the specific demands placed by its particular instances (e.g., in experimental tasks). To illustrate, several accounts have described mechanisms targeted at explaining false-belief understanding, which is assumed to be a hallmark of human social cognition (e.g., Premack \& Woodruff, 1978; Saxe \& Kanwisher, 2003; Wimmer \& Perner, 1983). It turns out to be difficult to predict whether and how these mechanisms are recruited by other social cognition tasks. For example, how would a mechanism for decoupling beliefs from knowledge about reality (e.g., Frith \& Frith, 2003) work in the context of a Trait Judgment task? This question is relevant as meta-analytic maps for False Belief and Trait Judgment tasks showed high similarity (see, e.g., Figure 4A). Our approach addresses this issue by placing the most situationspecific mechanisms, such as belief decoupling, at the lower level of our hierarchical model. Decoupling beliefs represents a specific implementation of the broader function of self-generated and decoupled thought in social cognition (cognitive cluster). The multilevel perspective accommodates the fact that (a) a mechanism for decoupling false beliefs is not perfectly applicable to other task contexts, but (b) a broader functional class of self-generated thought in social cognition forms the basis for belief decoupling (but does not completely specify it).

\section{Separated Versus Combined Social Processes}

The central novel finding of our three-cluster solution is the intermediate cluster. Our results show that rather than being a distinct (sub-)form of processing, this cluster combines processes from the cognitive and affective clusters. Whereas previous labels such as affective ToM and cognitive empathy claim this process for either the domain of ToM or empathy, we suggest that referring to this function as conjoint ToM and empathy provides a more unbiased positioning in the terminological landscape. Perhaps more important than its terminology, however, is the functional relevance of this cluster. The cooccurrence of cognitive and affective processes has been linked to more naturalistic forms of social cognition. For instance, Zaki et al. 
(2009) demonstrated the relevance of combining cognitive and affective processes for understanding others. In an fMRI experiment, participants viewed videos of persons discussing emotional autobiographical events. After filming, the person shown in the video had been asked to rate their own emotional states during the clip on a moment-to-moment basis. In addition, participants observing the scanner were asked to rate what the person in the video likely felt at each point in time. By comparing the person's own assessment with participants' ratings, an index of empathic accuracy could be generated. At time points where empathic accuracy of the participants was high, activation levels were increased both in areas linked to cognitive (e.g., mPFC, superior temporal sulcus) and affective (e.g., inferior parietal lobule, premotor cortex) processes. The task by Zaki et al. (2009) is part of the Evaluating Situated Emotions task group, which ended up in the intermediate cluster of our analysis.

Another central case of coactivation of cognitive and affective processes are everyday social interactions, which are essential for understanding other minds (see Schilbach et al., 2013). For example, Schilbach, Eickhoff, Mojzisch, and Vogeley (2008) recorded facial mimicry-related brain activity during online social interactions and found conjoint activation in the cortical midline (e.g., precuneus) and motor areas (e.g., precentral gyrus). This pattern of coactivated areas resembles our intermediate cluster, that is, the combination of cognitive and affective processes. Also, other studies presenting scenes or videos of social interactions reported a coactivation of cognitive and affective processes (e.g., Deuse et al., 2016; Wolf, Dziobek, \& Heekeren, 2010). Note, however, that both naturalistic social cognition (see Zaki \& Ochsner, 2012) and social interaction (Schilbach et al., 2013) were argued to engage additional processes not covered by the cognitive and affective clusters (e.g., reward-related areas during social interactions). Another group of tasks where coactivation of cognitive and affective clusters was observed is altruistic decisions (Hare et al., 2010; Tusche, Böckler, Kanske, Trautwein, \& Singer, 2016; see also Hein, Silani, Preuschoff, Batson, \& Singer, 2010). Tusche et al. (2016) found that the level of generosity in donations for charitable organizations was predicted by brain activity patterns in both the right temporo-parietal junction (TPJ) and right anterior insula during that task, again indicating a cooccurrence of cognitive and affective processes.

Taken together, the reviewed studies suggest that the coactivation of cognitive and affective processes might have particular relevance for ecologically valid social cognition. Our meta-analytic clustering demonstrates that a portion of the tasks typically assumed to measure either ToM or empathy (the intermediate cluster) engages cognitive and affective processes concurrently. Furthermore, our review of behavioral studies showed that in terms of performance, tasks linked to the intermediate cluster (e.g., social animations) are correlated to both the cognitive (e.g., strange stories) and affective clusters (e.g., facial emotion recognition) tasks. This has implications for selecting tasks when measuring different aspects of social cognition. In fact, tasks linked to the intermediate cluster often show good clinical discrimination, such as the Faux Pas test (e.g., for autism spectrum: Baron-Cohen, O'Riordan, et al., 1999; frontotemporal dementia: Gregory et al., 2002; schizophrenia: Konstantakopoulos et al., 2014) or social animations (e.g., for autism spectrum: White, Coniston, Rogers, \& Frith, 2011; schizophrenia: Bliksted et al., 2019). Although these findings put the spotlight on tasks from the intermediate cluster with respect to ecological and clinical relevance, they also trigger a novel question regarding their interpretation. Because such tasks contain both cognitive and affective processes, their interindividual differences could reflect different sources-a difference in cognitive processes only, affective processes only, or both (combined). Therefore, we suggest to select tasks according to the three-cluster solution identified in this meta-analysis and ideally present a combination of them (cognitive, affective, and intermediate), because this may increase the ability to evaluate separate as well as conjoint social processes.

\section{Outlook}

The capacity to understand what other people think and feel remains one of the most elusive mental faculties. We have summarized neuroimaging research from more than two decades (188 studies, 4,207 subjects), based on which we propose to model social cognition as a hierarchical multilevel construct. Thereby, we are seeking to accommodate the diversity of processes and features of social cognition (on a lower level), while making explicit a level of coherence among them (i.e., a higher level). Based on our research focus and the evidence available to date, this meta-analysis has produced a first sample of processes, levels, and mechanisms that such a model might have. At the highest level of our model, we suggest to capture social-cognitive processes in terms of two overarching networks which are flexibly combined and relate to more sensory-affective versus more abstract and decoupled representations of others' mental states.

\section{References}

References marked with an asterisk indicate studies included in the meta-analysis.

*Adams, R. B., Jr., Rule, N. O., Franklin, R. G., Jr., Wang, E., Stevenson, M. T., Yoshikawa, S., . . Ambady, N. (2010). Cross-cultural reading the mind in the eyes: An fMRI investigation. Journal of Cognitive Neuroscience, 22, 97-108. http://dx.doi.org/10.1162/jocn.2009.21187

Adolphs, R. (2009). The social brain: Neural basis of social knowledge. Annual Review of Psychology, 60, 693-716. http://dx.doi.org/10.1146/ annurev.psych.60.110707.163514

*Aichhorn, M., Perner, J., Weiss, B., Kronbichler, M., Staffen, W., \& Ladurner, G. (2009). Temporo-parietal junction activity in theory-ofmind tasks: Falseness, beliefs, or attention. Journal of Cognitive Neuroscience, 21, 1179-1192. http://dx.doi.org/10.1162/jocn.2009.21082

*Akitsuki, Y., \& Decety, J. (2009). Social context and perceived agency affects empathy for pain: An event-related fMRI investigation. NeuroImage, 47, 722-734. http://dx.doi.org/10.1016/j.neuroimage.2009.04 .091

Alcalá-López, D., Smallwood, J., Jefferies, E., Van Overwalle, F., Vogeley, K., Mars, R. B., . . Bzdok, D. (2018). Computing the social brain connectome across systems and states. Cerebral Cortex, 28, 2207-2232. http://dx.doi.org/10.1093/cercor/bhx121

Alcalá-López, D., Vogeley, K., Binkofski, F., \& Bzdok, D. (2019). Building blocks of social cognition: Mirror, mentalize, share? Cortex, 118, 4-18. http://dx.doi.org/10.1016/j.cortex.2018.05.006

*Ammons, C. J., Doss, C. F., Bala, D., \& Kana, R. K. (2018). Brain responses underlying anthropomorphism, agency, and social attribution in autism spectrum disorder. The Open Neuroimaging Journal, 12, 16-29. http://dx.doi.org/10.2174/1874440001812010016

*Andersson, F., Glaser, B., Spiridon, M., Debbané, M., Vuilleumier, P., \& Eliez, S. (2008). Impaired activation of face processing networks revealed by functional magnetic resonance imaging in 22q11.2 deletion syndrome. Biological Psychiatry, 63, 49-57. http://dx.doi.org/10.1016/ j.biopsych.2007.02.022 
*Andrews-Hanna, J. R., Saxe, R., \& Yarkoni, T. (2014). Contributions of episodic retrieval and mentalizing to autobiographical thought: Evidence from functional neuroimaging, resting-state connectivity, and fMRI meta-analyses. NeuroImage, 91, 324-335. http://dx.doi.org/10.1016/j .neuroimage.2014.01.032

Andrews-Hanna, J. R., Smallwood, J., \& Spreng, R. N. (2014). The default network and self-generated thought: Component processes, dynamic control, and clinical relevance. Annals of the New York Academy of Sciences, 1316, 29-52. http://dx.doi.org/10.1111/nyas.12360

Anticevic, A., Cole, M. W., Murray, J. D., Corlett, P. R., Wang, X. J., \& Krystal, J. H. (2012). The role of default network deactivation in cognition and disease. Trends in Cognitive Sciences, 16, 584-592. http://dx.doi.org/10.1016/j.tics.2012.10.008

Apps, M. A., Rushworth, M. F., \& Chang, S. W. (2016). The anterior cingulate gyrus and social cognition: Tracking the motivation of others. Neuron, 90, 692-707. http://dx.doi.org/10.1016/j.neuron.2016.04.018

*Assaf, M., Kahn, I., Pearlson, G. D., Johnson, M. R., Yeshurun, Y., Calhoun, V. D., \& Hendler, T. (2009). Brain activity dissociates mentalization from motivation during an interpersonal competitive game. Brain Imaging and Behavior, 3, 24-37. http://dx.doi.org/10.1007/ s11682-008-9047-y

*Azevedo, R. T., Macaluso, E., Avenanti, A., Santangelo, V., Cazzato, V., \& Aglioti, S. M. (2013). Their pain is not our pain: Brain and autonomic correlates of empathic resonance with the pain of same and different race individuals. Human Brain Mapping, 34, 3168-3181. http://dx.doi.org/ $10.1002 / \mathrm{hbm} .22133$

*Azevedo, R. T., Macaluso, E., Viola, V., Sani, G., \& Aglioti, S. M. (2014). Weighing the stigma of weight: An fMRI study of neural reactivity to the pain of obese individuals. NeuroImage, 91, 109-119. http://dx.doi .org/10.1016/j.neuroimage.2013.11.041

*Bahnemann, M., Dziobek, I., Prehn, K., Wolf, I., \& Heekeren, H. R. (2010). Sociotopy in the temporoparietal cortex: Common versus distinct processes. Social Cognitive and Affective Neuroscience, 5, 48-58. http://dx.doi.org/10.1093/scan/nsp045

*Ballotta, D., Lui, F., Porro, C. A., Nichelli, P. F., \& Benuzzi, F. (2018). Modulation of neural circuits underlying temporal production by facial expressions of pain. PLOS ONE, 13, e0193100. http://dx.doi.org/10 .1371/journal.pone. 0193100

Baron-Cohen, S. (2002). The extreme male brain theory of autism. Trends in Cognitive Sciences, 6, 248-254. http://dx.doi.org/10.1016/S13646613(02)01904-6

Baron-Cohen, S., \& Hammer, J. (1997). Parents of children with Asperger syndrome: What is the cognitive phenotype? Journal of Cognitive Neuroscience, 9, 548-554. http://dx.doi.org/10.1162/jocn.1997.9.4.548

Baron-Cohen, S., Jolliffe, T., Mortimore, C., \& Robertson, M. (1997). Another advanced test of theory of mind: Evidence from very high functioning adults with autism or Asperger syndrome. Journal of Child Psychology and Psychiatry, and Allied Disciplines, 38, 813-822. http:// dx.doi.org/10.1111/j.1469-7610.1997.tb01599.x

Baron-Cohen, S., O’Riordan, M., Jones, R., Stone, V., \& Plaisted, K. (1999). A new test of social sensitivity: Detection of faux pas in normal children and children with Asperger syndrome. Journal of Autism and Developmental Disorders, 29, 407-418. http://dx.doi.org/10.1023/A: 1023035012436

Baron-Cohen, S., Ring, H., Moriarty, J., Schmitz, B., Costa, D., \& Ell, P. (1994). Recognition of mental state terms. Clinical findings in children with autism and a functional neuroimaging study of normal adults. The British Journal of Psychiatry, 165, 640-649. http://dx.doi.org/10.1192/ bjp.165.5.640

*Baron-Cohen, S., Ring, H. A., Wheelwright, S., Bullmore, E. T., Brammer, M. J., Simmons, A., \& Williams, S. C. (1999). Social intelligence in the normal and autistic brain: An fMRI study. The European Journal of Neuroscience, 11, 1891-1898. http://dx.doi.org/10.1046/j.1460-9568 1999.00621.x
Barrett, L. F., Lindquist, K. A., \& Gendron, M. (2007). Language as context for the perception of emotion. Trends in Cognitive Sciences, 11, 327-332. http://dx.doi.org/10.1016/j.tics.2007.06.003

*Batut, A.-C., Gounot, D., Namer, I. J., Hirsch, E., Kehrli, P., \& Metz-Lutz, M.-N. (2006). Neural responses associated with positive and negative emotion processing in patients with left versus right temporal lobe epilepsy. Epilepsy \& Behavior, 9, 415-423. http://dx.doi.org/10.1016/j .yebeh.2006.07.013

Binder, J. R., Desai, R. H., Graves, W. W., \& Conant, L. L. (2009). Where is the semantic system? A critical review and meta-analysis of 120 functional neuroimaging studies. Cerebral Cortex, 19, 2767-2796. http://dx.doi.org/10.1093/cercor/bhp055

*Blakemore, S.-J., Boyer, P., Pachot-Clouard, M., Meltzoff, A., Segebarth, C., \& Decety, J. (2003). The detection of contingency and animacy from simple animations in the human brain. Cerebral Cortex, 13, 837-844. http://dx.doi.org/10.1093/cercor/13.8.837

*Bliksted, V., Frith, C., Videbech, P., Fagerlund, B., Emborg, C., Simonsen, A., . . Campbell-Meiklejohn, D. (2019). Hyper- and hypomentalizing in patients with first-episode schizophrenia: fMRI and behavioral studies. Schizophrenia Bulletin, 45, 377-385. http://dx.doi.org/10.1093/ schbul/sby027

Bloom, P. (2017). Empathy, schmempathy: Response to Zaki. Trends in Cognitive Sciences, 21, 60-61. http://dx.doi.org/10.1016/j.tics.2016.12 .003

Boccadoro, S., Cracco, E., Hudson, A. R., Bardi, L., Nijhof, A. D., Wiersema, J. R., . . Mueller, S. C. (2019). Defining the neural correlates of spontaneous theory of mind (ToM): An fMRI multi-study investigation. NeuroImage, 203, 116193. http://dx.doi.org/10.1016/j.neuroimage .2019 .116193

*Bos, P. A., Hofman, D., Hermans, E. J., Montoya, E. R., Baron-Cohen, S., \& van Honk, J. (2016). Testosterone reduces functional connectivity during the 'Reading the Mind in the Eyes' Test. Test Psychoneuroendocrinology, 68, 194-201. http://dx.doi.org/10.1016/j.psyneuen.2016.03 .006

*Bos, P. A., Montoya, E. R., Hermans, E. J., Keysers, C., \& van Honk, J. (2015). Oxytocin reduces neural activity in the pain circuitry when seeing pain in others. NeuroImage, 113, 217-224. http://dx.doi.org/10 .1016/j.neuroimage.2015.03.049

Brass, M., Ruby, P., \& Spengler, S. (2009). Inhibition of imitative behaviour and social cognition. Philosophical Transactions of the Royal Society of London Series B, Biological Sciences, 364, 2359-2367. http://dx.doi.org/10.1098/rstb.2009.0066

Brewer, N., Young, R. L., \& Barnett, E. (2017). Measuring theory of mind in adults with autism spectrum disorder. Journal of Autism and Developmental Disorders, 47, 1927-1941. http://dx.doi.org/10.1007/s10803017-3080-x

Brooks, J. A., Shablack, H., Gendron, M., Satpute, A. B., Parrish, M. H., \& Lindquist, K. A. (2017). The role of language in the experience and perception of emotion: A neuroimaging meta-analysis. Social Cognitive and Affective Neuroscience, 12, 169-183. http://dx.doi.org/10.1093/ scan/nsw121

*Brüne, M., Lissek, S., Fuchs, N., Witthaus, H., Peters, S., Nicolas, V., . . Tegenthoff, M. (2008). An fMRI study of theory of mind in schizophrenic patients with "passivity" symptoms. Neuropsychologia, 46, 1992-2001. http://dx.doi.org/10.1016/j.neuropsychologia.2008.01.023

Brunet, E., Sarfati, Y., \& Hardy-Baylé, M. C. (2003). Reasoning about physical causality and other's intentions in schizophrenia. Cognitive Neuropsychiatry, 8, 129-139. http://dx.doi.org/10.1080/13546 800244000256

*Brunet, E., Sarfati, Y., Hardy-Baylé, M. C., \& Decety, J. (2000). A PET investigation of the attribution of intentions with a nonverbal task NeuroImage, 11, 157-166. http://dx.doi.org/10.1006/nimg.1999.0525 
Buckner, R. L., \& Carroll, D. C. (2007). Self-projection and the brain. Trends in Cognitive Sciences, 11, 49-57. http://dx.doi.org/10.1016/j.tics .2006.11.004

Bzdok, D., Langner, R., Schilbach, L., Jakobs, O., Roski, C., Caspers, S., . . . Eickhoff, S. B. (2013). Characterization of the temporo-parietal junction by combining data-driven parcellation, complementary connectivity analyses, and functional decoding. Neurolmage, 81, 381-392. http://dx.doi.org/10.1016/j.neuroimage.2013.05.046

Bzdok, D., Schilbach, L., Vogeley, K., Schneider, K., Laird, A. R., Langner, R., \& Eickhoff, S. B. (2012). Parsing the neural correlates of moral cognition: ALE meta-analysis on morality, theory of mind, and empathy. Brain Structure \& Function, 217, 783-796. http://dx.doi.org/10.1007/ s00429-012-0380-y

*Carr, L., Iacoboni, M., Dubeau, M. C., Mazziotta, J. C., \& Lenzi, G. L. (2003). Neural mechanisms of empathy in humans: A relay from neural systems for imitation to limbic areas. Proceedings of the National Academy of Sciences of the United States of America, 100, 5497-5502. http://dx.doi.org/10.1073/pnas.0935845100

Carrillo, M., Han, Y., Migliorati, F., Liu, M., Gazzola, V., \& Keysers, C. (2019). Emotional mirror neurons in the rat's anterior cingulate cortex. Current Biology, 29, 1301-1312.e6. http://dx.doi.org/10.1016/j.cub 2019.03.024

Castelli, F., Frith, C., Happé, F., \& Frith, U. (2002). Autism, Asperger syndrome and brain mechanisms for the attribution of mental states to animated shapes. Brain: A Journal of Neurology, 125, 1839-1849. http://dx.doi.org/10.1093/brain/awf189

"Castelli, F., Happé, F., Frith, U., \& Frith, C. (2000). Movement and mind: A functional imaging study of perception and interpretation of complex intentional movement patterns. NeuroImage, 12, 314-325. http://dx.doi .org/10.1006/nimg.2000.0612

"Castelli, I., Baglio, F., Blasi, V., Alberoni, M., Falini, A., Liverta-Sempio, O., . . Marchetti, A. (2010). Effects of aging on mindreading ability through the eyes: An fMRI study. Neuropsychologia, 48, 2586-2594. http://dx.doi.org/10.1016/j.neuropsychologia.2010.05.005

Chai, X. J., Castañón, A. N., Ongür, D., \& Whitfield-Gabrieli, S. (2012). Anticorrelations in resting state networks without global signal regression. NeuroImage, 59, 1420-1428. http://dx.doi.org/10.1016/j .neuroimage.2011.08.048

*Chakrabarti, B., Bullmore, E., \& Baron-Cohen, S. (2006). Empathizing with basic emotions: Common and discrete neural substrates. Social Neuroscience, 1, 364-384. http://dx.doi.org/10.1080/17470910601041317

*Chaminade, T., Rosset, D., Da Fonseca, D., Nazarian, B., Lutcher, E., Cheng, G., \& Deruelle, C. (2012). How do we think machines think? An fMRI study of alleged competition with an artificial intelligence. Frontiers in Human Neuroscience, 6, 103. http://dx.doi.org/10.3389/fnhum .2012 .00103

Cheong, J. H., Jolly, E., Sul, S., \& Chang, L. J. (2017). Computational models in social neuroscience. In A. A. Moustafa (Ed.), Computational models of brain and behavior (pp. 229-244). Hoboken, NJ: Wiley. http://dx.doi.org/10.1002/9781119159193.ch17

*Christov-Moore, L., Conway, P., \& Iacoboni, M. (2017). Deontological dilemma response tendencies and sensorimotor representations of harm to others. Frontiers in Integrative Neuroscience, 11, 34. http://dx.doi .org/10.3389/fnint.2017.00034

*Contreras, J. M., Schirmer, J., Banaji, M. R., \& Mitchell, J. P. (2013). Common brain regions with distinct patterns of neural responses during mentalizing about groups and individuals. Journal of Cognitive Neuroscience, 25, 1406-1417. http://dx.doi.org/10.1162/jocn_a_00403

Conway, J. R., Catmur, C., \& Bird, G. (2019). Understanding individual differences in theory of mind via representation of minds, not mental states. Psychonomic Bulletin \& Review, 26, 798-812. http://dx.doi.org/ 10.3758/s13423-018-1559-x

"Cools, R., Calder, A. J., Lawrence, A. D., Clark, L., Bullmore, E., \& Robbins, T. W. (2005). Individual differences in threat sensitivity pre- dict serotonergic modulation of amygdala response to fearful faces. Psychopharmacology, 180, 670-679. http://dx.doi.org/10.1007/s00213005-2215-5

Corbetta, M., Patel, G., \& Shulman, G. L. (2008). The reorienting system of the human brain: From environment to theory of mind. Neuron, 58, 306-324. http://dx.doi.org/10.1016/j.neuron.2008.04.017

*Corradi-Dell'Acqua, C., Hofstetter, C., \& Vuilleumier, P. (2014). Cognitive and affective theory of mind share the same local patterns of activity in posterior temporal but not medial prefrontal cortex. Social Cognitive and Affective Neuroscience, 9, 1175-1184. http://dx.doi.org/10.1093/ scan/nst097

Corradi-Dell'Acqua, C., Tusche, A., Vuilleumier, P., \& Singer, T. (2016) Cross-modal representations of first-hand and vicarious pain, disgust and fairness in insular and cingulate cortex. Nature Communications, 7, 10904. http://dx.doi.org/10.1038/ncomms 10904

Cracco, E., Bardi, L., Desmet, C., Genschow, O., Rigoni, D., De Coster, L., . . Brass, M. (2018). Automatic imitation: A meta-analysis. Psychological Bulletin, 144, 453-500. http://dx.doi.org/10.1037/bul0000143

*Craik, F. I. M., Moroz, T. M., Moscovitch, M., Stuss, D. T., Winocur, G., Tulving, E., \& Kapur, S. (1999). In Search of the Self: A Positron Emission Tomography Study. Psychological Science, 10, 26-34. http:// dx.doi.org/10.1111/1467-9280.00102

${ }^{*}$ Critchley, H., Daly, E., Phillips, M., Brammer, M., Bullmore, E., Williams, S., . . . Murphy, D. (2000). Explicit and implicit neural mechanisms for processing of social information from facial expressions: A functional magnetic resonance imaging study. Human Brain Mapping, 9, 93-105. http://dx.doi.org/10.1002/(SICI)1097-0193(200002)9:2<93:: AID-HBM4 $>3.0 . \mathrm{CO} ; 2-\mathrm{Z}$

Darda, K. M., \& Ramsey, R. (2019). The inhibition of automatic imitation: A meta-analysis and synthesis of fMRI studies. NeuroImage, 197, 320 329. http://dx.doi.org/10.1016/j.neuroimage.2019.04.059

*Das, P., Lagopoulos, J., Coulston, C. M., Henderson, A. F., \& Malhi, G. S. (2012). Mentalizing impairment in schizophrenia: A functional MRI study. Schizophrenia Research, 134, 158-164. http://dx.doi.org/10 .1016/j.schres.2011.08.019

Davis, M. H. (1994). Empathy: A social psychological approach. Boulder, CO: Westview Press. http://dx.doi.org/10.4324/9780429493898

*de Achával, D., Villarreal, M. F., Costanzo, E. Y., Douer, J., Castro, M. N., Mora, M. C., . . . Guinjoan, S. M. (2012). Decreased activity in right-hemisphere structures involved in social cognition in siblings discordant for schizophrenia. Schizophrenia Research, 134, 171-179. http://dx.doi.org/10.1016/j.schres.2011.11.010

*Decety, J., Echols, S., \& Correll, J. (2010). The blame game: The effect of responsibility and social stigma on empathy for pain. Journal of Cognitive Neuroscience, 22, 985-997. http://dx.doi.org/10.1162/jocn 2009.21266

Decety, J., \& Jackson, P. L. (2004). The functional architecture of human empathy. Behavioral and Cognitive Neuroscience Reviews, 3, 71-100. http://dx.doi.org/10.1177/1534582304267187

*de Greck, M., Shi, Z., Wang, G., Zuo, X., Yang, X., Wang, X., . . Han, S. (2012). Culture modulates brain activity during empathy with anger. NeuroImage, 59, 2871-2882. http://dx.doi.org/10.1016/j.neuroimage 2011.09.052

*de Greck, M., Wang, G., Yang, X., Wang, X., Northoff, G., \& Han, S. (2012). Neural substrates underlying intentional empathy. Social Cognitive and Affective Neuroscience, 7, 135-144. http://dx.doi.org/10 1093/scan/nsq093

Dennett, D. C. (1971). Intentional systems. The Journal of Philosophy, 68, 87-106. http://dx.doi.org/10.2307/2025382

Derntl, B., Finkelmeyer, A., Eickhoff, S., Kellermann, T., Falkenberg, D. I., Schneider, F., \& Habel, U. (2010). Multidimensional assessment of empathic abilities: Neural correlates and gender differences. Psychoneuroendocrinology, 35, 67-82. http://dx.doi.org/10.1016/j.psyneuen.2009 .10 .006 
Derntl, B., Finkelmeyer, A., Voss, B., Eickhoff, S. B., Kellermann, T., Schneider, F., \& Habel, U. (2012). Neural correlates of the core facets of empathy in schizophrenia. Schizophrenia Research, 136, 70-81. http:// dx.doi.org/10.1016/j.schres.2011.12.018

DerSimonian, R., \& Laird, N. (1986). Meta-analysis in clinical trials. Controlled Clinical Trials, 7, 177-188. http://dx.doi.org/10.1016/01972456(86)90046-2

Deuse, L., Rademacher, L. M., Winkler, L., Schultz, R. T., Gründer, G., \& Lammertz, S. E. (2016). Neural correlates of naturalistic social cognition: Brain-behavior relationships in healthy adults. Social Cognitive and Affective Neuroscience, 11, 1741-1751. http://dx.doi.org/10.1093/ scan/nsw094

de Waal, F. B. M. (2007). The 'Russian doll' model of empathy and imitation. In S. Bråten (Ed.), Advances in consciousness research: Vol. 68. On being moved: From mirror neurons to empathy (pp. 49-69). Amsterdam, the Netherlands: John Benjamins Publishing Company. http://dx.doi.org/10.1075/aicr.68.06waa

de Waal, F. B. (2012). The antiquity of empathy. Science, 336, 874-876. http://dx.doi.org/10.1126/science.1220999

de Waal, F. B. M., \& Preston, S. D. (2017). Mammalian empathy: Behavioural manifestations and neural basis. Nature Reviews Neuroscience, 18, 498-509. http://dx.doi.org/10.1038/nrn.2017.72

"Dodell-Feder, D., Koster-Hale, J., Bedny, M., \& Saxe, R. (2011). fMRI item analysis in a theory of mind task. Neurolmage, 55, 705-712. http://dx.doi.org/10.1016/j.neuroimage.2010.12.040

Dricu, M., \& Frühholz, S. (2020). A neurocognitive model of perceptual decision-making on emotional signals. Human Brain Mapping, 41, 1532-1556. http://dx.doi.org/10.1002/hbm.24893

Dumontheil, I., Küster, O., Apperly, I. A., \& Blakemore, S. J. (2010). Taking perspective into account in a communicative task. NeuroImage, 52, 1574-1583. http://dx.doi.org/10.1016/j.neuroimage.2010.05.056

Duncan, J. (2013). The structure of cognition: Attentional episodes in mind and brain. Neuron, 80, 35-50. http://dx.doi.org/10.1016/j.neuron.2013 .09 .015

Dziobek, I., Fleck, S., Kalbe, E., Rogers, K., Hassenstab, J., Brand, M., . . . Convit, A. (2006). Introducing MASC: A movie for the assessment of social cognition. Journal of Autism and Developmental Disorders, 36, 623-636. http://dx.doi.org/10.1007/s10803-006-0107-0

Dziobek, I., Preissler, S., Grozdanovic, Z., Heuser, I., Heekeren, H. R., \& Roepke, S. (2011). Neuronal correlates of altered empathy and social cognition in borderline personality disorder. NeuroImage, 57, 539-548. http://dx.doi.org/10.1016/j.neuroimage.2011.05.005

"Eddy, C. M., Cavanna, A. E., \& Hansen, P. C. (2017). Empathy and aversion: The neural signature of mentalizing in Tourette syndrome. Psychological Medicine, 47, 507-517. http://dx.doi.org/10.1017/ S0033291716002725

Eickhoff, S. B., Nichols, T. E., Laird, A. R., Hoffstaedter, F., Amunts, K., Fox, P. T., . . Eickhoff, C. R. (2016). Behavior, sensitivity, and power of activation likelihood estimation characterized by massive empirical simulation. NeuroImage, 137, 70-85. http://dx.doi.org/10.1016/j .neuroimage.2016.04.072

Eres, R., Louis, W. R., \& Molenberghs, P. (2018). Common and distinct neural networks involved in fMRI studies investigating morality: An ALE meta-analysis. Social Neuroscience, 13, 384-398. http://dx.doi .org/10.1080/17470919.2017.1357657

"Ernst, J., Northoff, G., Böker, H., Seifritz, E., \& Grimm, S. (2013). Interoceptive awareness enhances neural activity during empathy. $\mathrm{Hu}$ man Brain Mapping, 34, 1615-1624. http://dx.doi.org/10.1002/hbm .22014

*Fan, Y. T., Chen, C., Chen, S. C., Decety, J., \& Cheng, Y. (2014). Empathic arousal and social understanding in individuals with autism: Evidence from fMRI and ERP measurements. Social Cognitive and Affective Neuroscience, 9, 1203-1213. http://dx.doi.org/10.1093/scan/ nst101
Fan, Y., Duncan, N. W., de Greck, M., \& Northoff, G. (2011). Is there a core neural network in empathy? An fMRI based quantitative metaanalysis. Neuroscience and Biobehavioral Reviews, 35, 903-911. http:// dx.doi.org/10.1016/j.neubiorev.2010.10.009

Ferguson, F. J., \& Austin, E. J. (2010). Associations of trait and ability emotional intelligence with performance on Theory of Mind tasks in an adult sample. Personality and Individual Differences, 49, 414-418. http://dx.doi.org/10.1016/j.paid.2010.04.009

Fletcher, P. C., Happé, F., Frith, U., Baker, S. C., Dolan, R. J., Frackowiak, R. S., \& Frith, C. D. (1995). Other minds in the brain: A functional imaging study of "theory of mind" in story comprehension. Cognition, 57, 109-128. http://dx.doi.org/10.1016/0010-0277(95)00692-R

*Focquaert, F., Steven-Wheeler, M. S., Vanneste, S., Doron, K. W., \& Platek, S. M. (2010). Mindreading in individuals with an empathizing versus systemizing cognitive style: An fMRI study. Brain Research Bulletin, 83, 214-222. http://dx.doi.org/10.1016/j.brainresbull.2010.08 .008

*Fourie, M. M., Stein, D. J., Solms, M., Gobodo-Madikizela, P., \& Decety, J. (2017). Empathy and moral emotions in post-apartheid South Africa: An fMRI investigation. Social Cognitive and Affective Neuroscience, 12, 881-892. http://dx.doi.org/10.1093/scan/nsx019

*Fourie, M. M., Stein, D. J., Solms, M., Gobodo-Madikizela, P., \& Decety, J. (2019). Effects of early adversity and social discrimination on empathy for complex mental states: An fMRI investigation. Scientific Reports, 9, 12959. http://dx.doi.org/10.1038/s41598-019-49298-4

Fox, M. D., Snyder, A. Z., Vincent, J. L., Corbetta, M., Van Essen, D. C., \& Raichle, M. E. (2005). The human brain is intrinsically organized into dynamic, anticorrelated functional networks. Proceedings of the National Academy of Sciences of the United States of America, 102, 9673-9678. http://dx.doi.org/10.1073/pnas.0504136102

Frith, C. D., \& Frith, U. (2006). The neural basis of mentalizing. Neuron, 50, 531-534. http://dx.doi.org/10.1016/j.neuron.2006.05.001

Frith, C. D., \& Frith, U. (2012). Mechanisms of social cognition. Annual Review of Psychology, 63, 287-313. http://dx.doi.org/10.1146/annurevpsych-120710-100449

Frith, U., \& Frith, C. D. (2003). Development and neurophysiology of mentalizing. Philosophical Transactions of the Royal Society of London Series B: Biological Sciences, 358, 459-473. http://dx.doi.org/10.1098/ rstb.2002.1218

*Fujino, J., Yamasaki, N., Miyata, J., Kawada, R., Sasaki, H., Matsukawa, N., . . Murai, T. (2014). Altered brain response to others' pain in major depressive disorder. Journal of Affective Disorders, 165, 170-175. http://dx.doi.org/10.1016/j.jad.2014.04.058

*Fukui, H., Murai, T., Shinozaki, J., Aso, T., Fukuyama, H., Hayashi, T., \& Hanakawa, T. (2006). The neural basis of social tactics: An fMRI study. NeuroImage, 32, 913-920. http://dx.doi.org/10.1016/j.neuroimage.2006.03.039

Fusar-Poli, P., Placentino, A., Carletti, F., Landi, P., Allen, P., Surguladze, S., . . Politi, P. (2009). Functional atlas of emotional faces processing: A voxel-based meta-analysis of 105 functional magnetic resonance imaging studies. Journal of Psychiatry \& Neuroscience, 34, 418-432. https://www.ncbi.nlm.nih.gov/pubmed/19949718

Gallagher, H. L., \& Frith, C. D. (2003). Functional imaging of 'theory of mind'. Trends in Cognitive Sciences, 7, 77-83. http://dx.doi.org/10 .1016/S1364-6613(02)00025-6

*Gallagher, H. L., \& Frith, C. D. (2004). Dissociable neural pathways for the perception and recognition of expressive and instrumental gestures. Neuropsychologia, 42, 1725-1736. http://dx.doi.org/10.1016/j .neuropsychologia.2004.05.006

Gallagher, H. L., Happé, F., Brunswick, N., Fletcher, P. C., Frith, U., \& Frith, C. D. (2000). Reading the mind in cartoons and stories: An fMRI study of 'theory of mind' in verbal and nonverbal tasks. Neuropsychologia, 38, 11-21. http://dx.doi.org/10.1016/S0028-3932(99)00053-6 
*Gallagher, H. L., Jack, A. I., Roepstorff, A., \& Frith, C. D. (2002). Imaging the intentional stance in a competitive game. Neurolmage, 16, 814-821. http://dx.doi.org/10.1006/nimg.2002.1117

Gallese, V. (2003). The roots of empathy: The shared manifold hypothesis and the neural basis of intersubjectivity. Psychopathology, 36, 171-180. http://dx.doi.org/10.1159/000072786

Gallese, V. (2008). Mirror neurons and the social nature of language: The neural exploitation hypothesis. Social Neuroscience, 3, 317-333. http:// dx.doi.org/10.1080/17470910701563608

Gallese, V., \& Goldman, A. (1998). Mirror neurons and the simulation theory of mind-reading. Trends in Cognitive Sciences, 2, 493-501. http://dx.doi.org/10.1016/S1364-6613(98)01262-5

*Gao, X., Pan, W., Li, C., Weng, L., Yao, M., \& Chen, A. (2017). Long-time exposure to violent video games does not show desensitization on empathy for pain: An fMRI study. Frontiers in Psychology, 8, 650. http://dx.doi.org/10.3389/fpsyg.2017.00650

Gazzola, V., Aziz-Zadeh, L., \& Keysers, C. (2006). Empathy and the somatotopic auditory mirror system in humans. Current Biology, 16, 1824-1829. http://dx.doi.org/10.1016/j.cub.2006.07.072

*Gobbini, M. I., Koralek, A. C., Bryan, R. E., Montgomery, K. J., \& Haxby, J. V. (2007). Two takes on the social brain: A comparison of theory of mind tasks. Journal of Cognitive Neuroscience, 19, 18031814. http://dx.doi.org/10.1162/jocn.2007.19.11.1803

Gorgolewski, K. J., Varoquaux, G., Rivera, G., Schwarz, Y., Ghosh, S. S., Maumet, C., . . . Margulies, D. S. (2015). NeuroVault.org: A web-based repository for collecting and sharing unthresholded statistical maps of the human brain. Frontiers in Neuroinformatics, 9, 8. http://dx.doi.org/ 10.3389/fninf.2015.00008

*Gorno-Tempini, M. L., Pradelli, S., Serafini, M., Pagnoni, G., Baraldi, P., Porro, C., . . . Nichelli, P. (2001). Explicit and incidental facial expression processing: An fMRI study. NeuroImage, 14, 465-473. http://dx .doi.org/10.1006/nimg.2001.0811

Goulden, N., Khusnulina, A., Davis, N. J., Bracewell, R. M., Bokde, A. L., McNulty, J. P., \& Mullins, P. G. (2014). The salience network is responsible for switching between the default mode network and the central executive network: Replication from DCM. NeuroImage, 99, 180-190. http://dx.doi.org/10.1016/j.neuroimage.2014.05.052

Gregory, C., Lough, S., Stone, V., Erzinclioglu, S., Martin, L., BaronCohen, S., \& Hodges, J. R. (2002). Theory of mind in patients with frontal variant frontotemporal dementia and Alzheimer's disease: Theoretical and practical implications. Brain: A Journal of Neurology, 125(Pt 4), 752-764. http://dx.doi.org/10.1093/brain/awf079

"Greven, I. M., Downing, P. E., \& Ramsey, R. (2016). Linking person perception and person knowledge in the human brain. Social Cognitive and Affective Neuroscience, 11, 641-651. http://dx.doi.org/10.1093/ scan/nsv148

Grosbras, M. H., Beaton, S., \& Eickhoff, S. B. (2012). Brain regions involved in human movement perception: A quantitative voxel-based meta-analysis. Human Brain Mapping, 33, 431-454. http://dx.doi.org/ 10.1002/hbm. 21222

Gu, X., Hof, P. R., Friston, K. J., \& Fan, J. (2013). Anterior insular cortex and emotional awareness. Journal of Comparative Neurology, 521, 3371-3388. http://dx.doi.org/10.1002/cne.23368

*Guo, X., Zheng, L., Wang, H., Zhu, L., Li, J., Wang, Q., . . Yang, Z. (2013). Exposure to violence reduces empathetic responses to other's pain. Brain and Cognition, 82, 187-191. http://dx.doi.org/10.1016/j .bandc.2013.04.005

*Habel, U., Windischberger, C., Derntl, B., Robinson, S., Kryspin-Exner, I., Gur, R. C., \& Moser, E. (2007). Amygdala activation and facial expressions: Explicit emotion discrimination versus implicit emotion processing. Neuropsychologia, 45, 2369-2377. http://dx.doi.org/10 .1016/j.neuropsychologia.2007.01.023

Happé, F. G. (1994). An advanced test of theory of mind: Understanding of story characters' thoughts and feelings by able autistic, mentally handicapped, and normal children and adults. Journal of Autism and Developmental Disorders, 24, 129-154. http://dx.doi.org/10.1007/ BF02172093

Happé, F., Cook, J. L., \& Bird, G. (2017). The structure of social cognition: In (ter) dependence of sociocognitive processes. Annual Review of Psychology, 68, 243-267. http://dx.doi.org/10.1146/annurev-psych010416-044046

Happé, F., Ehlers, S., Fletcher, P., Frith, U., Johansson, M., Gillberg, C., ... Frith, C. (1996). 'Theory of mind' in the brain. Evidence from a PET scan study of Asperger syndrome. Neuroreport, 8, 197-201. http://dx .doi.org/10.1097/00001756-199612200-00040

Hare, T. A., Camerer, C. F., Knoepfle, D. T., O’Doherty, J. P., \& Rangel, A. (2010). Value computations in ventral medial prefrontal cortex during charitable decision making incorporate input from regions involved in social cognition. The Journal of Neuroscience, 30, 583-590. http://dx .doi.org/10.1523/JNEUROSCI.4089-09.2010

Hardwick, R. M., Caspers, S., Eickhoff, S. B., \& Swinnen, S. P. (2018) Neural correlates of action: Comparing meta-analyses of imagery, observation, and execution. Neuroscience \& Biobehavioral Reviews, 94, 31-44. http://dx.doi.org/10.1016/j.neubiorev.2018.08.003

*Hartwright, C. E., Apperly, I. A., \& Hansen, P. C. (2015). The special case of self-perspective inhibition in mental, but not non-mental, representation. Neuropsychologia, 67, 183-192. http://dx.doi.org/10.1016/j neuropsychologia.2014.12.015

*Harvey, P. O., Zaki, J., Lee, J., Ochsner, K., \& Green, M. F. (2013) Neural substrates of empathic accuracy in people with schizophrenia Schizophrenia Bulletin, 39, 617-628. http://dx.doi.org/10.1093/schbul/ sbs042

*Heatherton, T. F., Wyland, C. L., Macrae, C. N., Demos, K. E., Denny, B. T., \& Kelley, W. M. (2006). Medial prefrontal activity differentiates self from close others. Social Cognitive and Affective Neuroscience, 1, 18-25. http://dx.doi.org/10.1093/scan/ns1001

Heider, F., \& Simmel, M. (1944). An experimental study of apparent behavior. The American Journal of Psychology, 57, 243-259. http://dx doi.org/10.2307/1416950

*Heil, L., Colizoli, O., Hartstra, E., Kwisthout, J., van Pelt, S., van Rooij, I., \& Bekkering, H. (2019). Processing of prediction errors in mentalizing areas. Journal of Cognitive Neuroscience, 31, 900-912. http://dx.doi .org/10.1162/jocn_a_01381

Hein, G., Silani, G., Preuschoff, K., Batson, C. D., \& Singer, T. (2010). Neural responses to ingroup and outgroup members' suffering predict individual differences in costly helping. Neuron, 68, 149-160. http://dx .doi.org/10.1016/j.neuron.2010.09.003

*Heleven, E., van Dun, K., \& Van Overwalle, F. (2019). The posterior Cerebellum is involved in constructing Social Action Sequences: An fMRI Study. Scientific Reports, 9, 11110. http://dx.doi.org/10.1038/ s41598-019-46962-7

*Hennenlotter, A., Schroeder, U., Erhard, P., Castrop, F., Haslinger, B., Stoecker, D., . . Ceballos-Baumann, A. O. (2005). A common neura basis for receptive and expressive communication of pleasant facial affect. NeuroImage, 26, 581-591. http://dx.doi.org/10.1016/j.neuroimage.2005.01.057

"Hennion, S., Delbeuck, X., Koelkebeck, K., Brion, M., Tyvaert, L. Plomhause, L., . . . Szurhaj, W. (2016). A functional magnetic resonance imaging investigation of theory of mind impairments in patients with temporal lobe epilepsy. Neuropsychologia, 93, 271-279. http://dx.do .org/10.1016/j.neuropsychologia.2016.11.007

Heyes, C. (2011). Automatic imitation. Psychological Bulletin, 137, 463483. http://dx.doi.org/10.1037/a0022288

Heyes, C. (2018). Cognitive gadgets: The cultural evolution of thinking. Cambridge, MA: Harvard University Press. http://dx.doi.org/10.4159/ 9780674985155 
Heyes, C. M., \& Frith, C. D. (2014). The cultural evolution of mind reading. Science, 344, 1243091. http://dx.doi.org/10.1126/science .1243091

Hogeveen, J., Obhi, S. S., Banissy, M. J., Santiesteban, I., Press, C., Catmur, C., \& Bird, G. (2015). Task-dependent and distinct roles of the temporoparietal junction and inferior frontal cortex in the control of imitation. Social Cognitive and Affective Neuroscience, 10, 1003-1009. http://dx.doi.org/10.1093/scan/nsu148

*Hooker, C. I., Verosky, S. C., Germine, L. T., Knight, R. T., \& D'Esposito, M. (2008). Mentalizing about emotion and its relationship to empathy. Social Cognitive and Affective Neuroscience, 3, 204-217. http://dx.doi.org/10.1093/scan/nsn019

"Hooker, C. I., Verosky, S. C., Germine, L. T., Knight, R. T., \& D'Esposito, M. (2010). Neural activity during social signal perception correlates with self-reported empathy. Brain Research, 1308, 100-113. http://dx.doi.org/10.1016/j.brainres.2009.10.006

*Horan, W. P., Iacoboni, M., Cross, K. A., Korb, A., Lee, J., Nori, P., . . Green, M. F. (2014). Self-reported empathy and neural activity during action imitation and observation in schizophrenia. NeuroImage Clinical, 5, 100-108. http://dx.doi.org/10.1016/j.nicl.2014.06.006

*Hughes, C., Cassidy, B. S., Faskowitz, J., Avena-Koenigsberger, A., Sporns, O., \& Krendl, A. C. (2019). Age differences in specific neural connections within the Default Mode Network underlie theory of mind. NeuroImage, 191, 269-277. http://dx.doi.org/10.1016/j.neuroimage .2019 .02 .024

*Iidaka, T., Omori, M., Murata, T., Kosaka, H., Yonekura, Y., Okada, T., \& Sadato, N. (2001). Neural interaction of the amygdala with the prefrontal and temporal cortices in the processing of facial expressions as revealed by fMRI. Journal of Cognitive Neuroscience, 13, 10351047. http://dx.doi.org/10.1162/089892901753294338

*Immordino-Yang, M. H., McColl, A., Damasio, H., \& Damasio, A. (2009). Neural correlates of admiration and compassion. Proceedings of the National Academy of Sciences of the United States of America, 106, 8021-8026. http://dx.doi.org/10.1073/pnas.0810363106

Insel, T., Cuthbert, B., Garvey, M., Heinssen, R., Pine, D. S., Quinn, K., . . . Wang, P. (2010). Research domain criteria (RDoC): Toward a new classification framework for research on mental disorders. The American Journal of Psychiatry, 167, 748-751. http://dx.doi.org/10.1176/appi.ajp .2010 .09091379

Jabbi, M., Swart, M., \& Keysers, C. (2007). Empathy for positive and negative emotions in the gustatory cortex. NeuroImage, 34, 1744-1753. http://dx.doi.org/10.1016/j.neuroimage.2006.10.032

*Jack, A., \& Pelphrey, K. A. (2015). Neural correlates of animacy attribution include neocerebellum in healthy adults. Cerebral Cortex, 25, 4240-4247. http://dx.doi.org/10.1093/cercor/bhu146

Jackson, P. L., Meltzoff, A. N., \& Decety, J. (2005). How do we perceive the pain of others? A window into the neural processes involved in empathy. NeuroImage, 24, 771-779. http://dx.doi.org/10.1016/j .neuroimage.2004.09.006

Kalbe, E., Schlegel, M., Sack, A. T., Nowak, D. A., Dafotakis, M., Bangard, C., . . Kessler, J. (2010). Dissociating cognitive from affective theory of mind: A TMS study. Cortex, 46, 769-780. http://dx.doi.org/ 10.1016/j.cortex.2009.07.010

*Kana, R. K., Keller, T. A., Cherkassky, V. L., Minshew, N. J., \& Just, M. A. (2009). Atypical frontal-posterior synchronization of Theory of Mind regions in autism during mental state attribution. Social Neuroscience, 4, 135-152. http://dx.doi.org/10.1080/17470910802198510

"Kana, R. K., Libero, L. E., Hu, C. P., Deshpande, H. D., \& Colburn, J. S. (2014). Functional brain networks and white matter underlying theoryof-mind in autism. Social Cognitive and Affective Neuroscience, 9, 98-105. http://dx.doi.org/10.1093/scan/nss106

Kanske, P. (2018). The social mind: Disentangling affective and cognitive routes to understanding others. Interdisciplinary Science Reviews, 43, 115-124. http://dx.doi.org/10.1080/03080188.2018.1453243
Kanske, P., Böckler, A., \& Singer, T. (2017). Models, mechanisms and moderators dissociating empathy and theory of mind. Current Topics in Behavioral Neurosciences, 30, 193-206. http://dx.doi.org/10.1007/ 7854_2015_412

Kanske, P., Böckler, A., Trautwein, F. M., Parianen Lesemann, F. H., \& Singer, T. (2016). Are strong empathizers better mentalizers? Evidence for independence and interaction between the routes of social cognition. Social Cognitive and Affective Neuroscience, 11, 1383-1392. http://dx .doi.org/10.1093/scan/nsw052

"Kanske, P., Böckler, A., Trautwein, F. M., \& Singer, T. (2015). Dissecting the social brain: Introducing the EmpaToM to reveal distinct neural networks and brain-behavior relations for empathy and Theory of Mind. NeuroImage, 122, 6-19. http://dx.doi.org/10.1016/j.neuroimage.2015 .07 .082

Keysers, C., \& Gazzola, V. (2009). Expanding the mirror: Vicarious activity for actions, emotions, and sensations. Current Opinion in Neurobiology, 19, 666-671. http://dx.doi.org/10.1016/j.conb.2009.10.006

Keysers, C., Kaas, J. H., \& Gazzola, V. (2010). Somatosensation in social perception. Nature Reviews Neuroscience, 11, 417-428. http://dx.doi org $/ 10.1038 / \mathrm{nrn} 2833$

"Kim, Y. T., Lee, J. J., Song, H. J., Kim, J. H., Kwon, D. H., Kim, M. N., . . Chang, Y. (2010). Alterations in cortical activity of male methamphetamine abusers performing an empathy task: FMRI study. Human Psychopharmacology, 25, 63-70. http://dx.doi.org/10.1002/hup.1083

*Kircher, T., Blümel, I., Marjoram, D., Lataster, T., Krabbendam, L., Weber, J., . . . Krach, S. (2009). Online mentalising investigated with functional MRI. Neuroscience Letters, 454, 176-181. http://dx.doi.org/ 10.1016/j.neulet.2009.03.026

*Kliemann, D., Young, L., Scholz, J., \& Saxe, R. (2008). The influence of prior record on moral judgment. Neuropsychologia, 46, 2949-2957. http://dx.doi.org/10.1016/j.neuropsychologia.2008.06.010

*Koelkebeck, K., Hirao, K., Kawada, R., Miyata, J., Saze, T., Ubukata, S., . . . Murai, T. (2011). Transcultural differences in brain activation patterns during theory of mind (ToM) task performance in Japanese and Caucasian participants. Social Neuroscience, 6, 615-626. http://dx.doi .org/10.1080/17470919.2011.620763

Konstantakopoulos, G., Oulis, P., Ploumpidis, D., Patrikelis, P., Nikitopoulou, S., Papadimitriou, G. N., \& David, A. S. (2014). Self-rated and performance-based empathy in schizophrenia: The impact of cognitive deficits. Social Neuroscience, 9, 590-600. http://dx.doi.org/10.1080/ 17470919.2014.934395

Koster-Hale, J., \& Saxe, R. (2013). Theory of mind: A neural prediction problem. Neuron, 79, 836-848. http://dx.doi.org/10.1016/j.neuron.2013 .08 .020

*Krach, S., Bluemel, I., Marjoram, D., Lataster, T., Krabbendam, L., Weber, J., van Os, J., \& Kircher, T. (2009). Are women better mindreaders? Sex differences in neural correlates of mentalizing detected with functional MRI. BMC Neuroscience, 4, 10, 9. http://dx.doi.org/10 .1186/1471-2202-10-9

*Krach, S., Kamp-Becker, I., Einhäuser, W., Sommer, J., Frässle, S., Jansen, A., . . . Paulus, F. M. (2015). Evidence from pupillometry and fMRI indicates reduced neural response during vicarious social pain but not physical pain in autism. Human Brain Mapping, 36, 4730-4744. http://dx.doi.org/10.1002/hbm.22949

Krishnan, A., Woo, C. W., Chang, L. J., Ruzic, L., Gu, X., López-Solà, M., ... Wager, T. D. (2016). Somatic and vicarious pain are represented by dissociable multivariate brain patterns. eLife, 5, e15166. http://dx.doi org/10.7554/eLife.15166

*Kühn, S., Kugler, D., Schmalen, K., Weichenberger, M., Witt, C., \& Gallinat, J. (2018). The myth of blunted gamers: No evidence for desensitization in empathy for pain after a violent video game intervention in a longitudinal fMRI study on non-gamers. Neuro-Signals, 26, 22-30. http://dx.doi.org/10.1159/000487217 
*Kullmann, J. S., Grigoleit, J.-S., Wolf, O. T., Engler, H., Oberbeck, R., Elsenbruch, S., . . . Gizewski, E. R. (2014). Experimental human endotoxemia enhances brain activity during social cognition. Social Cognitive and Affective Neuroscience, 9, 786-793. http://dx.doi.org/10 $.1093 / \mathrm{scan} / \mathrm{nst} 049$

Laird, A. R., Fox, P. M., Eickhoff, S. B., Turner, J. A., Ray, K. L., McKay, D. R., . . . Fox, P. T. (2011). Behavioral interpretations of intrinsic connectivity networks. Journal of Cognitive Neuroscience, 23, 40224037. http://dx.doi.org/10.1162/jocn_a_00077

Laird, A. R., Riedel, M. C., Sutherland, M. T., Eickhoff, S. B., Ray, K. L., Uecker, A. M., . . . Fox, P. T. (2015). Neural architecture underlying classification of face perception paradigms. NeuroImage, 119, 70-80. http://dx.doi.org/10.1016/j.neuroimage.2015.06.044

Lamm, C., Decety, J., \& Singer, T. (2011). Meta-analytic evidence for common and distinct neural networks associated with directly experienced pain and empathy for pain. NeuroImage, 54, 2492-2502. http:// dx.doi.org/10.1016/j.neuroimage.2010.10.014

"Lamm, C., Meltzoff, A. N., \& Decety, J. (2010). How do we empathize with someone who is not like us? A functional magnetic resonance imaging study. Journal of Cognitive Neuroscience, 22, 362-376. http:// dx.doi.org/10.1162/jocn.2009.21186

"Lange, K., Williams, L. M., Young, A. W., Bullmore, E. T., Brammer, M. J., Williams, S. C., . . Phillips, M. L. (2003). Task instructions modulate neural responses to fearful facial expressions. Biological Psychiatry, 53, 226-232. http://dx.doi.org/10.1016/S0006-3223 (02)01455-5

*Lee, J., Quintana, J., Nori, P., \& Green, M. F. (2011). Theory of mind in schizophrenia: Exploring neural mechanisms of belief attribution. Social Neuroscience, 6, 569-581. http://dx.doi.org/10.1080/17470919.2011 .620774

*Lee, S. M., \& McCarthy, G. (2016). Functional heterogeneity and convergence in the right temporoparietal junction. Cerebral Cortex, 26, 1108-1116. http://dx.doi.org/10.1093/cercor/bhu292

Leslie, A. M., Friedman, O., \& German, T. P. (2004). Core mechanisms in "theory of mind." Trends in Cognitive Sciences, 8, 528-533. http://dx .doi.org/10.1016/j.tics.2004.10.001

Lieberman, M. D. (2007). Social cognitive neuroscience: A review of core processes. Annual Review of Psychology, 58, 259-289. http://dx.doi.org/ 10.1146/annurev.psych.58.110405.085654

Lieberman, M. D., Burns, S. M., Torre, J. B., \& Eisenberger, N. I. (2016). Reply to Wager et al.: Pain and the dACC: The importance of hit rate-adjusted effects and posterior probabilities with fair priors. Proceedings of the National Academy of Sciences of the United States of America, 113, E2476-E2479. http://dx.doi.org/10.1073/pnas .1603186113

Lieberman, M. D., \& Eisenberger, N. I. (2015). The dorsal anterior cingulate cortex is selective for pain: Results from large-scale reverse inference. Proceedings of the National Academy of Sciences of the United States of America, 112, 15250-15255. http://dx.doi.org/10.1073/ pnas. 1515083112

Lindquist, K. A. (2017). The role of language in emotion: Existing evidence and future directions. Current Opinion in Psychology, 17, 135139. http://dx.doi.org/10.1016/j.copsyc.2017.07.006

Lindquist, K. A., Satpute, A. B., \& Gendron, M. (2015). Does language do more than communicate emotion? Current Directions in Psychological Science, 24, 99-108. http://dx.doi.org/10.1177/0963721414553440

Lindquist, K. A., Wager, T. D., Kober, H., Bliss-Moreau, E., \& Barrett, L. F. (2012). The brain basis of emotion: A meta-analytic review. Behavioral and Brain Sciences, 35, 121-143. http://dx.doi.org/10.1017/ S0140525X11000446

Lockwood, P. L., Apps, M. A., Roiser, J. P., \& Viding, E. (2015). Encoding of vicarious reward prediction in anterior cingulate cortex and relationship with trait empathy. The Journal of Neuroscience, 35, 13720-13727. http://dx.doi.org/10.1523/JNEUROSCI.1703-15.2015
Lockwood, P. L., Bird, G., Bridge, M., \& Viding, E. (2013). Dissecting empathy: High levels of psychopathic and autistic traits are characterized by difficulties in different social information processing domains. Frontiers in Human Neuroscience, 7, 760. http://dx.doi.org/10.3389/ fnhum.2013.00760

*Lou, H. C., Luber, B., Crupain, M., Keenan, J. P., Nowak, M., Kjaer, T. W., . . . Lisanby, S. H. (2004). Parietal cortex and representation of the mental Self. Proceedings of the National Academy of Sciences of the United States of America, 101, 6827-6832. http://dx.doi.org/10.1073/ pnas.0400049101

"Luo, S., Shi, Z., Yang, X., Wang, X., \& Han, S. (2014). Reminders of mortality decrease midcingulate activity in response to others' suffering. Social Cognitive and Affective Neuroscience, 9, 477-486. http://dx.doi .org/10.1093/scan/nst010

*Ma, N., Vandekerckhove, M., Van Overwalle, F., Seurinck, R., \& Fias, W. (2011). Spontaneous and intentional trait inferences recruit a common mentalizing network to a different degree: Spontaneous inferences activate only its core areas. Social Neuroscience, 6, 123-138. http://dx doi.org/10.1080/17470919.2010.485884

*Ma, Y., Wang, C., \& Han, S. (2011). Neural responses to perceived pain in others predict real-life monetary donations in different socioeconomic contexts. NeuroImage, 57, 1273-1280. http://dx.doi.org/10.1016/j neuroimage.2011.05.003

*Mackes, N. K., Golm, D., O’Daly, O. G., Sarkar, S., Sonuga-Barke, E. J. S., Fairchild, G., \& Mehta, M. A. (2018). Tracking emotions in the brain - Revisiting the Empathic Accuracy Task. NeuroImage, 178, 677-686. http://dx.doi.org/10.1016/j.neuroimage.2018.05.080

*Malhi, G. S., Lagopoulos, J., Das, P., Moss, K., Berk, M., \& Coulston, C. M. (2008). A functional MRI study of Theory of Mind in euthymic bipolar disorder patients. Bipolar Disorders, 10, 943-956. http://dx.doi .org/10.1111/j.1399-5618.2008.00643.x

*Mano, Y., Harada, T., Sugiura, M., Saito, D. N., \& Sadato, N. (2009). Perspective-taking as part of narrative comprehension: A functional MRI study. Neuropsychologia, 47, 813-824. http://dx.doi.org/10.1016/ j.neuropsychologia.2008.12.011

Mar, R. A. (2011). The neural bases of social cognition and story comprehension. Annual Review of Psychology, 62, 103-134. http://dx.doi .org/10.1146/annurev-psych-120709-145406

Margulies, D. S., Ghosh, S. S., Goulas, A., Falkiewicz, M., Huntenburg, J. M., Langs, G., . . S Smallwood, J. (2016). Situating the default-mode network along a principal gradient of macroscale cortical organization. Proceedings of the National Academy of Sciences of the United States of America, 113, 12574-12579. http://dx.doi.org/10.1073/pnas .1608282113

Mars, R. B., Neubert, F. X., Noonan, M. P., Sallet, J., Toni, I., \& Rushworth, M. F. (2012). On the relationship between the "default mode network" and the "social brain." Frontiers in Human Neuroscience, 6, 189. http://dx.doi.org/10.3389/fnhum.2012.00189

Mars, R. B., Sallet, J., Schüffelgen, U., Jbabdi, S., Toni, I., \& Rushworth, M. F. (2012). Connectivity-based subdivisions of the human right "temporoparietal junction area": Evidence for different areas participating in different cortical networks. Cerebral Cortex, 22, 1894-1903. http://dx doi.org/10.1093/cercor/bhr268

*Martin, A., \& Weisberg, J. (2003). Neural foundations for understanding social and mechanical concepts. Cognitive Neuropsychology, 20, 575587. http://dx.doi.org/10.1080/02643290342000005

"Mascaro, J. S., Rilling, J. K., Tenzin Negi, L., \& Raison, C. L. (2013). Compassion meditation enhances empathic accuracy and related neural activity. Social Cognitive and Affective Neuroscience, 8, 48-55. http:// dx.doi.org/10.1093/scan/nss095

Mathur, V. A., Harada, T., Lipke, T., \& Chiao, J. Y. (2010). Neural basis of extraordinary empathy and altruistic motivation. Neurolmage, 51, 1468-1475. http://dx.doi.org/10.1016/j.neuroimage.2010.03.025 
*McAdams, C. J., \& Krawczyk, D. C. (2011). Impaired neural processing of social attribution in anorexia nervosa. Psychiatry Research, 194, 54-63. http://dx.doi.org/10.1016/j.pscychresns.2011.06.016

Meyer, M. L., Davachi, L., Ochsner, K. N., \& Lieberman, M. D. (2019). Evidence that default network connectivity during rest consolidates social information. Cerebral Cortex, 29, 1910-1920. http://dx.doi.org/ 10.1093/cercor/bhy071

Mier, D., Lis, S., Neuthe, K., Sauer, C., Esslinger, C., Gallhofer, B., \& Kirsch, P. (2010). The involvement of emotion recognition in affective theory of mind. Psychophysiology, 47, 1028-1039. http://dx.doi.org/10 $.1111 / \mathrm{j} .1469-8986.2010 .01031 . x$

Miller, L. E., \& Saygin, A. P. (2013). Individual differences in the perception of biological motion: Links to social cognition and motor imagery. Cognition, 128, 140-148. http://dx.doi.org/10.1016/j.cognition .2013 .03 .013

*Mitchell, J. P. (2008). Activity in right temporo-parietal junction is not selective for theory-of-mind. Cerebral Cortex, 18, 262-271. http://dx .doi.org/10.1093/cercor/bhm051

Mitchell, J. P. (2009). Inferences about mental states. Philosophical Transactions of the Royal Society of London Series B, Biological Sciences, 364, 1309-1316. http://dx.doi.org/10.1098/rstb.2008.0318

*Mitchell, J. P., Banaji, M. R., \& Macrae, C. N. (2005a). General and specific contributions of the medial prefrontal cortex to knowledge about mental states. NeuroImage, 28, 757-762. http://dx.doi.org/10.1016/j .neuroimage.2005.03.011

*Mitchell, J. P., Banaji, M. R., \& Macrae, C. N. (2005b). The link between social cognition and self-referential thought in the medial prefrontal cortex. Journal of Cognitive Neuroscience, 17, 1306-1315. http://dx.doi .org/10.1162/0898929055002418

*Mitchell, J. P., Cloutier, J., Banaji, M. R., \& Macrae, C. N. (2006). Medial prefrontal dissociations during processing of trait diagnostic and nondiagnostic person information. Social Cognitive and Affective Neuroscience, 1, 49-55. http://dx.doi.org/10.1093/scan/ns1007

*Mitchell, J. P., Heatherton, T. F., \& Macrae, C. N. (2002). Distinct neural systems subserve person and object knowledge. Proceedings of the National Academy of Sciences of the United States of America, 99, 15238-15243. http://dx.doi.org/10.1073/pnas.232395699

*Mitchell, J. P., Macrae, C. N., \& Banaji, M. R. (2004). Encoding-specific effects of social cognition on the neural correlates of subsequent memory. The Journal of Neuroscience, 24, 4912-4917. http://dx.doi.org/10 .1523/JNEUROSCI.0481-04.2004

*Mitchell, J. P., Neil Macrae, C., \& Banaji, M. R. (2005c). Forming impressions of people versus inanimate objects: Social-cognitive processing in the medial prefrontal cortex. Neurolmage, 26, 251-257. http://dx.doi.org/10.1016/j.neuroimage.2005.01.031

"Mochizuki, H., Baumgärtner, U., Kamping, S., Ruttorf, M., Schad, L. R., Flor, H., . . . Treede, R.-D. (2013). Cortico-subcortical activation patterns for itch and pain imagery. Pain, 154, 1989-1998. http://dx.doi.org/ 10.1016/j.pain.2013.06.007

*Modinos, G., Renken, R., Ormel, J., \& Aleman, A. (2011). Self-reflection and the psychosis-prone brain: An fMRI study. Neuropsychology, 25, 295-305. http://dx.doi.org/10.1037/a0021747

"Moessnang, C., Schäfer, A., Bilek, E., Roux, P., Otto, K., Baumeister, S., ... Tost, H. (2016). Specificity, reliability and sensitivity of social brain responses during spontaneous mentalizing. Social Cognitive and Affective Neuroscience, 11, 1687-1697. http://dx.doi.org/10.1093/scan/ nsw098

Molenberghs, P., Johnson, H., Henry, J. D., \& Mattingley, J. B. (2016). Understanding the minds of others: A neuroimaging meta-analysis. Neuroscience and Biobehavioral Reviews, 65, 276-291. http://dx.doi .org/10.1016/j.neubiorev.2016.03.020

*Moor, B. G., Macks, Z. A., Güroglu, B., Rombouts, S. A., Molen, M. W., \& Crone, E. A. (2012). Neurodevelopmental changes of reading the mind in the eyes. Social Cognitive and Affective Neuroscience, 7, 44-52. http://dx.doi.org/10.1093/scan/nsr020

Morelli, S. A., Sacchet, M. D., \& Zaki, J. (2015). Common and distinct neural correlates of personal and vicarious reward: A quantitative metaanalysis. NeuroImage, 112, 244-253. http://dx.doi.org/10.1016/j .neuroimage.2014.12.056

*Moriguchi, Y., Ohnishi, T., Kawachi, T., Mori, T., Hirakata, M., Yamada, M., . . Komaki, G. (2005). Specific brain activation in Japanese and Caucasian people to fearful faces. Neuroreport, 16, 133-136. http://dx .doi.org/10.1097/00001756-200502080-00012

"Moriguchi, Y., Ohnishi, T., Lane, R. D., Maeda, M., Mori, T., Nemoto, K., . . Komaki, G. (2006). Impaired self-awareness and theory of mind: An fMRI study of mentalizing in alexithymia. Neurolmage, 32, 1472 1482. http://dx.doi.org/10.1016/j.neuroimage.2006.04.186

*Morrison, I., Lloyd, D., di Pellegrino, G., \& Roberts, N. (2004). Vicarious responses to pain in anterior cingulate cortex: Is empathy a multisensory issue? Cognitive, Affective \& Behavioral Neuroscience, 4, 270-278. http://dx.doi.org/10.3758/CABN.4.2.270

*Murphy, E. R., Brent, B. K., Benton, M., Pruitt, P., Diwadkar, V., Rajarethinam, R. P., \& Keshavan, M. S. (2010). Differential processing of metacognitive evaluation and the neural circuitry of the self and others in schizophrenia: A pilot study. Schizophrenia Research, 116(23), 252-258. http://dx.doi.org/10.1016/j.schres.2009.11.009

Murray, R. J., Schaer, M., \& Debbané, M. (2012). Degrees of separation: A quantitative neuroimaging meta-analysis investigating self-specificity and shared neural activation between self- and other-reflection. Neuroscience and Biobehavioral Reviews, 36, 1043-1059. http://dx.doi.org/10 .1016/j.neubiorev.2011.12.013

*Naughtin, C. K., Horne, K., Schneider, D., Venini, D., York, A., \& Dux P. E. (2017). Do implicit and explicit belief processing share neural substrates? Human Brain Mapping, 38, 4760-4772. http://dx.doi.org/10 $.1002 / \mathrm{hbm} .23700$

Nichols, T., Brett, M., Andersson, J., Wager, T., \& Poline, J. B. (2005). Valid conjunction inference with the minimum statistic. NeuroImage, 25, 653-660. http://dx.doi.org/10.1016/j.neuroimage.2004.12.005

*Nolte, T., Bolling, D. Z., Hudac, C. M., Fonagy, P., Mayes, L., \& Pelphrey, K. A. (2013). Brain mechanisms underlying the impact of attachment-related stress on social cognition. Frontiers in Human Neuroscience, 7, 816. http://dx.doi.org/10.3389/fnhum.2013.00816

*Nomi, J. S., Scherfeld, D., Friederichs, S., Schäfer, R., Franz, M., Wittsack, H. J., . . Seitz, R. J. (2008). On the neural networks of empathy: A principal component analysis of an fMRI study. Behavioral and Brain Functions, 4, 41. http://dx.doi.org/10.1186/1744-9081-4-41

Oakley, B. F. M., Brewer, R., Bird, G., \& Catmur, C. (2016). Theory of mind is not theory of emotion: A cautionary note on the Reading the Mind in the Eyes Test. Journal of Abnormal Psychology, 125, 818-823. http://dx.doi.org/10.1037/abn0000182

*'Ochsner, K. N., Beer, J. S., Robertson, E. R., Cooper, J. C., Gabrieli, J. D., Kihsltrom, J. F., \& D'Esposito, M. (2005). The neural correlates of direct and reflected self-knowledge. NeuroImage, 28, 797-814. http:// dx.doi.org/10.1016/j.neuroimage.2005.06.069

*Ochsner, K. N., Zaki, J., Hanelin, J., Ludlow, D. H., Knierim, K., Ramachandran, T., . . . Mackey, S. C. (2008). Your pain or mine? Common and distinct neural systems supporting the perception of pain in self and other. Social Cognitive and Affective Neuroscience, 3, 144 160. http://dx.doi.org/10.1093/scan/nsn006

Olderbak, S., Wilhelm, O., Olaru, G., Geiger, M., Brenneman, M. W., \& Roberts, R. D. (2015). A psychometric analysis of the reading the mind in the eyes test: Toward a brief form for research and applied settings. Frontiers in Psychology, 6, 1503. http://dx.doi.org/10.3389/fpsyg.2015 .01503

*Oliver, L. D., Vieira, J. B., Neufeld, R. W. J., Dziobek, I., \& Mitchell, D. G. V. (2018). Greater involvement of action simulation mechanisms 
in emotional vs cognitive empathy. Social Cognitive and Affective Neuroscience, 13, 367-380. http://dx.doi.org/10.1093/scan/nsy013

*Olsson, A., Nearing, K. I., \& Phelps, E. A. (2007). Learning fears by observing others: The neural systems of social fear transmission. Social Cognitive and Affective Neuroscience, 2, 3-11. http://dx.doi.org/10 $.1093 / \mathrm{scan} / \mathrm{nsm} 005$

*Otti, A., Wohlschlaeger, A. M., \& Noll-Hussong, M. (2015). Is the medial prefrontal cortex necessary for theory of mind? PLOS ONE, 10, e0135912. http://dx.doi.org/10.1371/journal.pone.0135912

*Özdem, C., Brass, M., Van der Cruyssen, L., \& Van Overwalle, F. (2017). The overlap between false belief and spatial reorientation in the temporo-parietal junction: The role of input modality and task. Social Neuroscience, 12, 207-217. http://dx.doi.org/10.1080/17470919.2016 .1143027

*Pehrs, C., Zaki, J., Schlochtermeier, L. H., Jacobs, A. M., Kuchinke, L., $\&$ Koelsch, S. (2017). The temporal pole top-down modulates the ventral visual stream during social cognition. Cerebral Cortex, 27, 777-792. http://dx.doi.org/10.1093/cercor/bhv226

*Perner, J., Aichhorn, M., Kronbichler, M., Staffen, W., \& Ladurner, G. (2006). Thinking of mental and other representations: The roles of left and right temporo-parietal junction. Social Neuroscience, 1, 245-258. http://dx.doi.org/10.1080/17470910600989896

Perner, J., \& Leekam, S. (2008). The curious incident of the photo that was accused of being false: Issues of domain specificity in development, autism, and brain imaging. Quarterly Journal of Experimental Psychology: Human Experimental Psychology, 61, 76-89. http://dx.doi.org/10 $.1080 / 17470210701508756$

Perner, J., \& Roessler, J. (2012). From infants' to children's appreciation of belief. Trends in Cognitive Sciences, 16, 519-525. http://dx.doi.org/ 10.1016/j.tics.2012.08.004

Pfeifer, J. H., \& Dapretto, M. (2009). "Mirror, mirror, in my mind": Empathy, interpersonal competence, and the mirror neuron system. In J. Decety \& W. Ickes (Eds.), Social neuroscience. The social neuroscience of empathy (pp. 183-197). Cambridge, MA: MIT Press. http://dx.doi .org/10.7551/mitpress/9780262012973.003.0015

*Phillips, M. L., Young, A. W., Senior, C., Brammer, M., Andrew, C., Calder, A. J., . . Gray, J. A. (1997). A specific neural substrate for perceiving facial expressions of disgust. Nature, 389, 495. http://dx.doi .org/10.1038/39051

"Platek, S. M., Keenan, J. P., Gallup, G. G., Jr., \& Mohamed, F. B. (2004). Where am I? The neurological correlates of self and other. Cognitive Brain Research, 19, 114-122. http://dx.doi.org/10.1016/j.cogbrainres .2003.11.014

*Powell, J. L., Grossi, D., Corcoran, R., Gobet, F., \& García-Fiñana, M. (2017). The neural correlates of theory of mind and their role during empathy and the game of chess: A functional magnetic resonance imaging study. Neuroscience, 355, 149-160. http://dx.doi.org/10.1016/ j.neuroscience.2017.04.042

Preckel, K., Kanske, P., \& Singer, T. (2018). On the interaction of social affect and cognition: Empathy, compassion and theory of mind. Current Opinion in Behavioral Sciences, 19, 1-6. http://dx.doi.org/10.1016/j .cobeha.2017.07.010

"Preis, M. A., Schmidt-Samoa, C., Dechent, P., \& Kroener-Herwig, B. (2013). The effects of prior pain experience on neural correlates of empathy for pain: An fMRI study. Pain, 154, 411-418. http://dx.doi .org/10.1016/j.pain.2012.11.014

Premack, D., \& Woodruff, G. (1978). Does the chimpanzee have a theory of mind? Behavioral and Brain Sciences, 1, 515-526. http://dx.doi.org/ 10.1017/S0140525X00076512

Preston, S. D. (2007). A perception-action model for empathy. In T. Farrow \& P. Woodruff (Eds.), Empathy in mental illness (pp. 428-447). New York, NY: Cambridge University Press. http://dx.doi.org/10.1017/ CBO9780511543753.024
Preston, S. D., Bechara, A., Damasio, H., Grabowski, T. J., Stansfield, R. B., Mehta, S., \& Damasio, A. R. (2007). The neural substrates of cognitive empathy. Social Neuroscience, 2, 254-275. http://dx.doi.org/ 10.1080/17470910701376902

Preston, S. D., \& de Waal, F. B. (2002). Empathy: Its ultimate and proximate bases. Behavioral and Brain Sciences, 25, 1-20. http://dx.doi .org/10.1017/S0140525X02000018

Preston, S. D., \& Hofelich, A. J. (2012). The many faces of empathy: Parsing empathic phenomena through a proximate, dynamic-systems view of representing the other in the self. Emotion Review, 4, 24-33. http://dx.doi.org/10.1177/1754073911421378

*Quaio-Tasserit, E., Corradi-Dell'Acqua, C., \& Vuilleumier, P. (2018). The good, the bad, and the suffering. Transient emotional episodes modulate the neural circuits of pain and empathy. Neuropsychologia, 116, 99-116. http://dx.doi.org/10.1016/j.neuropsychologia.2017.12.027

Radua, J., Mataix-Cols, D., Phillips, M. L., El-Hage, W., Kronhaus, D. M., Cardoner, N., \& Surguladze, S. (2012). A new meta-analytic method for neuroimaging studies that combines reported peak coordinates and statistical parametric maps. European Psychiatry, 27, 605-611. http://dx .doi.org/10.1016/j.eurpsy.2011.04.001

*Rameson, L. T., Morelli, S. A., \& Lieberman, M. D. (2012). The neural correlates of empathy: Experience, automaticity, and prosocial behavior. Journal of Cognitive Neuroscience, 24, 235-245. http://dx.doi.org/10 .1162/jocn_a_00130

*Regenbogen, C., Schneider, D. A., Gur, R. E., Schneider, F., Habel, U., \& Kellermann, T. (2012). Multimodal human communication-Targeting facial expressions, speech content and prosody. NeuroImage, 60, 23462356. http://dx.doi.org/10.1016/j.neuroimage.2012.02.043

Reniers, R. L., Völlm, B. A., Elliott, R., \& Corcoran, R. (2014). Empathy, ToM, and self-other differentiation: An fMRI study of internal states. Social Neuroscience, 9, 50-62. http://dx.doi.org/10.1080/17470919 .2013 .861360

*Reniers, R. L., Völlm, B. A., Elliott, R., \& Corcoran, R. (2014). Empathy, ToM, and self-other differentiation: An fMRI study of internal states. Social Neuroscience, 9, 50-62. http://dx.doi.org/10.1080/17470919 .2013 .861360

*Reyes-Aguilar, A., Fernandez-Ruiz, J., Pasaye, E. H., \& Barrios, F. A. (2017). Executive mechanisms for thinking about negative situations in both cooperative and non-cooperative contexts. Frontiers in Human Neuroscience, 11, 275. http://dx.doi.org/10.3389/fnhum.2017.00275

Rice, K., Anderson, L. C., Velnoskey, K., Thompson, J. C., \& Redcay, E. (2016). Biological motion perception links diverse facets of theory of mind during middle childhood. Journal of Experimental Child Psychology, 146, 238-246. http://dx.doi.org/10.1016/j.jecp.2015.09.003

Riedel, M. C., Ray, K. L., Dick, A. S., Sutherland, M. T., Hernandez, Z., Fox, P. M., . . Laird, A. R. (2015). Meta-analytic connectivity and behavioral parcellation of the human cerebellum. NeuroImage, 117, 327-342. http://dx.doi.org/10.1016/j.neuroimage.2015.05.008

Riedel, M. C., Yanes, J. A., Ray, K. L., Eickhoff, S. B., Fox, P. T., Sutherland, M. T., \& Laird, A. R. (2018). Dissociable meta-analytic brain networks contribute to coordinated emotional processing. Human Brain Mapping, 39, 2514-2531. http://dx.doi.org/10.1002/hbm.24018

*Riedl, R., Mohr, P., Kenning, P., Davis, F., \& Heekeren, H. (2014). Trusting humans and avatars: A brain imaging study based on evolution theory. Journal of Management Information Systems, 30, 83-114. http:// dx.doi.org/10.2753/MIS0742-1222300404

"Rilling, J. K., Sanfey, A. G., Aronson, J. A., Nystrom, L. E., \& Cohen, J. D. (2004). The neural correlates of theory of mind within interpersonal interactions. NeuroImage, 22, 1694-1703. http://dx.doi.org/10.1016/j neuroimage.2004.04.015

Rimé, B., Boulanger, B., Laubin, P., Richir, M., \& Stroobants, K. (1985). The perception of interpersonal emotions originated by patterns of movement. Motivation and Emotion, 9, 241-260. http://dx.doi.org/10 $.1007 / \mathrm{BF} 00991830$ 
Rizzolatti, G., \& Craighero, L. (2004). The mirror-neuron system. Annual Review of Neuroscience, 27, 169-192. http://dx.doi.org/10.1146/ annurev.neuro.27.070203.144230

*Roser, P., Lissek, S., Tegenthoff, M., Nicolas, V., Juckel, G., \& Brüne, M. (2012). Alterations of theory of mind network activation in chronic cannabis users. Schizophrenia Research, 139, 19-26. http://dx.doi.org/ 10.1016/j.schres.2012.05.020

*Ross, L. A., \& Olson, I. R. (2010). Social cognition and the anterior temporal lobes. NeuroImage, 49, 3452-3462. http://dx.doi.org/10.1016/ j.neuroimage.2009.11.012

Ruby, P., \& Decety, J. (2004). How would you feel versus how do you think she would feel? A neuroimaging study of perspective-taking with social emotions. Journal of Cognitive Neuroscience, 16, 988-999. http:// dx.doi.org/10.1162/0898929041502661

"Russell, T. A., Rubia, K., Bullmore, E. T., Soni, W., Suckling, J., Brammer, M. J., . . . Sharma, T. (2000). Exploring the social brain in schizophrenia: Left prefrontal underactivation during mental state attribution. The American Journal of Psychiatry, 157, 2040-2042. http://dx .doi.org/10.1176/appi.ajp.157.12.2040

Rütgen, M., Seidel, E. M., Silani, G., Riečanský, I., Hummer, A., Windischberger, C., .. L Lamm, C. (2015). Placebo analgesia and its opioidergic regulation suggest that empathy for pain is grounded in self pain. Proceedings of the National Academy of Sciences of the United States of America, 112, E5638-E5646. http://dx.doi.org/10.1073/pnas .1511269112

Santiesteban, I., Banissy, M. J., Catmur, C., \& Bird, G. (2012). Enhancing social ability by stimulating right temporoparietal junction. Current Biology, 22, 2274-2277. http://dx.doi.org/10.1016/j.cub.2012.10.018

"Santos, N. S., Kuzmanovic, B., David, N., Rotarska-Jagiela, A., Eickhoff, S. B., Shah, J. N., . . Vogeley, K. (2010). Animated brain: A functional neuroimaging study on animacy experience. Neurolmage, 53, 291-302. http://dx.doi.org/10.1016/j.neuroimage.2010.05.080

Sarfati, Y., Hardy-Baylé, M. C., Besche, C., \& Widlöcher, D. (1997). Attribution of intentions to others in people with schizophrenia: A non-verbal exploration with comic strips. Schizophrenia Research, 25, 199-209. http://dx.doi.org/10.1016/S0920-9964(97)00025-X

"Saxe, R., \& Kanwisher, N. (2003). People thinking about thinking people. The role of the temporo-parietal junction in "theory of mind." NeuroImage, 19, 1835-1842. http://dx.doi.org/10.1016/S1053-8119 (03)00230-1

*Saxe, R., \& Powell, L. J. (2006). It's the thought that counts: Specific brain regions for one component of theory of mind. Psychological Science, 17, 692-699. http://dx.doi.org/10.1111/j.1467-9280.2006 .01768.x

*Saxe, R., Schulz, L. E., \& Jiang, Y. V. (2006). Reading minds versus following rules: Dissociating theory of mind and executive control in the brain. Social Neuroscience, 1(3-4), 284-298. http://dx.doi.org/10.1080/ 17470910601000446

*Saxe, R., \& Wexler, A. (2005). Making sense of another mind: The role of the right temporo-parietal junction. Neuropsychologia, 43, 13911399. http://dx.doi.org/10.1016/j.neuropsychologia.2005.02.013

Schaafsma, S. M., Pfaff, D. W., Spunt, R. P., \& Adolphs, R. (2015). Deconstructing and reconstructing theory of mind. Trends in Cognitive Sciences, 19, 65-72. http://dx.doi.org/10.1016/j.tics.2014.11.007

"Schiffer, B., Pawliczek, C., Müller, B. W., Gizewski, E. R., \& Walter, H. (2013). Why don't men understand women? Altered neural networks for reading the language of male and female eyes. PLOS ONE, 8, e60278. http://dx.doi.org/10.1371/journal.pone.0060278

Schilbach, L., Eickhoff, S. B., Mojzisch, A., \& Vogeley, K. (2008). What's in a smile? Neural correlates of facial embodiment during social interaction. Social Neuroscience, 3, 37-50. http://dx.doi.org/10.1080/ 17470910701563228

Schilbach, L., Timmermans, B., Reddy, V., Costall, A., Bente, G., Schlicht, T., \& Vogeley, K. (2013). Toward a second-person neuroscience. Be- havioral and Brain Sciences, 36, 393-414. http://dx.doi.org/10.1017/ S0140525X12000660

*Schlaffke, L., Lissek, S., Lenz, M., Juckel, G., Schultz, T., Tegenthoff, M., . . . Brüne, M. (2015). Shared and nonshared neural networks of cognitive and affective theory-of-mind: A neuroimaging study using cartoon picture stories. Human Brain Mapping, 36, 29-39. http://dx.doi .org/10.1002/hbm.22610

*Schmitgen, M. M., Walter, H., Drost, S., Rückl, S., \& Schnell, K. (2016). Stimulus-dependent amygdala involvement in affective theory of mind generation. NeuroImage, 129, 450-459. http://dx.doi.org/10.1016/j .neuroimage.2016.01.029

${ }^{*}$ Schmitz, T. W., Kawahara-Baccus, T. N., \& Johnson, S. C. (2004) Metacognitive evaluation, self-relevance, and the right prefrontal cortex. NeuroImage, 22, 941-947. http://dx.doi.org/10.1016/j.neuroimage.2004 .02 .018

*Schneider, K., Regenbogen, C., Pauly, K. D., Gossen, A., Schneider, D. A., Mevissen, L., . . . Schneider, F. (2013). Evidence for genderspecific endophenotypes in high-functioning autism spectrum disorder during empathy. Autism Research, 6, 506-521. http://dx.doi.org/10 .1002/aur.1310

*Schnell, K., Bluschke, S., Konradt, B., \& Walter, H. (2011). Functional relations of empathy and mentalizing: An fMRI study on the neural basis of cognitive empathy. NeuroImage, 54, 1743-1754. http://dx.doi.org/10 .1016/j.neuroimage.2010.08.024

"Schroeder, U., Hennenlotter, A., Erhard, P., Haslinger, B., Stahl, R., Lange, K. W., \& Ceballos-Baumann, A. O. (2004). Functional neuroanatomy of perceiving surprised faces. Human Brain Mapping, 23, 181-187. http://dx.doi.org/10.1002/hbm.20057

"Schulte-Rüther, M., Greimel, E., Markowitsch, H. J., Kamp-Becker, I., Remschmidt, H., Fink, G. R., \& Piefke, M. (2011). Dysfunctions in brain networks supporting empathy: An fMRI study in adults with autism spectrum disorders. Social Neuroscience, 6, 1-21. http://dx.doi.org/10 .1080/17470911003708032

"Schulte-Rüther, M., Greimel, E., Piefke, M., Kamp-Becker, I., Remschmidt, H., Fink, G. R., . . Konrad, K. (2014). Age-dependent changes in the neural substrates of empathy in autism spectrum disorder. Social Cognitive and Affective Neuroscience, 9, 1118-1126. http://dx.doi.org/ 10.1093/scan/nst088

Schulte-Rüther, M., Markowitsch, H. J., Fink, G. R., \& Piefke, M. (2007). Mirror neuron and theory of mind mechanisms involved in face-to-face interactions: A functional magnetic resonance imaging approach to empathy. Journal of Cognitive Neuroscience, 19, 1354-1372. http://dx .doi.org/10.1162/jocn.2007.19.8.1354

*Schultz, J., Imamizu, H., Kawato, M., \& Frith, C. D. (2004). Activation of the human superior temporal gyrus during observation of goal attribution by intentional objects. Journal of Cognitive Neuroscience, 16, 16951705. http://dx.doi.org/10.1162/0898929042947874

Schurz, M., Aichhorn, M., Martin, A., \& Perner, J. (2013). Common brain areas engaged in false belief reasoning and visual perspective taking: A meta-analysis of functional brain imaging studies. Frontiers in Human Neuroscience, 7, 712. http://dx.doi.org/10.3389/fnhum.2013.00712

Schurz, M., Radua, J., Aichhorn, M., Richlan, F., \& Perner, J. (2014). Fractionating theory of mind: A meta-analysis of functional brain imaging studies. Neuroscience and Biobehavioral Reviews, 42, 9-34. http://dx.doi.org/10.1016/j.neubiorev.2014.01.009

*Seara-Cardoso, A., Viding, E., Lickley, R. A., \& Sebastian, C. L. (2015). Neural responses to others' pain vary with psychopathic traits in healthy adult males. Cognitive, Affective \& Behavioral Neuroscience, 15, 578588. http://dx.doi.org/10.3758/s13415-015-0346-7

*Sebastian, C. L., Fontaine, N. M., Bird, G., Blakemore, S. J., Brito, S. A., McCrory, E. J., \& Viding, E. (2012). Neural processing associated with cognitive and affective Theory of Mind in adolescents and adults. Social Cognitive and Affective Neuroscience, 7, 53-63. http://dx.doi.org/10 $.1093 /$ scan/nsr023 
Shamay-Tsoory, S. G., \& Aharon-Peretz, J. (2007). Dissociable prefrontal networks for cognitive and affective theory of mind: A lesion study. Neuropsychologia, 45, 3054-3067. http://dx.doi.org/10.1016/j .neuropsychologia.2007.05.021

Shamay-Tsoory, S. G., Aharon-Peretz, J., \& Perry, D. (2009). Two systems for empathy: A double dissociation between emotional and cognitive empathy in inferior frontal gyrus versus ventromedial prefrontal lesions. Brain: A Journal of Neurology, 132, 617-627. http://dx.doi.org/10 .1093/brain/awn279

Singer, T. (2006). The neuronal basis and ontogeny of empathy and mind reading: Review of literature and implications for future research. Neuroscience and Biobehavioral Reviews, 30, 855-863. http://dx.doi.org/10 .1016/j.neubiorev.2006.06.011

Singer, T., \& Lamm, C. (2009). The social neuroscience of empathy. Annals of the New York Academy of Sciences, 1156, 81-96. http://dx .doi.org/10.1111/j.1749-6632.2009.04418.x

Singer, T., Seymour, B., O’Doherty, J., Kaube, H., Dolan, R. J., \& Frith, C. D. (2004). Empathy for pain involves the affective but not sensory components of pain. Science, 303, 1157-1162. http://dx.doi.org/10 $.1126 /$ science. 1093535

Spreng, R. N., \& Grady, C. L. (2010). Patterns of brain activity supporting autobiographical memory, prospection, and theory of mind, and their relationship to the default mode network. Journal of Cognitive Neuroscience, 22, 1112-1123. http://dx.doi.org/10.1162/jocn.2009.21282

Spreng, R. N., Mar, R. A., \& Kim, A. S. (2009). The common neural basis of autobiographical memory, prospection, navigation, theory of mind, and the default mode: A quantitative meta-analysis. Journal of Cognitive Neuroscience, 21, 489-510. http://dx.doi.org/10.1162/jocn.2008.21029

"Sprengelmeyer, R., Rausch, M., Eysel, U. T., \& Przuntek, H. (1998). Neural structures associated with recognition of facial expressions of basic emotions. Proceedings Biological Sciences, 265, 1927-1931. http://dx.doi.org/10.1098/rspb.1998.0522

Spunt, R. P., \& Adolphs, R. (2017). A new look at domain specificity: Insights from social neuroscience. Nature Reviews Neuroscience, 18, 559-567. http://dx.doi.org/10.1038/nrn.2017.76

Spunt, R. P., Meyer, M. L., \& Lieberman, M. D. (2015). The default mode of human brain function primes the intentional stance. Journal of Cognitive Neuroscience, 27, 1116-1124. http://dx.doi.org/10.1162/ jocn_a_00785

"Sripada, C. S., Angstadt, M., Banks, S., Nathan, P. J., Liberzon, I., \& Phan, K. L. (2009). Functional neuroimaging of mentalizing during the trust game in social anxiety disorder. Neuroreport, 20, 984-989. http:// dx.doi.org/10.1097/WNR.0b013e32832d0a67

"Surguladze, S. A., Brammer, M. J., Young, A. W., Andrew, C., Travis, M. J., Williams, S. C., \& Phillips, M. L. (2003). A preferential increase in the extrastriate response to signals of danger. NeuroImage, 19, 13171328. http://dx.doi.org/10.1016/S1053-8119(03)00085-5

"Surguladze, S. A., Elkin, A., Ecker, C., Kalidindi, S., Corsico, A., Giampietro, V., . . . Phillips, M. L. (2008). Genetic variation in the serotonin transporter modulates neural system-wide response to fearful faces. Genes, Brain, \& Behavior, 7, 543-551. http://dx.doi.org/10.1111/ j.1601-183X.2008.00390.x

"Suzuki, S., Niki, K., Fujisaki, S., \& Akiyama, E. (2011). Neural basis of conditional cooperation. Social Cognitive and Affective Neuroscience, 6 , 338-347. http://dx.doi.org/10.1093/scan/nsq042

Tager-Flusberg, H., Boshart, J., \& Baron-Cohen, S. (1998). Reading the windows to the soul: Evidence of domain-specific sparing in Williams syndrome. Journal of Cognitive Neuroscience, 10, 631-639. http://dx .doi.org/10.1162/089892998563031

"Takahashi, H., Izuma, K., Matsumoto, M., Matsumoto, K., \& Omori, T. (2015). The anterior insula tracks behavioral entropy during an interpersonal competitive game. PLoS ONE, 10(6), e0123329. http://dx.doi.org/ 10.1371/journal.pone.0123329
*Takahashi, H., Terada, K., Morita, T., Suzuki, S., Haji, T., Kozima, H., .. . Naito, E. (2014). Different impressions of other agents obtained through social interaction uniquely modulate dorsal and ventral pathway activities in the social human brain. Cortex, 58, 289-300. http://dx.doi.org/ 10.1016/j.cortex.2014.03.011

Tamir, D. I., \& Thornton, M. A. (2018). Modeling the predictive social mind. Trends in Cognitive Sciences, 22, 201-212. http://dx.doi.org/10 .1016/j.tics.2017.12.005

*Tavares, P., Lawrence, A. D., \& Barnard, P. J. (2008). Paying attention to social meaning: An FMRI study. Cerebral Cortex, 18, 1876-1885. http://dx.doi.org/10.1093/cercor/bhm212

*Tei, S., Becker, C., Kawada, R., Fujino, J., Jankowski, K. F., Sugihara, G., . . . Takahashi, H. (2014). Can we predict burnout severity from empathy-related brain activity? Translational Psychiatry, 4, e393. http:// dx.doi.org/10.1038/tp.2014.34

The Math Works, Inc. (2013). MATLAB 8.1 (Version R2013a) [Computer software]. Retrieved from https://www.mathworks.com/

Tholen, M. G., Trautwein, F. M., Böckler, A., Singer, T., \& Kanske, P. (2020). Functional magnetic resonance imaging (fMRI) item analysis of empathy and theory of mind. Human Brain Mapping, 41, 2611-2628. http://dx.doi.org/10.1002/hbm.24966

Thornton, M. A., Weaverdyck, M. E., \& Tamir, D. I. (2019). The social brain automatically predicts others' future mental states. The Journal of Neuroscience, 39, 140-148. http://dx.doi.org/10.1523/JNEUROSCI .1431-18.2018

*Thye, M. D., Murdaugh, D. L., \& Kana, R. K. (2018). Brain mechanisms underlying reading the mind from eyes, voices, and actions. Neuroscience, 374, 172-186. http://dx.doi.org/10.1016/j.neuroscience.2018.01 .045

Timmers, I., Park, A. L., Fischer, M. D., Kronman, C. A., Heathcote, L. C., Hernandez, J. M., \& Simons, L. E. (2018). Is empathy for pain unique in its neural correlates? A meta-analysis of neuroimaging studies of empathy. Frontiers in Behavioral Neuroscience, 12, 289. http://dx.doi .org/10.3389/fnbeh.2018.00289

Titchener, E. B. (1909). Experimental psychology of the thought-processes. New York, NY: MacMillan. http://dx.doi.org/10.1037/10877-000

*Todorov, A., Gobbini, M. I., Evans, K. K., \& Haxby, J. V. (2007). Spontaneous retrieval of affective person knowledge in face perception. Neuropsychologia, 45, 163-173. http://dx.doi.org/10.1016/j.neuropsychologia.2006.04.018

*Toller, G., Adhimoolam, B., Grunwald, T., Huppertz, H. J., Kurthen, M., Rankin, K. P., \& Jokeit, H. (2015). Right mesial temporal lobe epilepsy impairs empathy-related brain responses to dynamic fearful faces. Jour nal of Neurology, 262, 729-741. http://dx.doi.org/10.1007/s00415-014$7622-2$

Toni, I., de Lange, F. P., Noordzij, M. L., \& Hagoort, P. (2008). Language beyond action. Journal of Physiology, Paris, 102, 71-79. http://dx.doi .org/10.1016/j.jphysparis.2008.03.005

Trautwein, F. M., Singer, T., \& Kanske, P. (2016). Stimulus-driven reorienting impairs executive control of attention: Evidence for a common bottleneck in anterior insula. Cerebral Cortex, 26, 4136-4147. http:// dx.doi.org/10.1093/cercor/bhw225

Tusche, A., Böckler, A., Kanske, P., Trautwein, F. M., \& Singer, T. (2016). Decoding the charitable brain: Empathy, perspective taking, and attention shifts differentially predict altruistic giving. The Journal of Neuroscience, 36, 4719-4732. http://dx.doi.org/10.1523/JNEUROSCI.339215.2016

"Ushida, T., Ikemoto, T., Tanaka, S., Shinozaki, J., Taniguchi, S., Murata, Y., .. Tamura, Y. (2008). Virtual needle pain stimuli activates cortical representation of emotions in normal volunteers. Neuroscience Letters, 439, 7-12. http://dx.doi.org/10.1016/j.neulet.2008.04.085

*Van der Cruyssen, L., Heleven, E., Ma, N., Vandekerckhove, M., \& Van Overwalle, F. (2015). Distinct neural correlates of social categories and personality traits. NeuroImage, 104, 336-346. http://dx.doi.org/10.1016/ j.neuroimage.2014.09.022 
*van der Gaag, C., Minderaa, R. B., \& Keysers, C. (2007). Facial expressions: What the mirror neuron system can and cannot tell us. Social Neuroscience, 2, 179-222. http://dx.doi.org/10.1080/ 17470910701376878

"van der Heiden, L., Scherpiet, S., Konicar, L., Birbaumer, N., \& Veit, R. (2013). Inter-individual differences in successful perspective taking during pain perception mediates emotional responsiveness in self and others: An fMRI study. NeuroImage, 65, 387-394. http://dx.doi.org/10 .1016/j.neuroimage.2012.10.003

Van Overwalle, F. (2009). Social cognition and the brain: A meta-analysis. Human Brain Mapping, 30, 829-858. http://dx.doi.org/10.1002/hbm .20547

Van Overwalle, F., \& Baetens, K. (2009). Understanding others' actions and goals by mirror and mentalizing systems: A meta-analysis. NeuroImage, 48, 564-584. http://dx.doi.org/10.1016/j.neuroimage.2009.06 .009

Vijayakumar, N., Cheng, T. W., \& Pfeifer, J. H. (2017). Neural correlates of social exclusion across ages: A coordinate-based meta-analysis of functional MRI studies. NeuroImage, 153, 359-368. http://dx.doi.org/ 10.1016/j.neuroimage.2017.02.050

*Völlm, B. A., Taylor, A. N., Richardson, P., Corcoran, R., Stirling, J., McKie, S., . . Elliott, R. (2006). Neuronal correlates of theory of mind and empathy: A functional magnetic resonance imaging study in a nonverbal task. NeuroImage, 29, 90-98. http://dx.doi.org/10.1016/j .neuroimage.2005.07.022

"Vuilleumier, P., Armony, J. L., Driver, J., \& Dolan, R. J. (2001). Effects of attention and emotion on face processing in the human brain: An event-related fMRI study. Neuron, 30, 829-841. http://dx.doi.org/10 1016/S0896-6273(01)00328-2

*Vuilleumier, P., Richardson, M. P., Armony, J. L., Driver, J., \& Dolan, R. J. (2004). Distant influences of amygdala lesion on visual cortical activation during emotional face processing. Nature Neuroscience, 7 , 1271-1278. http://dx.doi.org/10.1038/nn1341

Wager, T. D., Atlas, L. Y., Botvinick, M. M., Chang, L. J., Coghill, R. C., Davis, K. D., . . Yarkoni, T. (2016). Pain in the ACC? Proceedings of the National Academy of Sciences of the United States of America, 113, E2474-E2475. http://dx.doi.org/10.1073/pnas.1600282113

Wager, T. D., Lindquist, M., \& Kaplan, L. (2007). Meta-analysis of functional neu-roimaging data: Current and future directions. Social Cognitive and Affective Neuroscience, 2, 150-158. http://dx.doi.org/10 1093/scan/nsm015

Walter, H. (2012). Social cognitive neuroscience of empathy: Concepts, circuits, and genes. Emotion Review, 4, 9-17. http://dx.doi.org/10.1177/ 1754073911421379

"Walter, H., Adenzato, M., Ciaramidaro, A., Enrici, I., Pia, L., \& Bara, B. G. (2004). Understanding intentions in social interaction: The role of the anterior paracingulate cortex. Journal of Cognitive Neuroscience, 16, 1854-1863. http://dx.doi.org/10.1162/0898929042947838

"Walter, H., Ciaramidaro, A., Adenzato, M., Vasic, N., Ardito, R. B., Erk, S., \& Bara, B. G. (2009). Dysfunction of the social brain in schizophrenia is modulated by intention type: An fMRI study. Social Cognitive and Affective Neuroscience, 4, 166-176. http://dx.doi.org/10.1093/scan/ nsn047

*Wang, Y., Liu, W.-H., Li, Z., Wei, X.-H., Jiang, X.-Q., Neumann, D. L., ... Chan, R. C. (2015). Dimensional schizotypy and social cognition: An fMRI imaging study. Frontiers in Behavioral Neuroscience, 9, 133. http://dx.doi.org/10.3389/fnbeh.2015.00133

Wen, X., Liu, Y., Yao, L., \& Ding, M. (2013). Top-down regulation of default mode activity in spatial visual attention. The Journal of Neuroscience, 33, 6444-6453. http://dx.doi.org/10.1523/JNEUROSCI.493912.2013

White, S. J., Coniston, D., Rogers, R., \& Frith, U. (2011). Developing the Frith-Happé animations: A quick and objective test of Theory of Mind for adults with autism. Autism Research, 4, 149-154. http://dx.doi.org/ 10.1002/aur.174

White, S., Hill, E., Happé, F., \& Frith, U. (2009). Revisiting the strange stories: Revealing mentalizing impairments in autism. Child Development, 80, 1097-1117. http://dx.doi.org/10.1111/j.1467-8624.2009 .01319.x

"Wicker, B., Keysers, C., Plailly, J., Royet, J. P., Gallese, V., \& Rizzolatti, G. (2003). Both of us disgusted in My insula: The common neural basis of seeing and feeling disgust. Neuron, 40, 655-664. http://dx.doi.org/ 10.1016/S0896-6273(03)00679-2

"Wicker, B., Perrett, D. I., Baron-Cohen, S., \& Decety, J. (2003). Being the target of another's emotion: A PET study. Neuropsychologia, 41, 139146. http://dx.doi.org/10.1016/S0028-3932(02)00144-6

"Willert, A., Mohnke, S., Erk, S., Schnell, K., Romanczuk-Seiferth, N., Quinlivan, E., . . . Walter, H. (2015). Alterations in neural Theory of Mind processing in euthymic patients with bipolar disorder and unaffected relatives. Bipolar Disorders, 17, 880-891. http://dx.doi.org/10 $.1111 /$ bdi.12352

"Williams, L. M., Liddell, B. J., Kemp, A. H., Bryant, R. A., Meares, R. A., Peduto, A. S., \& Gordon, E. (2006). Amygdala-prefrontal dissociation of subliminal and supraliminal fear. Human Brain Mapping, 27, 652-661. http://dx.doi.org/10.1002/hbm.20208

Wilson-Mendenhall, C. D., Barrett, L. F., Simmons, W. K., \& Barsalou, L. W (2011). Grounding emotion in situated conceptualization. Neuropsychologia, 49, 1105-1127. http://dx.doi.org/10.1016/j.neuropsychologia.2010.12 .032

Wimmer, H., \& Perner, J. (1983). Beliefs about beliefs: Representation and constraining function of wrong beliefs in young children's understanding of deception. Cognition, 13, 103-128. http://dx.doi.org/10.1016/ 0010-0277(83)90004-5

Wolf, I., Dziobek, I., \& Heekeren, H. R. (2010). Neural correlates of social cognition in naturalistic settings: A model-free analysis approach. NeuroImage, 49, 894-904. http://dx.doi.org/10.1016/j.neuroimage.2009.08 .060

"Wolfensberger, S. P., Veltman, D. J., Hoogendijk, W. J., Boomsma, D. I., \& de Geus, E. J. (2008). Amygdala responses to emotional faces in twins discordant or concordant for the risk for anxiety and depression. NeuroImage, 41, 544-552. http://dx.doi.org/10.1016/j.neuroimage.2008.01 .053

Yarkoni, T., Poldrack, R. A., Nichols, T. E., Van Essen, D. C., \& Wager, T. D. (2011). Large-scale automated synthesis of human functional neuroimaging data. Nature Methods, 8, 665-670. http://dx.doi.org/10 1038/nmeth. 1635

Yeo, B. T., Krienen, F. M., Sepulcre, J., Sabuncu, M. R., Lashkari, D., Hollinshead, M., . . . Buckner, R. L. (2011). The organization of the human cerebral cortex estimated by intrinsic functional connectivity. Journal of Neurophysiology, 106, 1125-1165. http://dx.doi.org/10.1152/ jn.00338.2011

*Young, L., Cushman, F., Hauser, M., \& Saxe, R. (2007). The neural basis of the interaction between theory of mind and moral judgment. Proceedings of the National Academy of Sciences of the United States of America, 104, 8235-8240. http://dx.doi.org/10.1073/pnas.0701408104

*Young, L., Dodell-Feder, D., \& Saxe, R. (2010). What gets the attention of the temporo-parietal junction? An fMRI investigation of attention and theory of mind. Neuropsychologia, 48, 2658-2664. http://dx.doi.org/10 .1016/j.neuropsychologia.2010.05.012

*Young, L., \& Saxe, R. (2009). An FMRI investigation of spontaneous mental state inference for moral judgment. Journal of Cognitive Neuroscience, 21, 1396-1405. http://dx.doi.org/10.1162/jocn.2009.21137

"Young, L., Scholz, J., \& Saxe, R. (2011). Neural evidence for "intuitive prosecution": The use of mental state information for negative moral verdicts. Social Neuroscience, 6, 302-315. http://dx.doi.org/10.1080/ 17470919.2010.529712 
Zaki, J. (2017). Moving beyond stereotypes of empathy. Trends in Cognitive Sciences, 21, 59-60. http://dx.doi.org/10.1016/j.tics.2016.12.004

Zaki, J., \& Ochsner, K. N. (2012). The neuroscience of empathy: Progress, pitfalls and promise. Nature Neuroscience, 15, 675-680. http://dx.doi .org/10.1038/nn.3085

*Zaki, J., Ochsner, K. N., Hanelin, J., Wager, T. D., \& Mackey, S. C. (2007). Different circuits for different pain: Patterns of functional connectivity reveal distinct networks for processing pain in self and others. Social Neuroscience, 2, 276-291. http://dx.doi.org/10.1080/ 17470910701401973

*Zaki, J., Weber, J., Bolger, N., \& Ochsner, K. (2009). The neural bases of empathic accuracy. Proceedings of the National Academy of Sciences of the United States of America, 106, 11382-11387. http://dx.doi.org/10 .1073/pnas.0902666106

*Zaki, J., Weber, J., \& Ochsner, K. (2012). Task-dependent neural bases of perceiving emotionally expressive targets. Frontiers in Human Neuroscience, 6, 228. http://dx.doi.org/10.3389/fnhum.2012.00228
Zhou, Y., Friston, K. J., Zeidman, P., Chen, J., Li, S., \& Razi, A. (2018) The hierarchical organization of the default, dorsal attention and salience networks in adolescents and young adults. Cerebral Cortex, 28, $726-$ 737. http://dx.doi.org/10.1093/cercor/bhx307

"Zhou, Y., Wang, Y., Rao, L.-L., Yang, L.-Q., \& Li, S. (2014). Money talks: Neural substrate of modulation of fairness by monetary incentives. Frontiers in Behavioral Neuroscience, 8, 150. http://dx.doi.org/10.3389/ fnbeh.2014.00150

*Zhu, Y., Zhang, L., Fan, J., \& Han, S. (2007). Neural basis of cultural influence on self-representation. NeuroImage, 34, 1310-1316. http://dx .doi.org/10.1016/j.neuroimage.2006.08.047

Received July 10, 2019

Revision received July 17, 2020

Accepted July 21, 2020

\section{E-Mail Notification of Your Latest Issue Online!}

Would you like to know when the next issue of your favorite APA journal will be available online? This service is now available to you. Sign up at https://my.apa.org/portal/alerts/ and you will be notified by e-mail when issues of interest to you become available! 